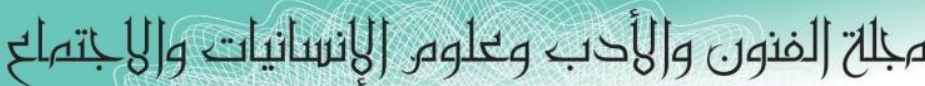

Journal of Arts, Literature, Humanities and Social Sciences

ISSN online: 2414 - 3383

ISSN print: 2616 - 3810

العدد (43) ايلول - سبتهبر 2019

\title{
البناء النفسي من وجهة نظريتي العلاقة بالموضوع وسيكولوجية الآنا

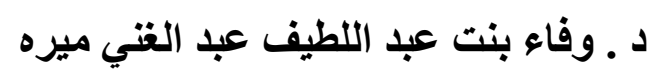

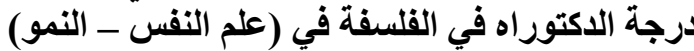 \\ جامعة أم القري - المملكة العربية السعودية
}

الملخص

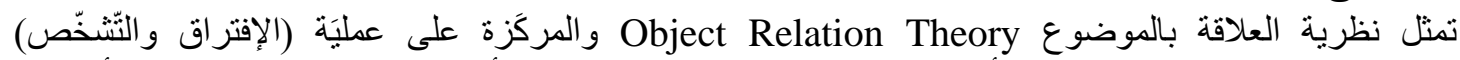
Separation Individuation

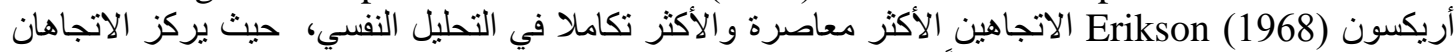

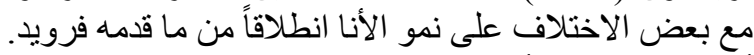

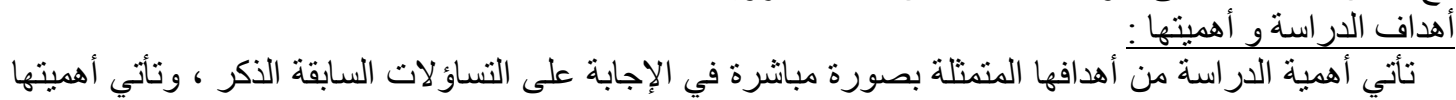

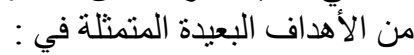

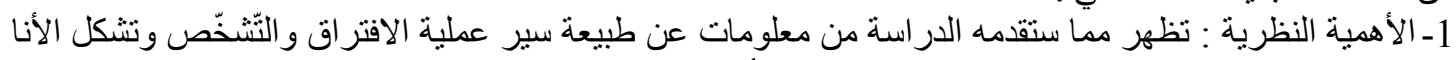

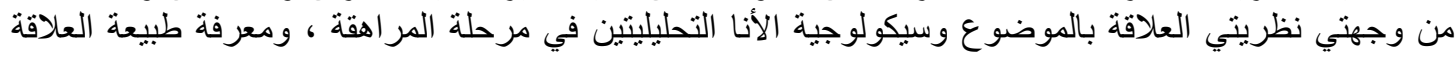

بينهما.

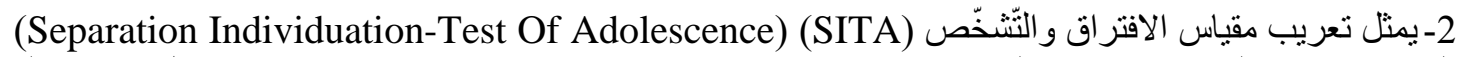
الذي قام بإعداده ليفين، جرين و ميلون (Levine, Green \& Millon, 1986) إضافة مهمة في مجال در اسة علم

نفس نمو المر اهقة.

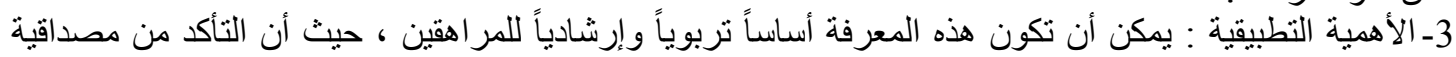

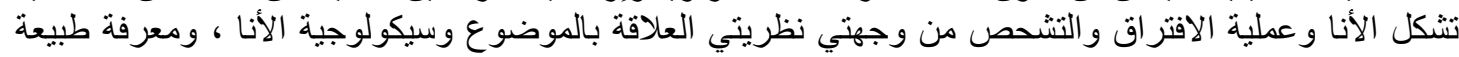

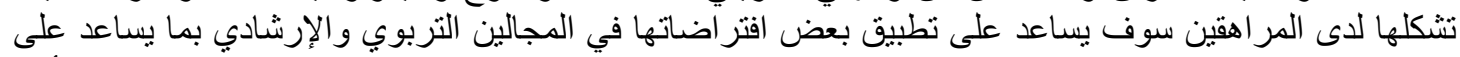

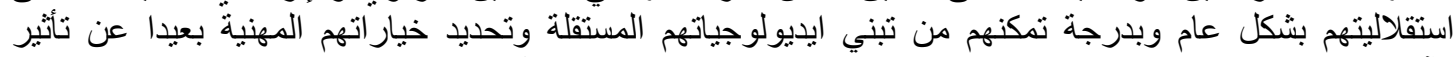

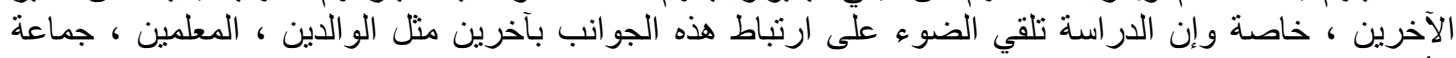
الأصدقاء.

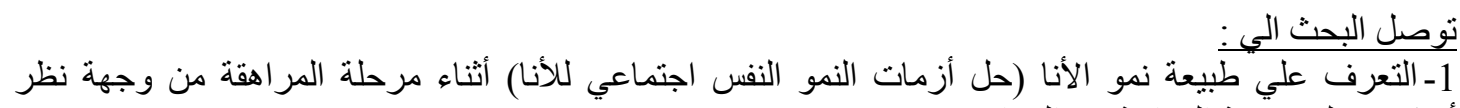

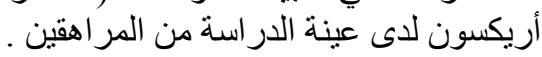

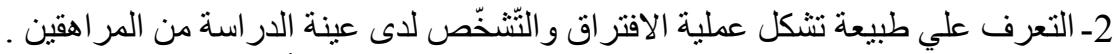

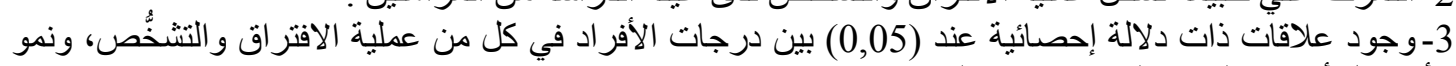

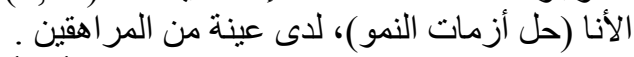

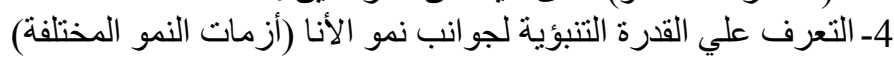

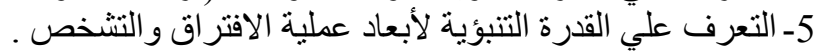

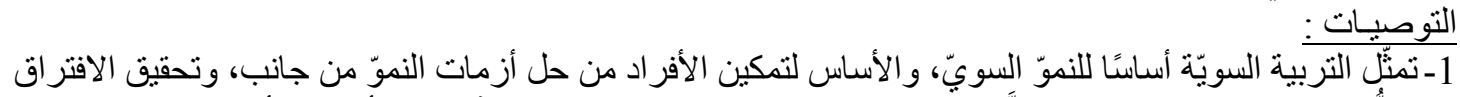

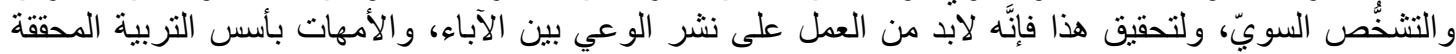

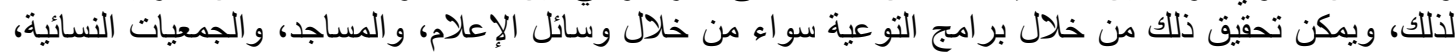

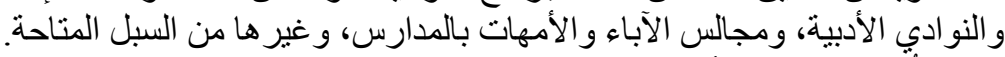

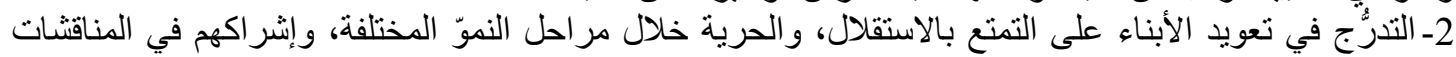

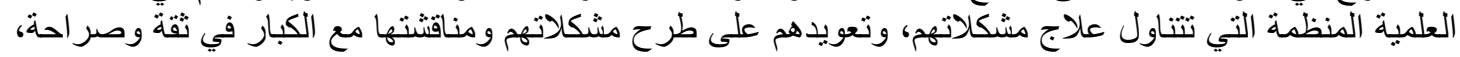

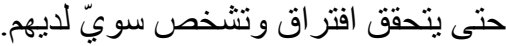

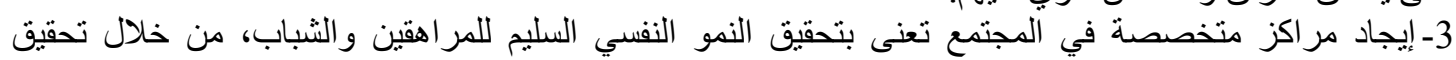

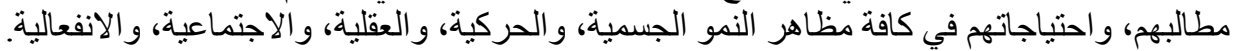




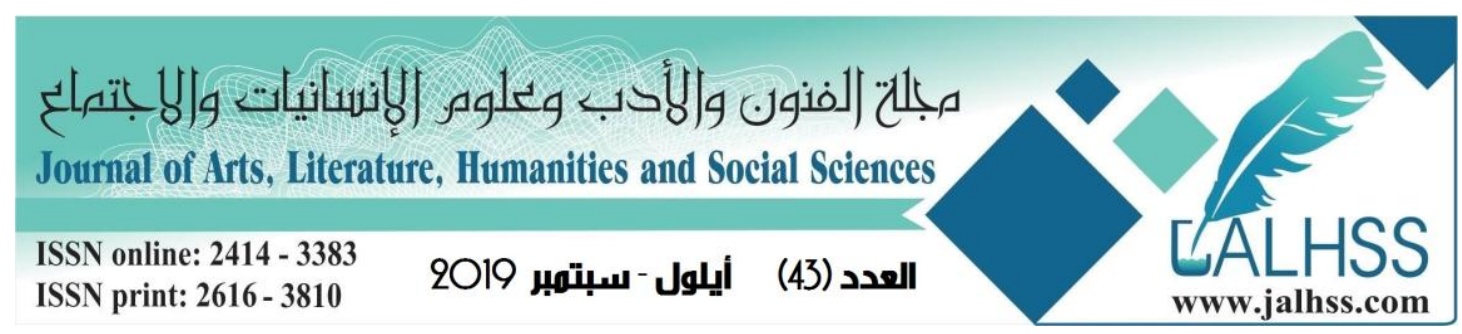

\title{
Psychological Construction from My Point of View and the Psychology of 'Anna'
}

\author{
ABSTRACT \\ Object Relation Theory, which focuses on Separation Individuation as Blos (1967) and Ego \\ Development as Erikson (1968), presents the most contemporary and most integrated approaches to \\ psychoanalysis, with two differences focusing on The growth of the ego based on what Freud \\ presented.
}

Study objectives and importance:

The importance of the study comes from its objectives, which are directly to answer the above questions, and its importance comes from the remote objectives of:

Theoretical significance: The study will provide information about the nature of the process of separation and diagnosis.

2. The Arabicization of the Separation Individuation-Test Of Adolescence (SITA), prepared by Levine, Green \& Millon, 1986, is an important addition in the study of adolescent development psychology.

3 - Applied importance: This knowledge can be an educational basis and guidance for adolescents, as ensuring the credibility of the formation of the ego and the process of separation and diagnosis from the two theories of the relationship to the subject and the psychology of the ego, and knowing the nature of the formation of adolescents will help to apply some of its assumptions in the educational and advisory areas to help The study sheds light on the relevance of these aspects to others such as parents, teachers, and friends.

Your search found:

1. Identify the nature of ego growth (solving the crisis of psychosocial development of the ego) during adolescence from the viewpoint of Ericsson in the study sample of adolescents.

2 - to identify the nature of the process of separation and diagnosis of the study sample of adolescents.

3 - There are statistically significant relationships at (0.05) between the degrees of individuals in the process of separation and diagnosis, and the growth of the ego (solving growth crises), in a sample of adolescents.

4 - Identify the predictive capacity of aspects of ego growth (different growth crises).

5 - Identify the predictive capacity of the dimensions of the process of separation and diagnosis.

Recommendations:

1.Educational education is the basis for proper growth, and the basis for enabling individuals to solve growth crises on the one hand, and achieve proper separation and diagnosis.To achieve this, it is necessary to work to spread awareness among parents and mothers of the foundations of education achieved, and this can be achieved through awareness programs Through the media, mosques, women's associations, literary clubs, parent school councils, and other avenues available.

Gradually accustom the children to enjoying independence and freedom during the different stages of development, and involve them in organized scientific discussions that address the treatment of their problems, and accustom them to put their problems and discuss them with adults in confidence and frankness, so as to achieve separation and diagnosis with them.

3 - Find specialized centers in the community to achieve the proper psychological development of adolescents and youth, through the fulfillment of their demands, and their needs in all aspects of physical, motor, mental, social and emotional growth. 


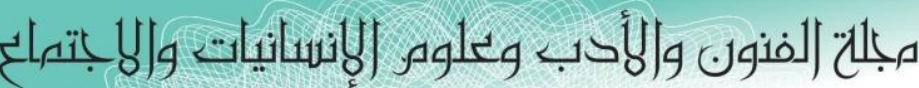

Journal of Arts, Literature, Humanities and Social Sciences

ISSN online: 2414 - 3383

ISSN print: 2616 - 3810

\section{العدد (43) ايلول -سبتمبر 2019}

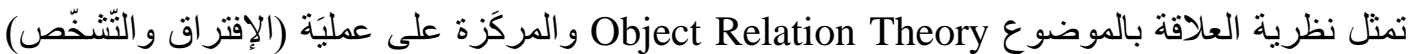
Separation Individuation أفترضه أريكسون Erikson (1968) الاتجاهين الأكثر معاصرة والأكثر تكاملا في التحليل النفسي، حيث

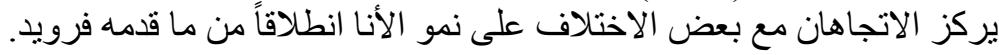

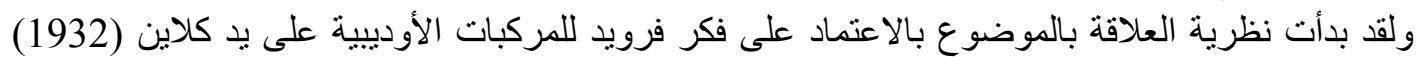

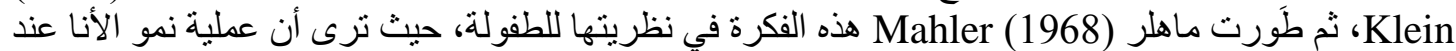

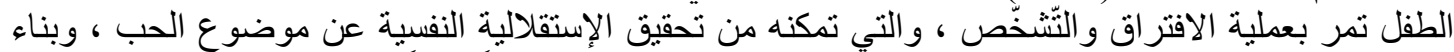

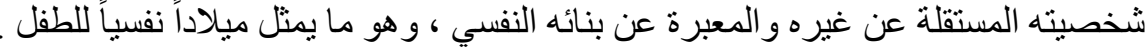

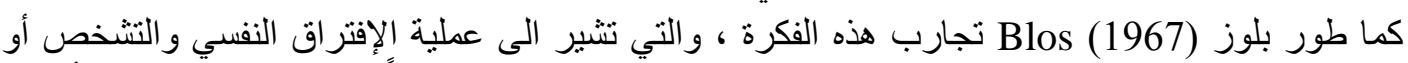

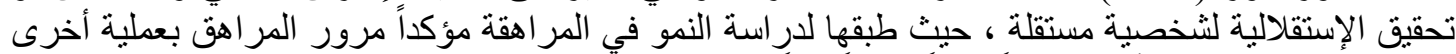

من الافتر اق و التُشخّص تُمثل ميلاداً نفسياً حقيقياً ثانياً. (Klein, 1932; Mahler, 1968; Blos, 1967). كما بدأت نظرية (سيكولوجية الأنا) على يد أنا فرويد (1965) Anna Freud بلإعنماد على فكر فرويا.

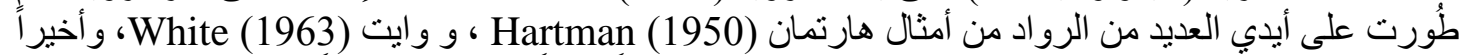

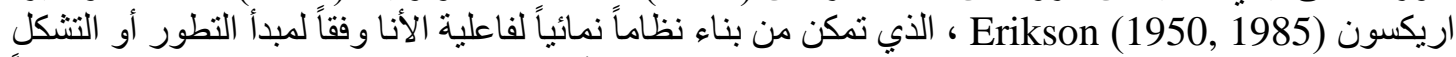

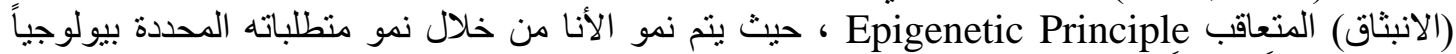

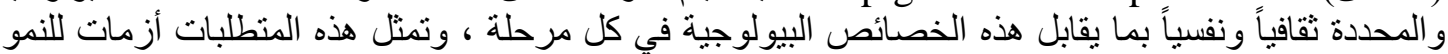

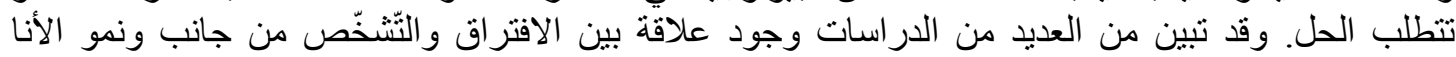

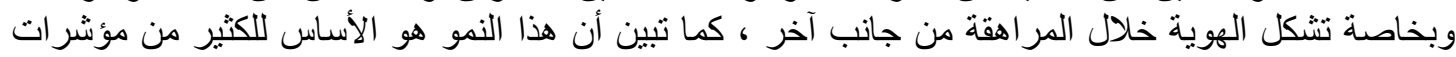

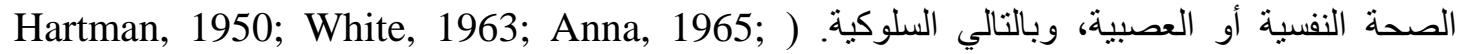
.(Erikson, 1950, 1985

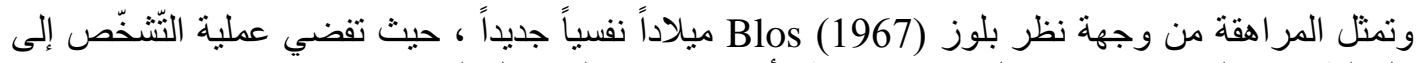

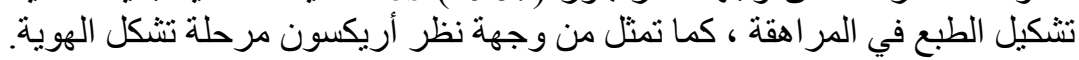

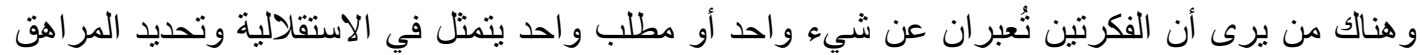

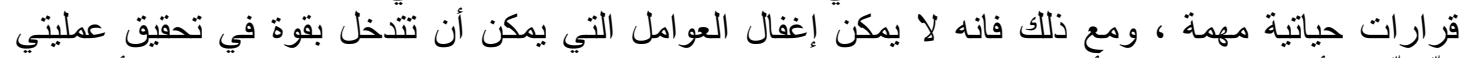

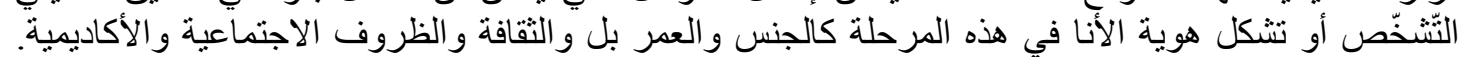

.(Blos, 1975; Blose, 1999)

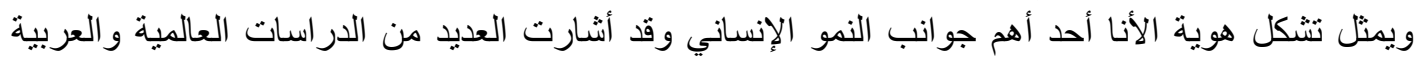

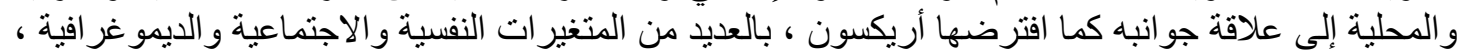

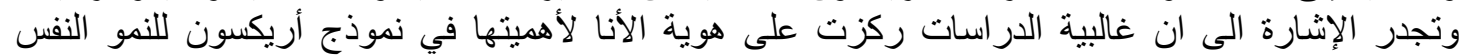

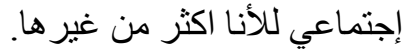

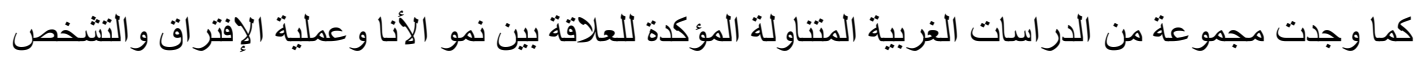

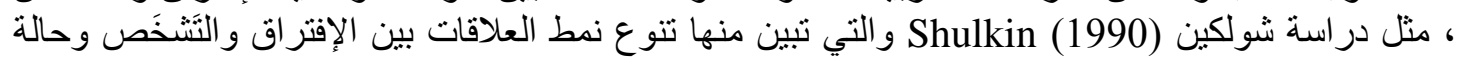
الهوية ، ودراسة مادلين (1991) Medlin والتي بينت أثر الجنس في تحديد طبينة التئ التفاعل بين الإفتراق

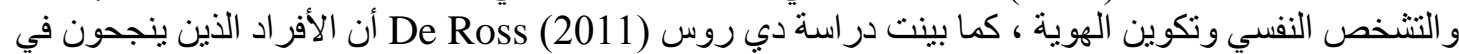
إجتياز عملية الافتراق و التشخص قادرون على تجنب الأعراض النفسية المرضية ، وتجنب الطرق السلبية في الني التو افق.

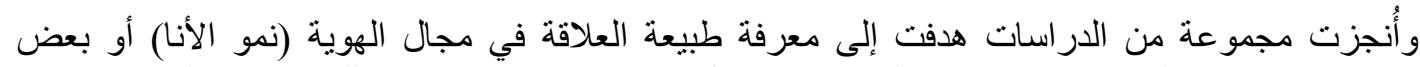

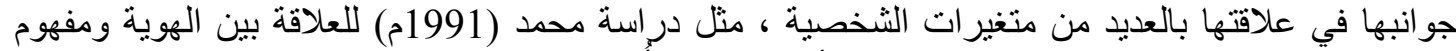
الذات ، ودراسة عبد المعطي (1991م) لدراسة أثر التنشئة الأسُرية على تثكيل الهوية ، ودر استة عبد المعطي 


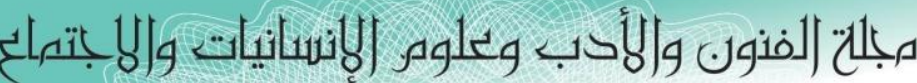

Journal of Arts, Literature, Humanities and Social Sciences

ISSN online: 2414 - 3383

ISSN print: 2616 - 3810

\section{العدد (43) ايلول -سبتمبر 2019}

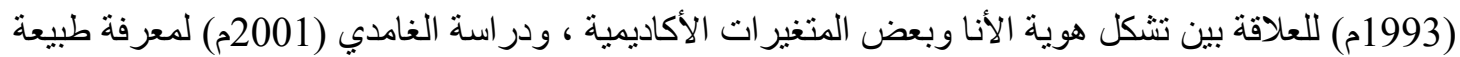

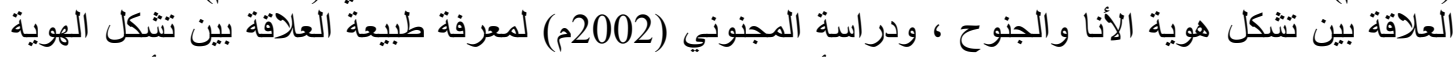

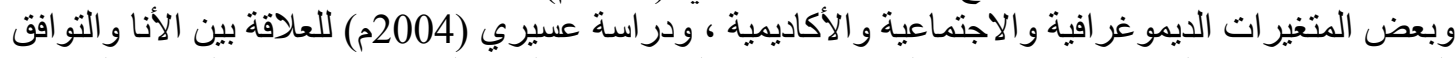

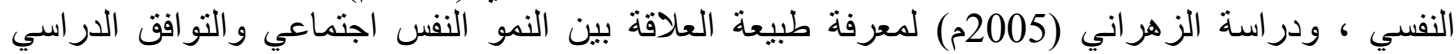

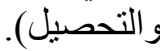

ويشير الاساس النظري لنظرية الافتراق و التشخص إلى نأثر نجاحه بالعديد من الخبر ات الاجتماعية و العلاقة

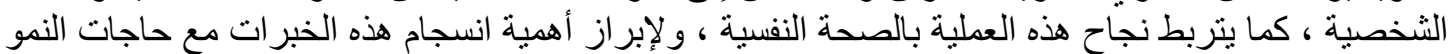

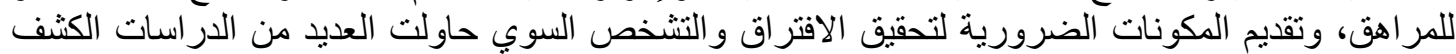

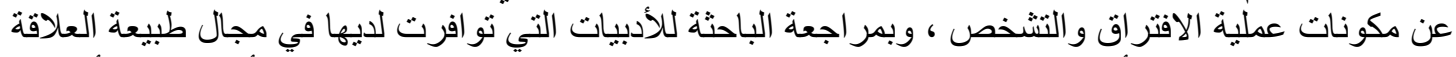

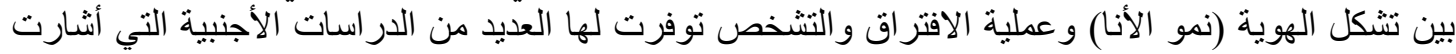

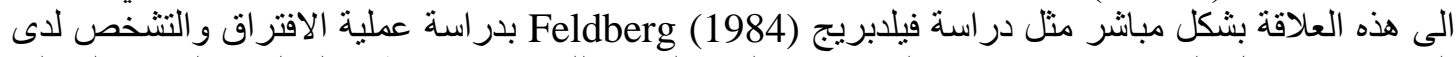

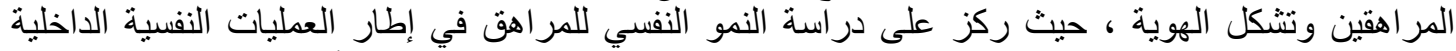

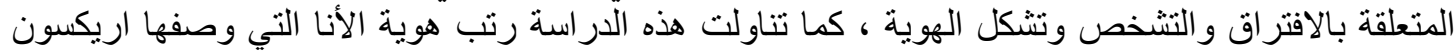

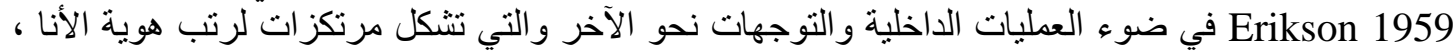

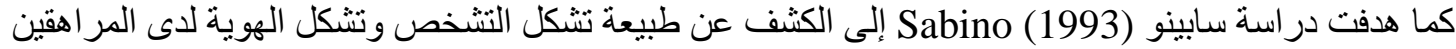

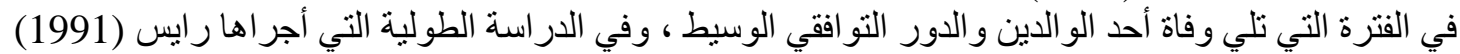
Rice

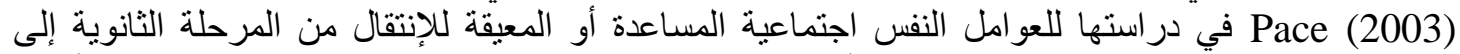

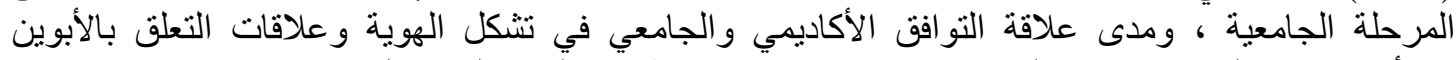

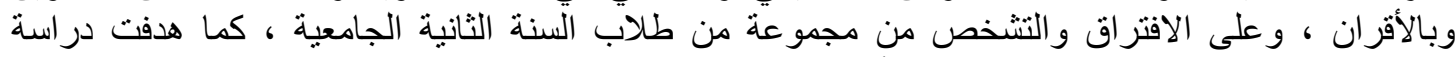

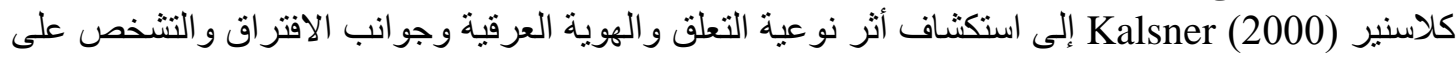

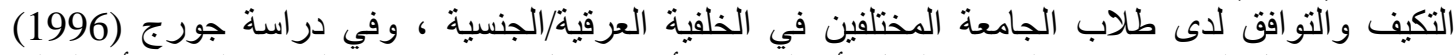
George

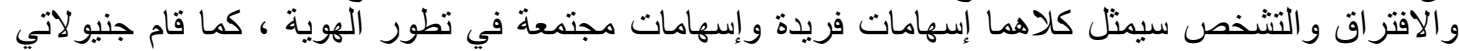

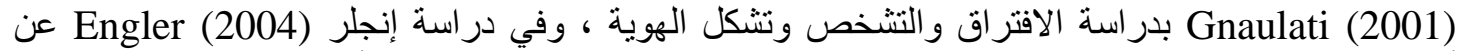
أنماط العلاقات بين عمليات الافتراق و التشخص و الهوية في مرحلة المر اهقة المتأخرة على عينة من طلاب

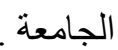

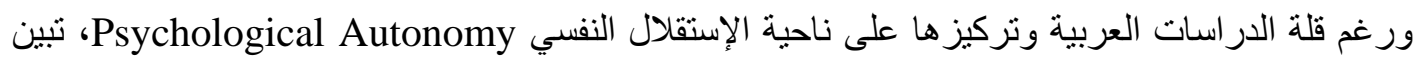

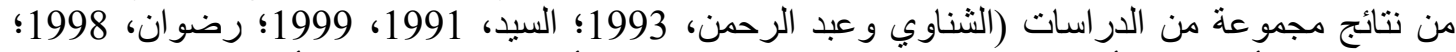
دليلة، 2011) أن الذكور أكثر استقلالية من الناحية العاطفية عن الأم مقارتة بالإناث ، و أنه لا فروق بينهما في الإستقلال النفسي عن الأب.

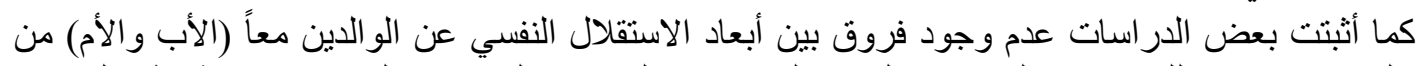

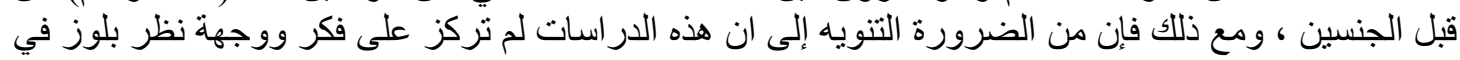
الإفتر اق والتشخص في في المر ذاهقة.

وبناء على ما سبق عرضه من الدراسات التئ التهات التاولت موضوع الدراسة ، تبين للباحثة مدى أهمية الدراسة الحالية.

و وعليه تحاول الدراسة الحالية إلقاء الضوء على الإلى البناء النفسي من وجهة نظريتي العلاقة بالموضوع

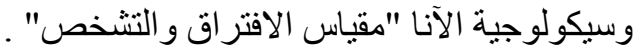

مشكلة البحث: :

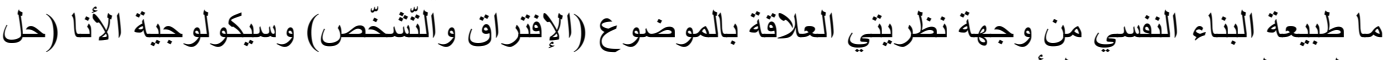

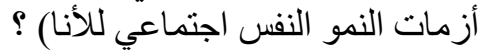




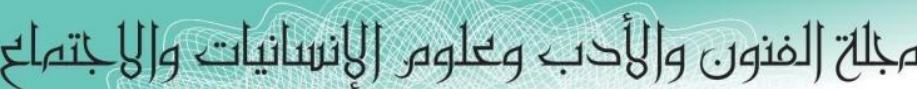

Journal of Arts, Literature, Humanities and Social Sciences

ISSN online: 2414 - 3383

ISSN print: 2616 - 3810

\section{العدد (43) ايلول - سبتمبر 2019}

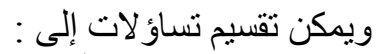

1- ما طبيعة نمو الأنا (حل أزمات النمو النفس اجتماعي للأنا) أثناء مرحلة المر اهقة من وجهة نظر أريكسون لاى

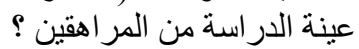

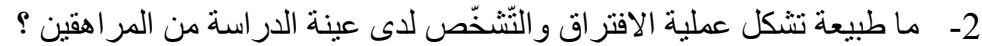

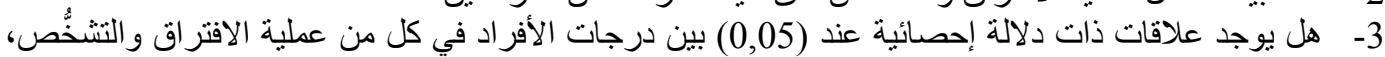

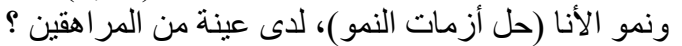

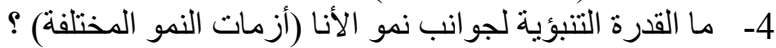

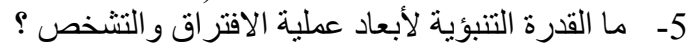

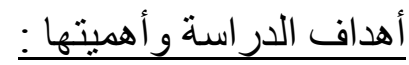

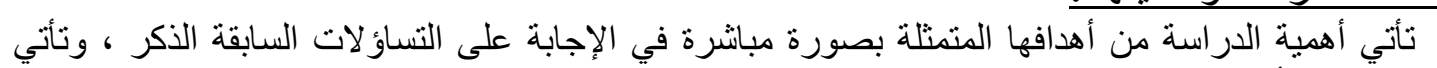

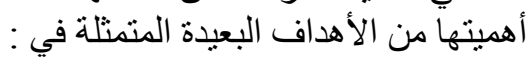

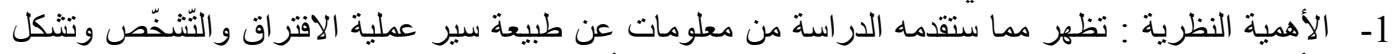

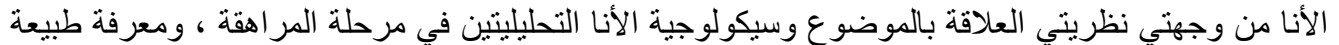

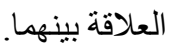

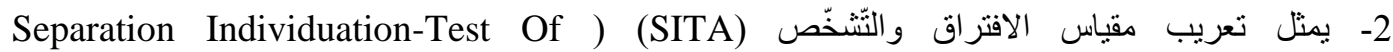

(Adolescence

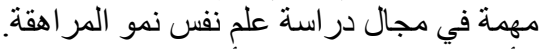

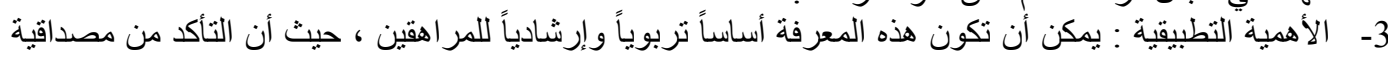

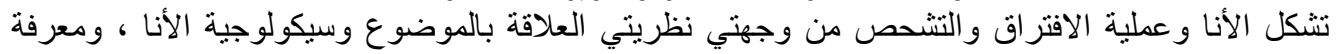

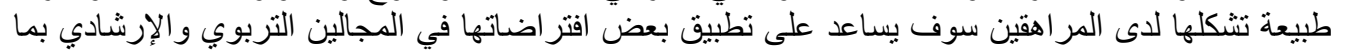

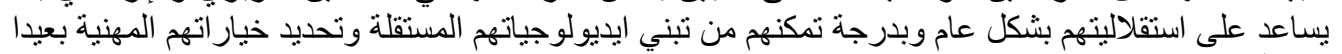
عن تأثير الآخرين ، خاصة وإن الدراسة تلقي الضوء على الثى ارتباط هذه الجو انب بآخرين مثل الو الدين ، المعلمين

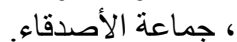

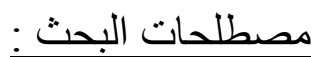

ـ Psychological Construction : البناء النفسي :

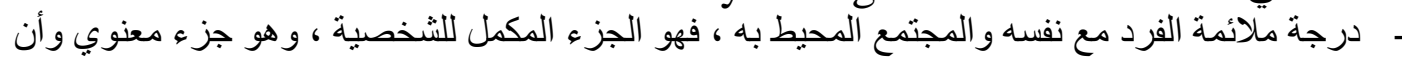

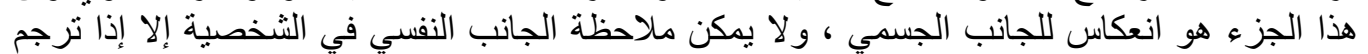

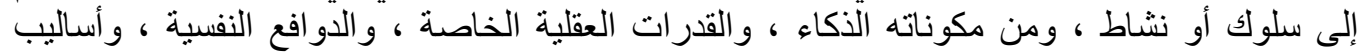
التو افق ومستوى الصحة النفسية. (طه، 1979: 38 38 النكاء ،

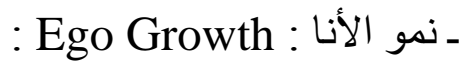

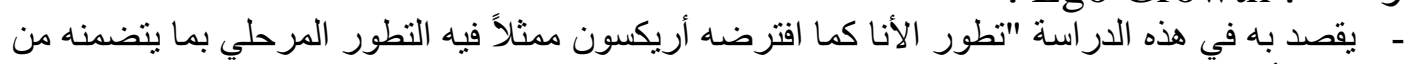

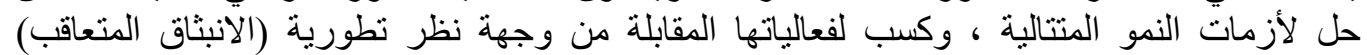
Epigenetic Principle

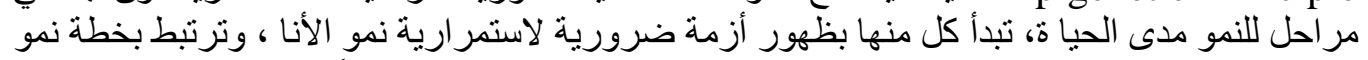

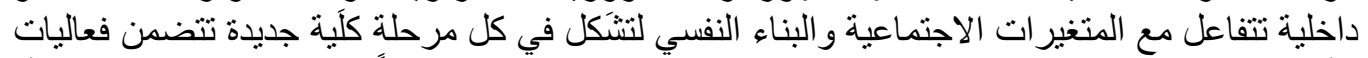

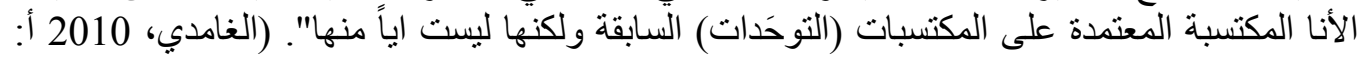

ويرى أريكسون (1968, 1974) أن الوظيفة البنائية للأنا السوية هو الثعور بالهوية أو تحقيق

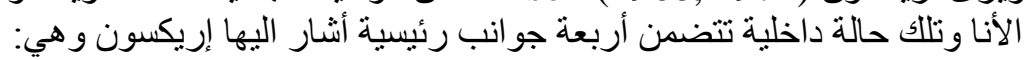

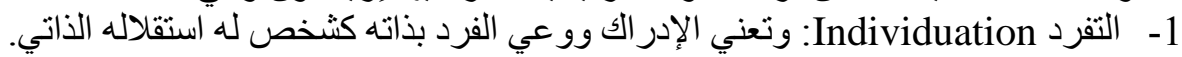

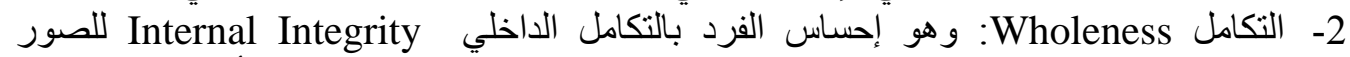

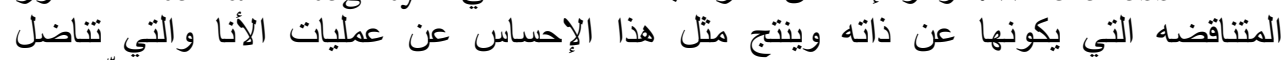

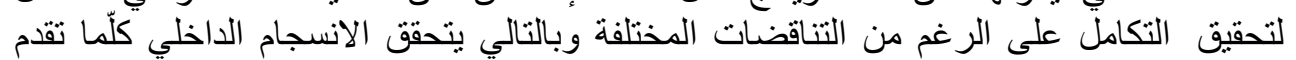




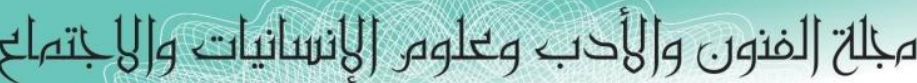

Journal of Arts, Literature, Humanities and Social Sciences

ISSN online: 2414 - 3383

ISSN print: 2616 - 3810

\section{العدد (43) ايلول - سبتمبر 2019}

3- التماتل و الاستمرارية Sameness and Continuity وهي عملية تتضمن التطور والاستمر ارية

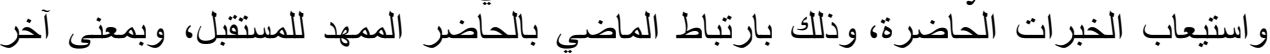

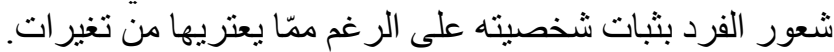

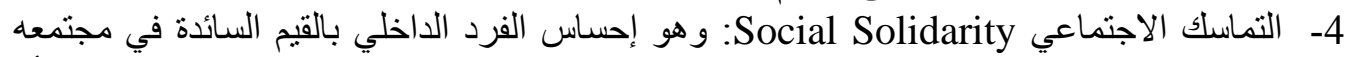

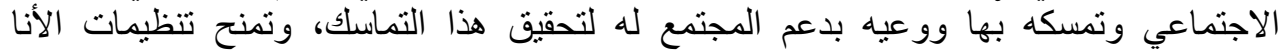
الثخصية تماسكها بالإضافة إلي تمانلها واستمر ارية إدر اكها من قبل التبل الآخرين.

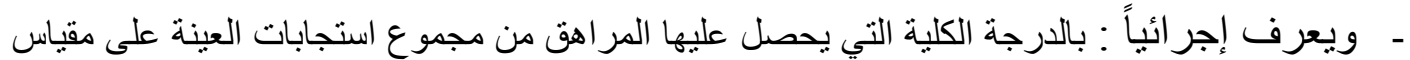

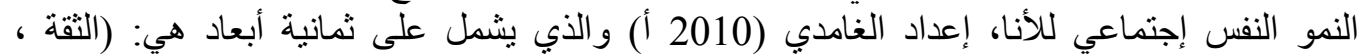
الاستقلال ، المبادرة ، الإنجاز ، الهوية ، الألفة ، الإنتاجية ، التكامل).

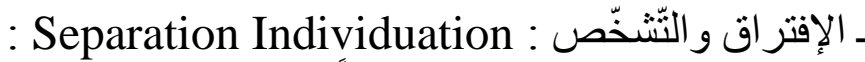

ـ ـ ـو عملية يحقق فيها الطفل نوعاً من الاختلاف و التمايز الذاتي النفسي عن الآخرين ، ويبدأ من خلالها

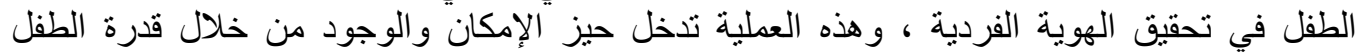

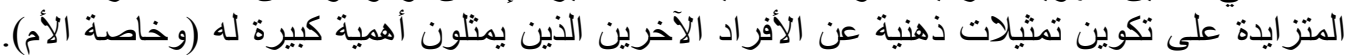

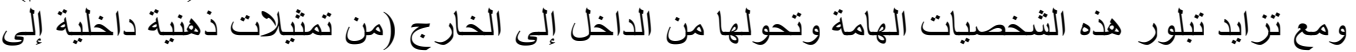

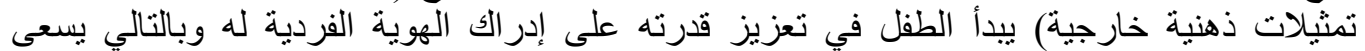

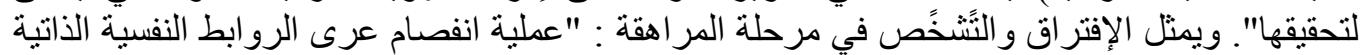

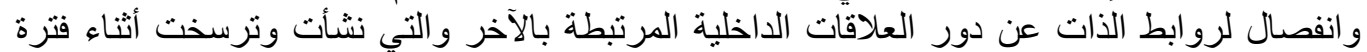

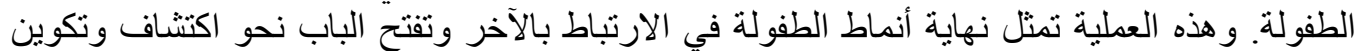

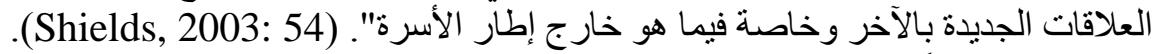

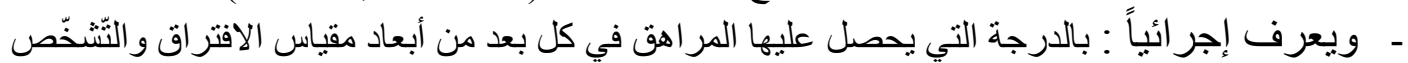
(Separation Individuation-Test Of Adolescence) (SITA) وميلون (Levine, Green \& Millon, 1986) تعريب الباحثة وتثمل: (قلق الغمر، الممارسة الإنة

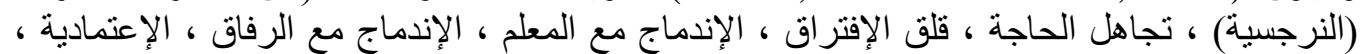
الإفتراق الصحي، نوقع الرفض) و التي تعبر عن استقلال المراهق الدق عن والديه وإدراكه لذاته ككيان

$$
\text { منهج البحث : مستقل. }
$$

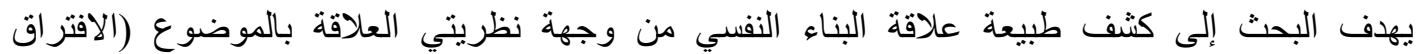

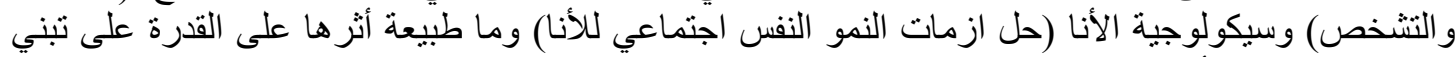

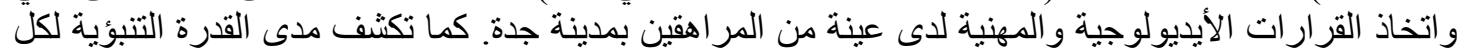

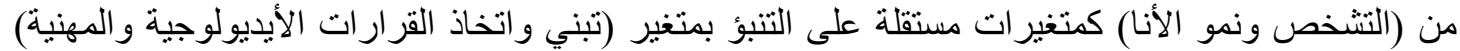

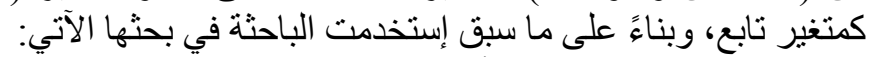

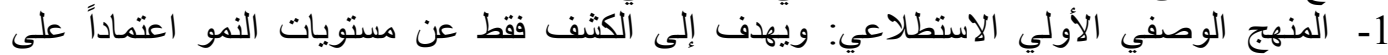
المتوسطات والآنحر الافات المعيارية.

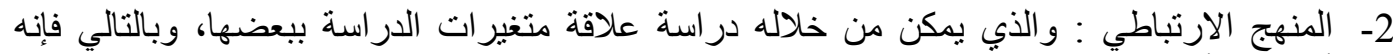

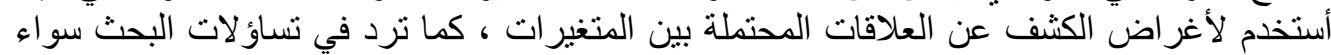
كانت علاقة ارتباطية أو تنبؤية. حدود البحث : مانث:

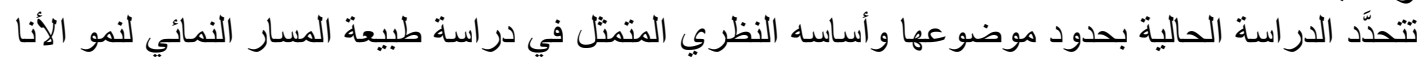

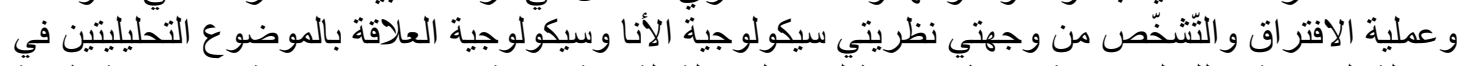

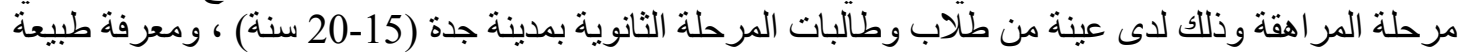




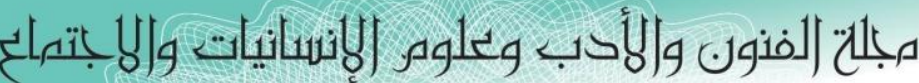

Journal of Arts, Literature, Humanities and Social Sciences

ISSN online: 2414 - 3383

ISSN print: 2616 - 3810

\section{العدد (43) ايلول - سبتمبر 2019}

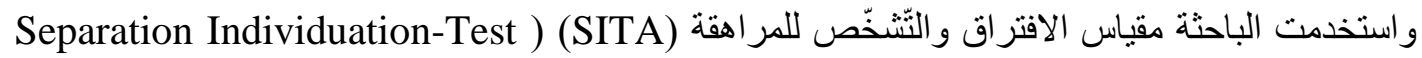
(Of Adolescence

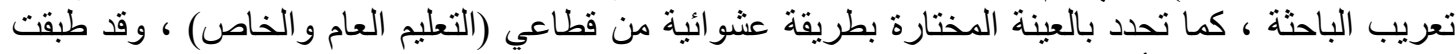

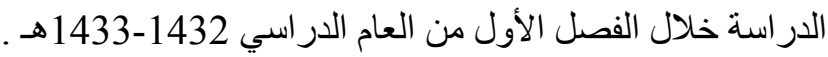

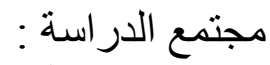

تكون مجتمع الدر اسة من الذكور و الإناث العاديين الو اقعة أعمار هم بين (15- 20 سنة) في مدينة جدة ، و ويمثل

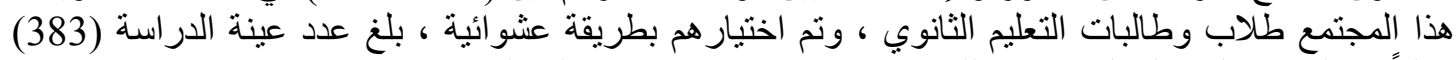

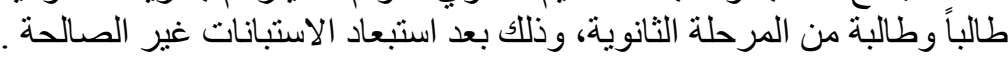

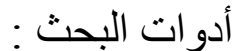

فامت الباحثة بتطبيق مقياس الافتراق والنّشخّص (SITA) Separation Individuation-Test Of ) (Adolescence الباحثة.

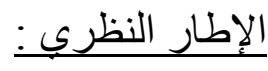

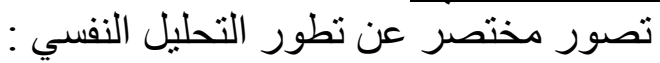

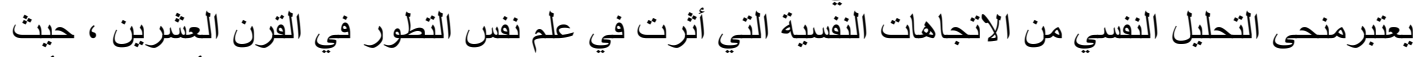

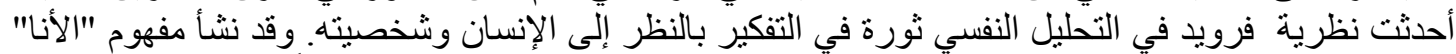

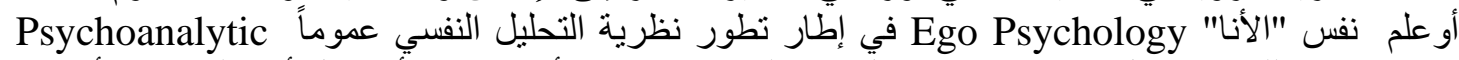

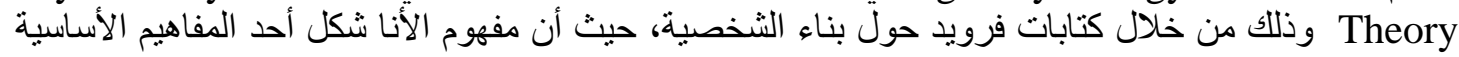

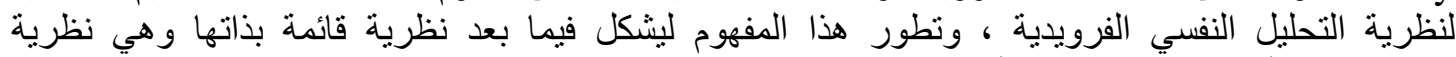

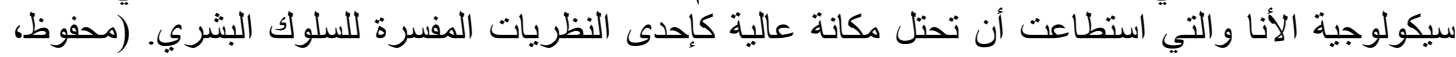
.Coles, 2001 1986

ويظهر أن علم نفس "الأنا" قد نشأوتطور في إطار تطور نظرية التحليل النفسي الكلاسيكية فرويد 1905-

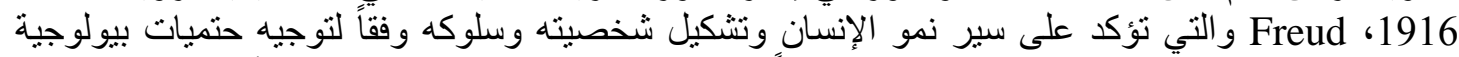

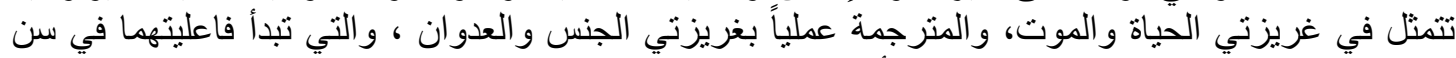

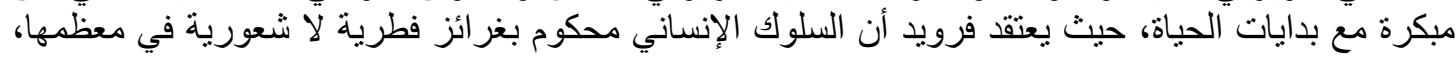

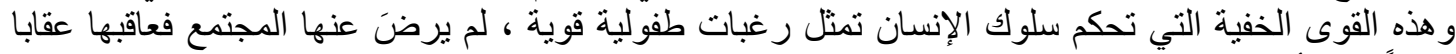

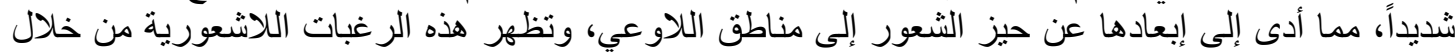

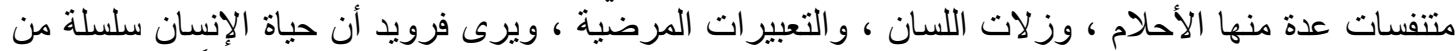

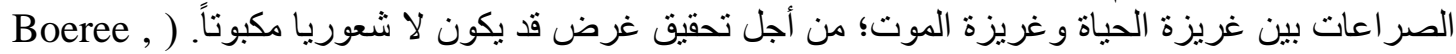

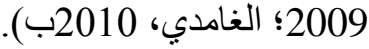

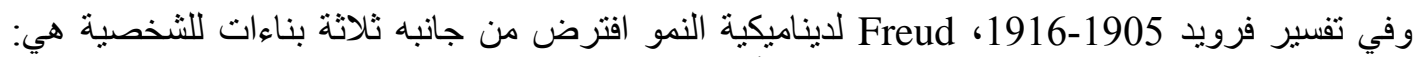

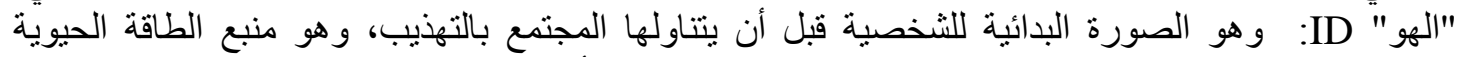

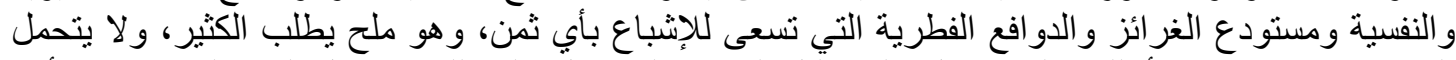

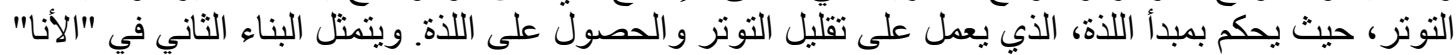

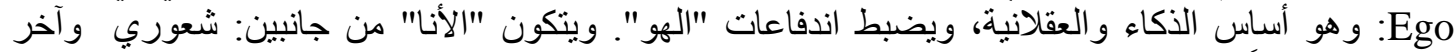

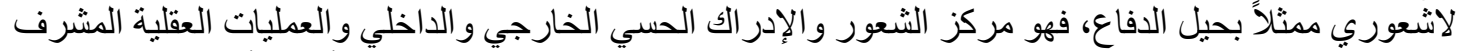

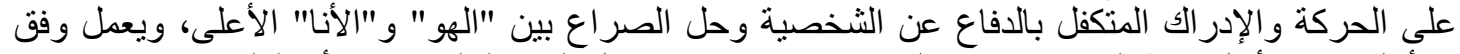

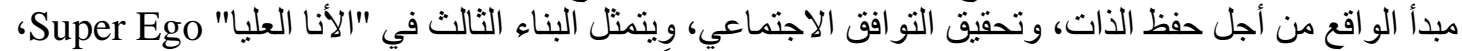

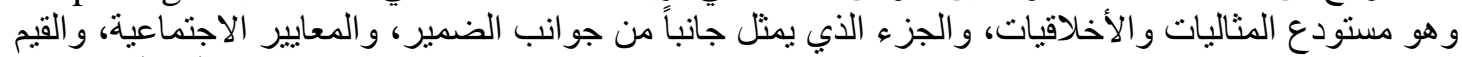

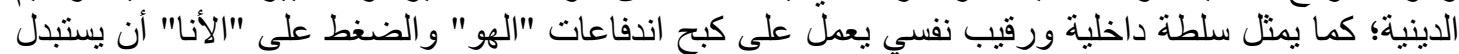

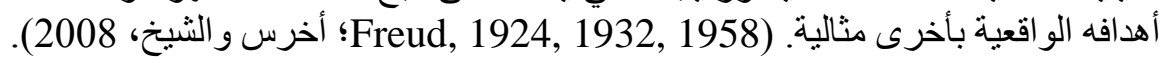




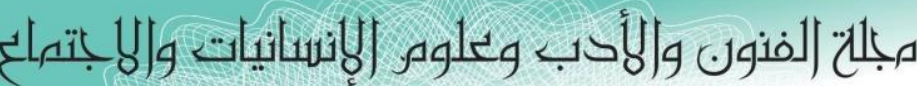

Journal of Arts, Literature, Humanities and Social Sciences

ISSN online: 2414 - 3383

ISSN print: 2616 - 3810

\section{أيلول - سبتهبر 2O19}

العدد (43)

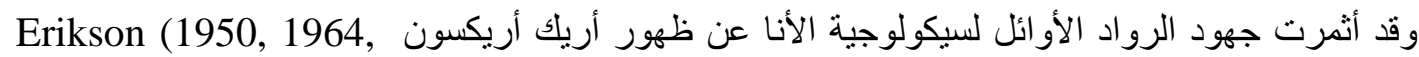

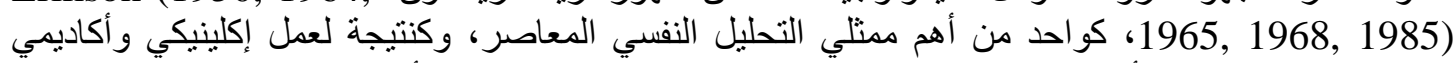

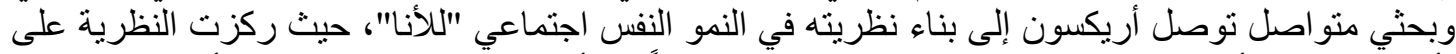

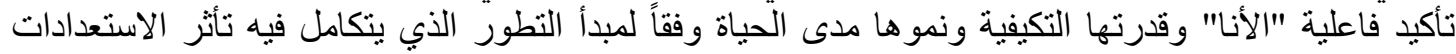

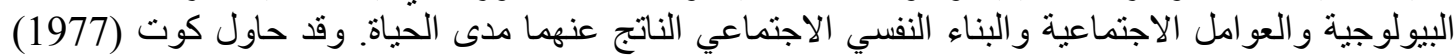

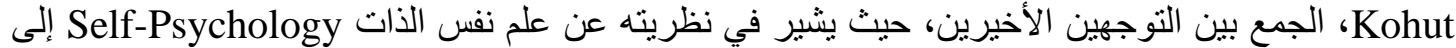

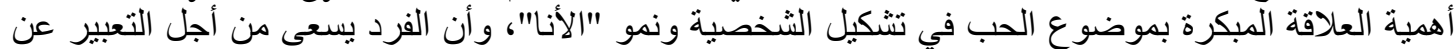

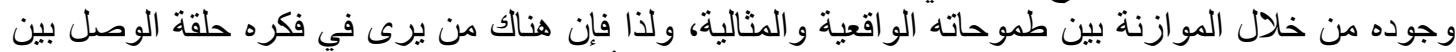

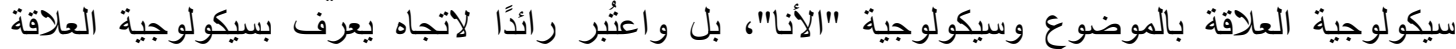

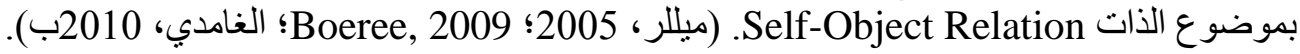
نظرية أريك أريكسون في النمو النفس إجتماعي للأنا (سايكولوجية الأنا) :

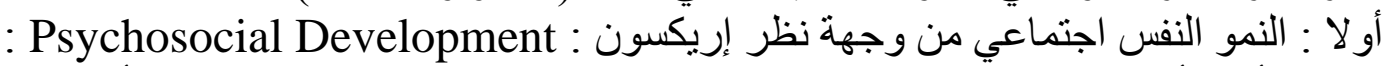

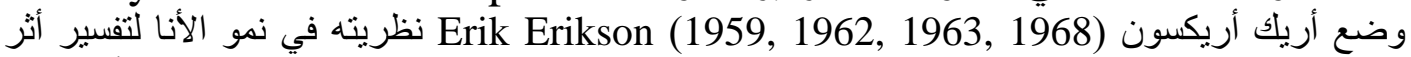

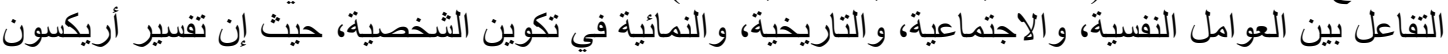

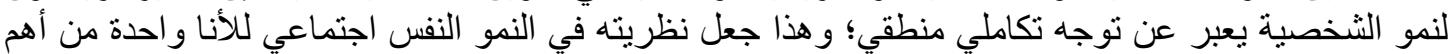

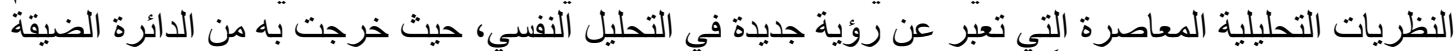

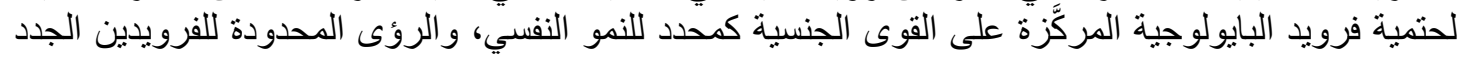
New Freudians

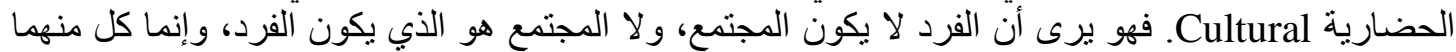
انعكاس للآخر ، يتأثز به ويؤثر فيه.

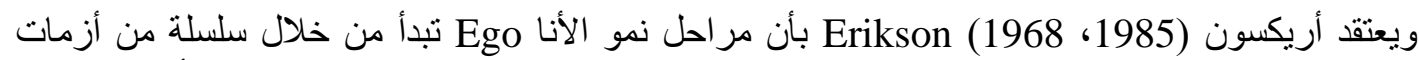

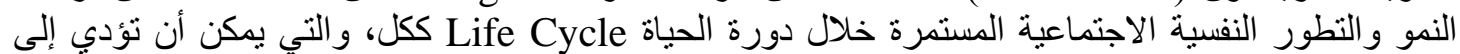

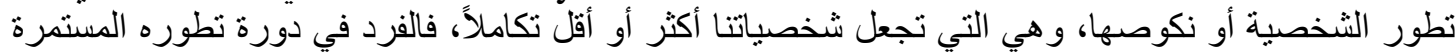

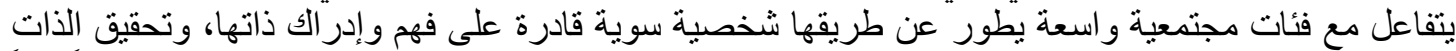

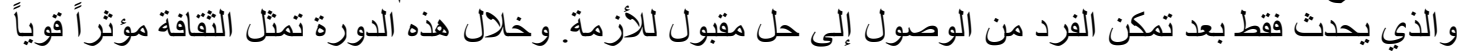

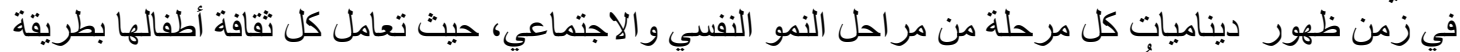

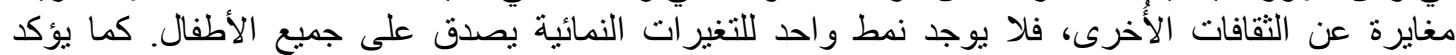

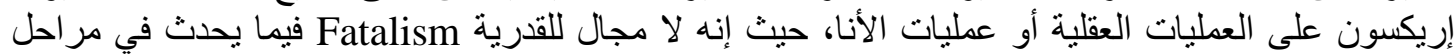

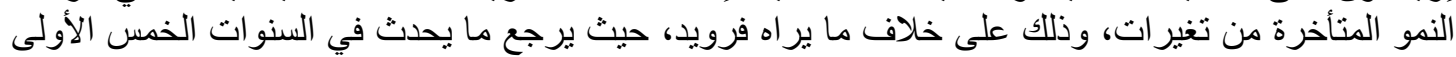

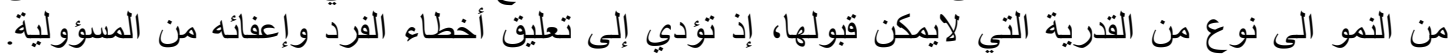

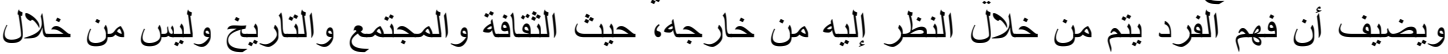

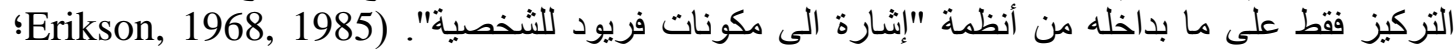

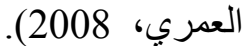

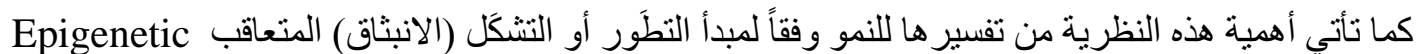
Principle

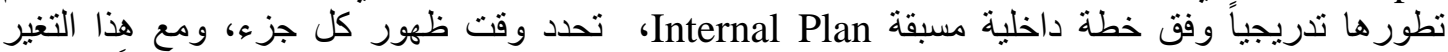

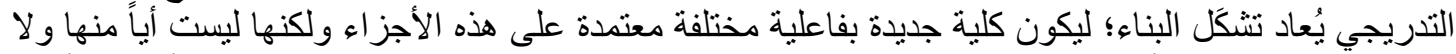

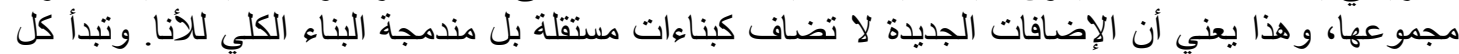

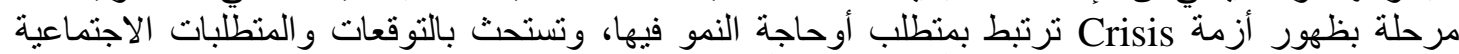

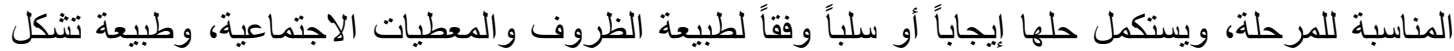
البناء النفسي خلال المر احل السابقة. (Friedman, 1999 ؛ الغامدي، 2010أ). 


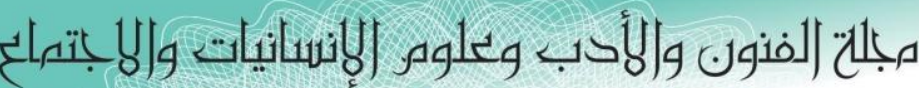

Journal of Arts, Literature, Humanities and Social Sciences

ISSN online: 2414 - 3383

ISSN print: 2616 - 3810

\section{العدد (43) ايلول - سبتمبر 2019}

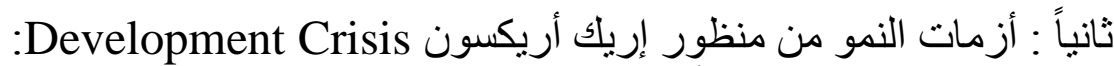

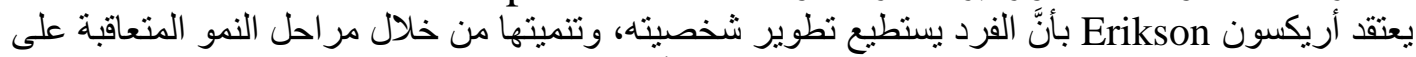

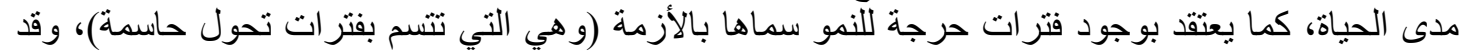

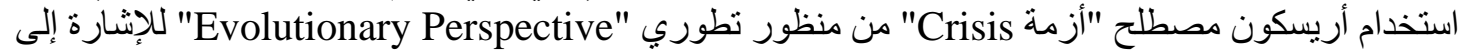

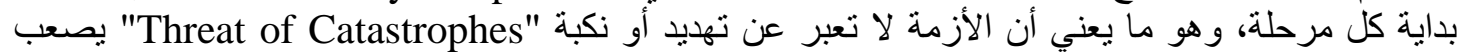

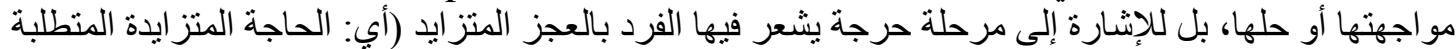

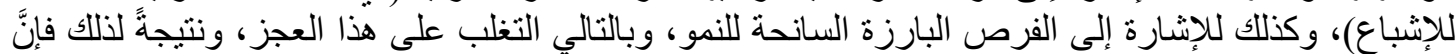

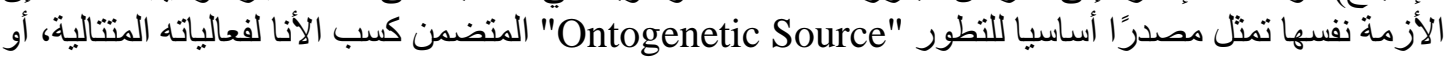
سوء التكيف في المقابل "Strengthen or Maladjustment". . Erikson, E. J., \& Kivnick, 1986; (Erikson J., 1988; Evans, 1967 وفيما يلي عرض لمراحل التطور النفس اجتماعي التي اقترحها إريكسون، وحدودها العمرية، وخصائصها

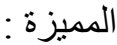
المرحلة الأولى : الإحساس بالثقة مقابل الإحساس بعدم الثقة :

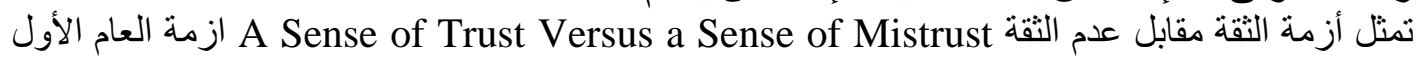

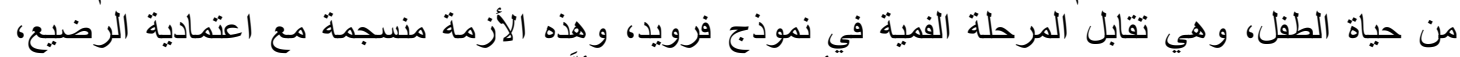

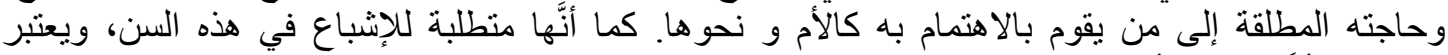

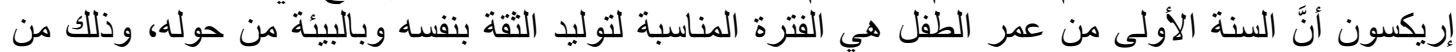

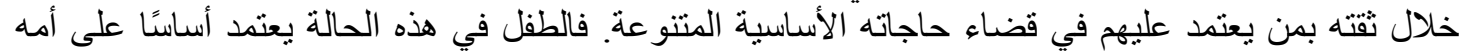

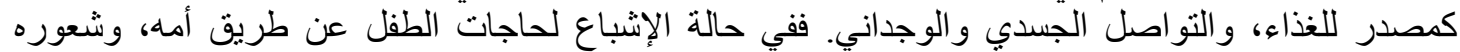

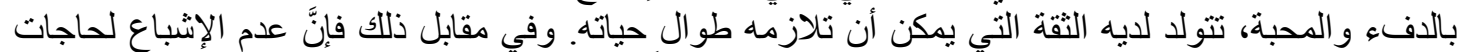

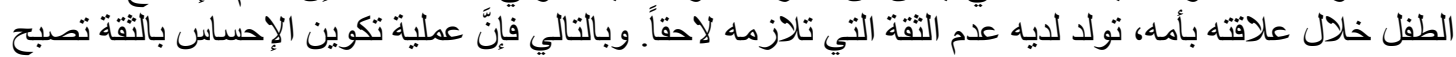

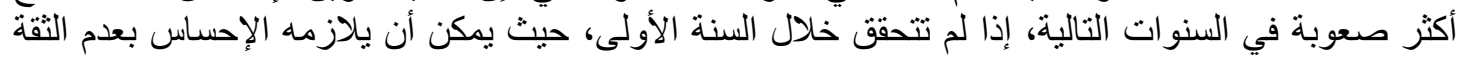

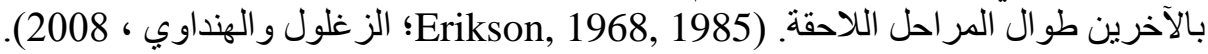

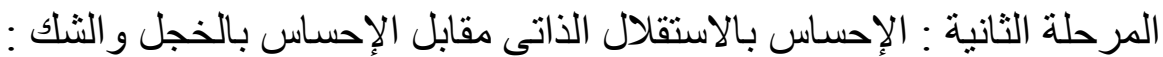

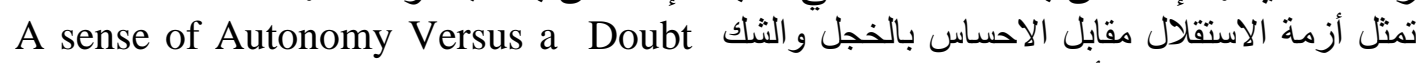
Sense of Shame and

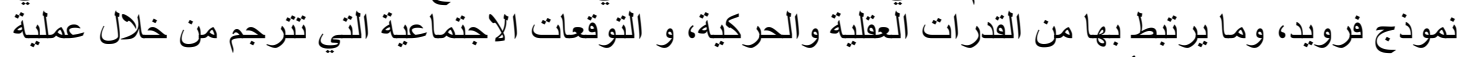

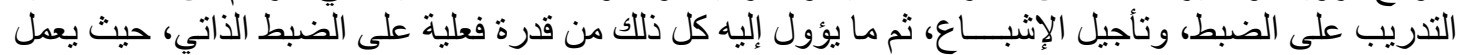

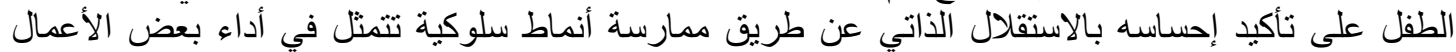

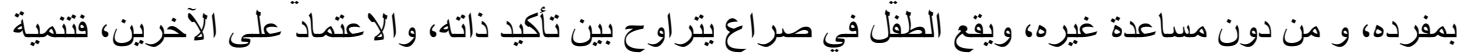

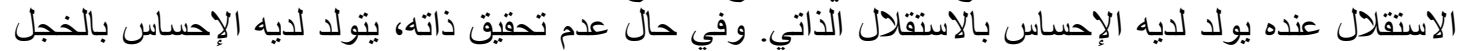

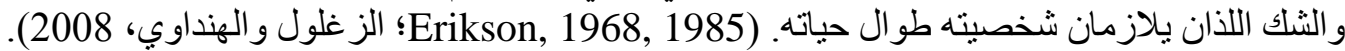

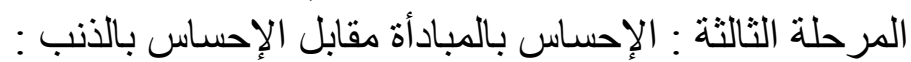

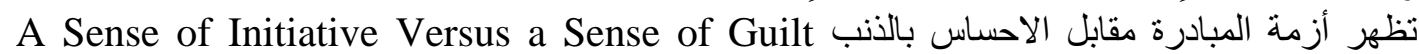

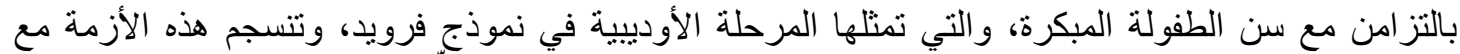

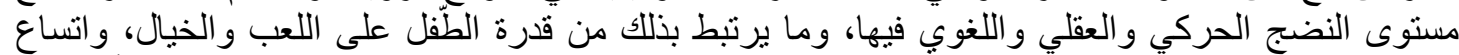

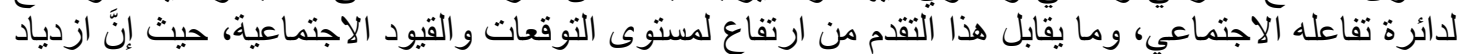

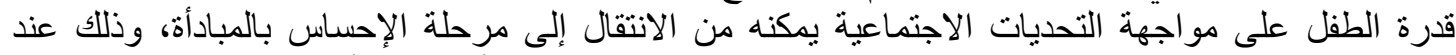

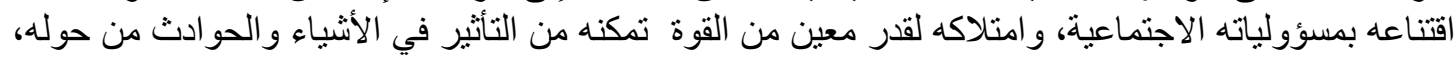

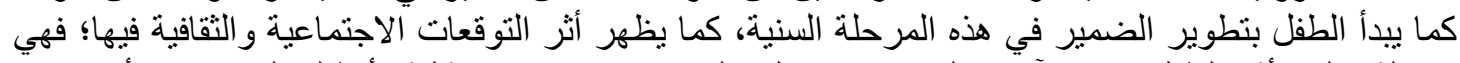

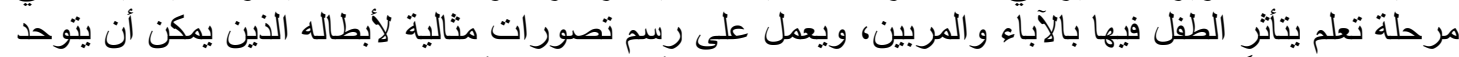

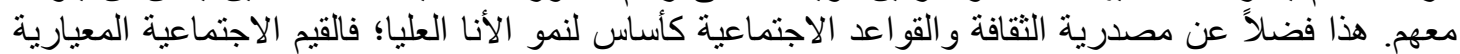




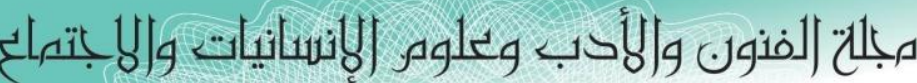

Journal of Arts, Literature, Humanities and Social Sciences

ISSN online: 2414 - 3383

ISSN print: 2616 - 3810

\section{أيلول - سبتمبر 2019}

العدد (43)

تعمل على التحكم في مبادرات الطفل، وتقييدها من خلال مبدأ مشاعر الذنب، ويظهر ذلك خلال اللعب الذي يمثل

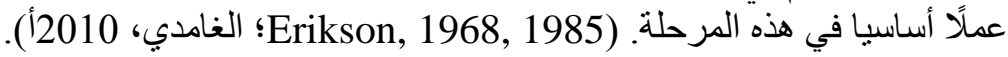

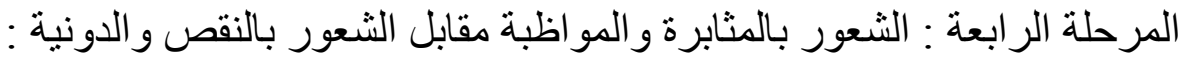

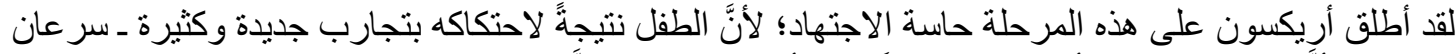

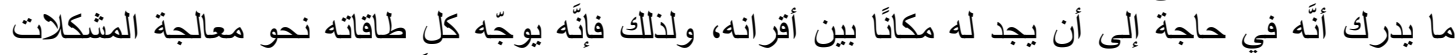

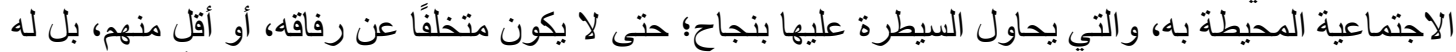

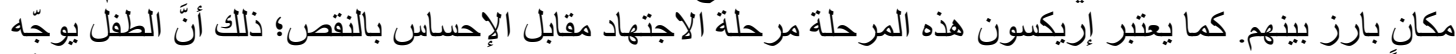

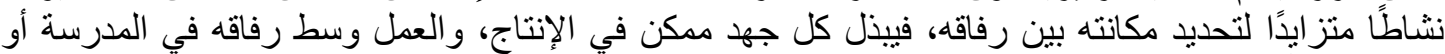

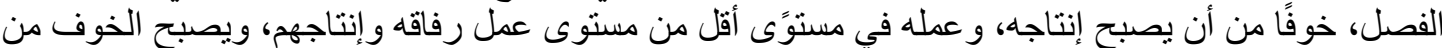

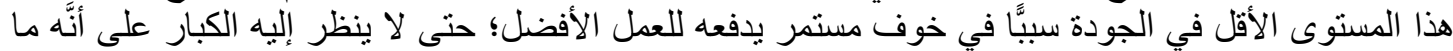

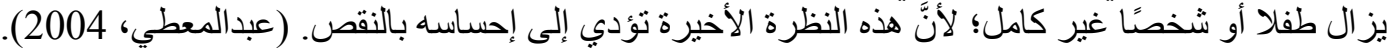

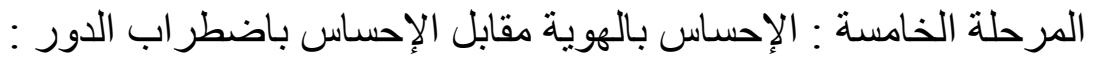

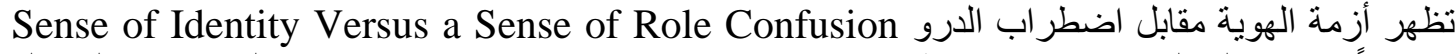

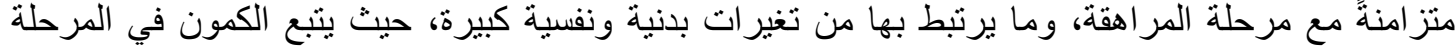

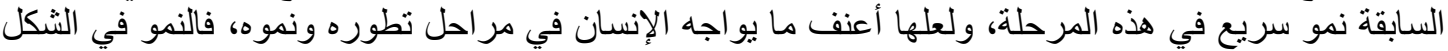

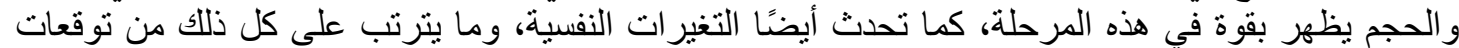

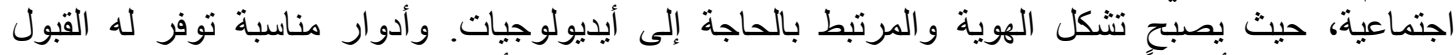

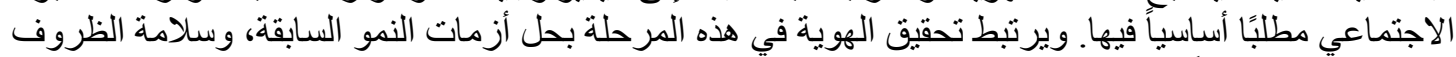

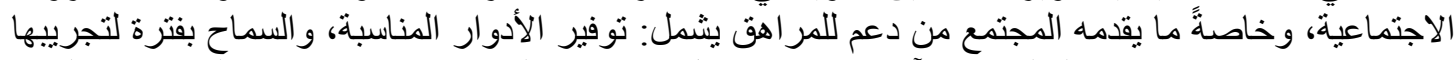

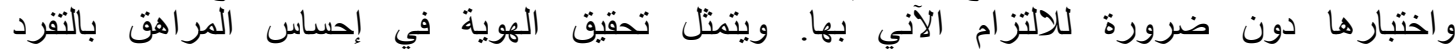

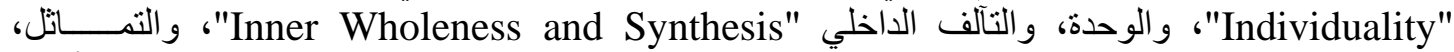

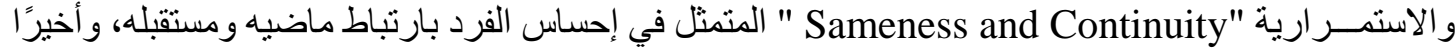

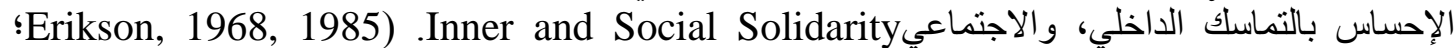

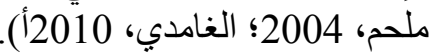

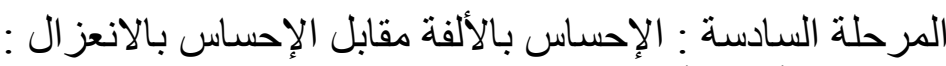

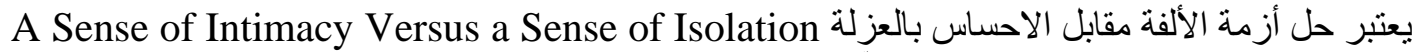

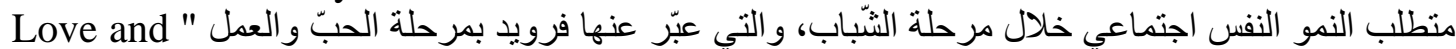

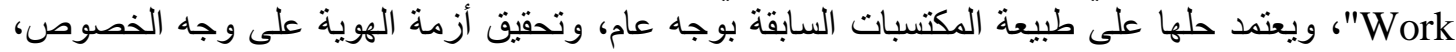

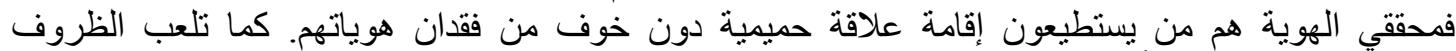

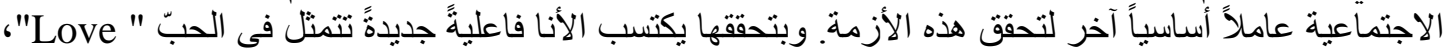

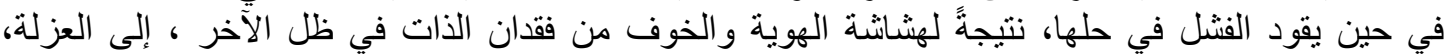

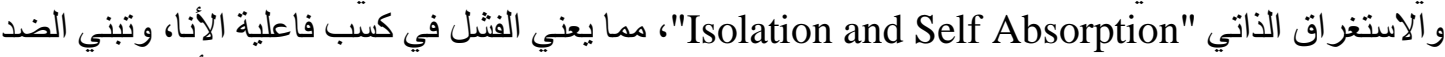

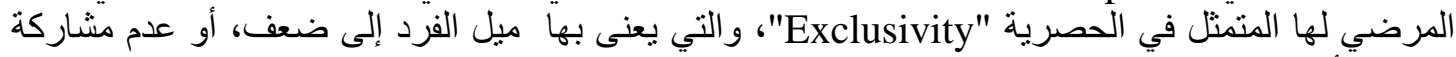

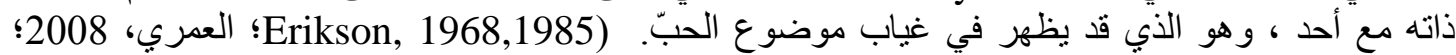

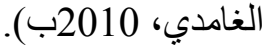

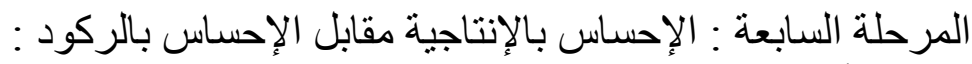

A Sense of Generativity versus a Sense of تظهر أزمة الإنتاجية مقابل الاحساس بالركودة الإنة Stagnation "Generativity"

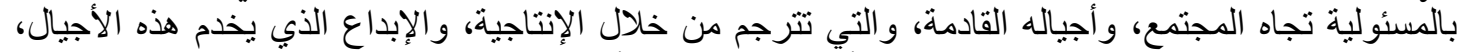

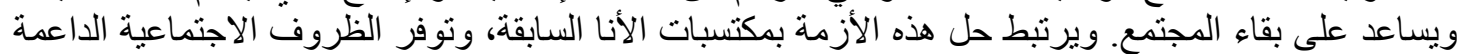

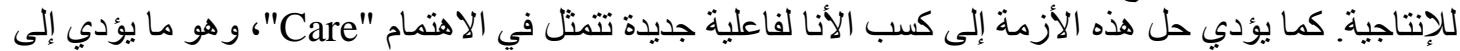




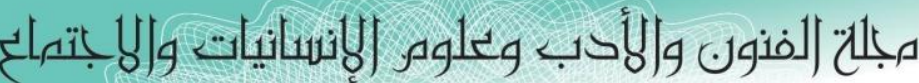

Journal of Arts, Literature, Humanities and Social Sciences

ISSN online: 2414 - 3383

ISSN print: 2616 - 3810

\section{العدد (43) ايلول - سبتمبر 2019}

انتقال الفرد من الحبّ المرتبط بأزمة الألفة، و القائم على التبادلية بين طرفين إلى اهتمام أوسع يشمل الأجبال

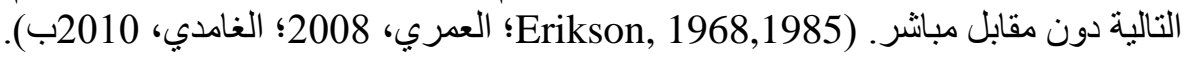

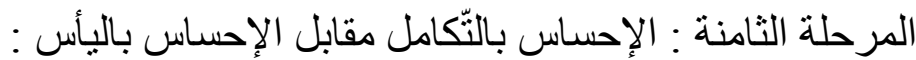

تمثل أزمة النكامل مقابل الئس بأس

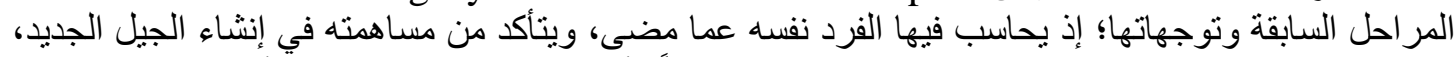

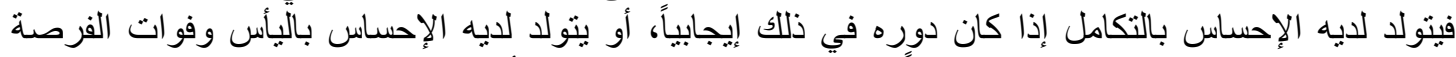

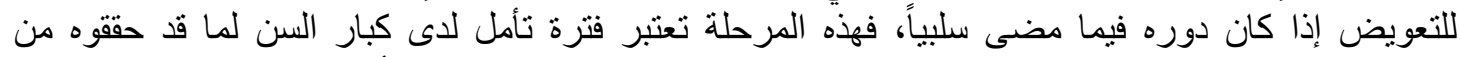

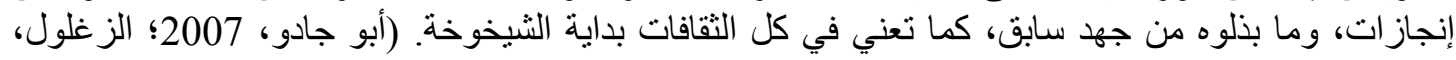

. (2008

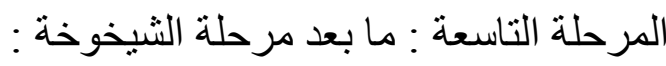

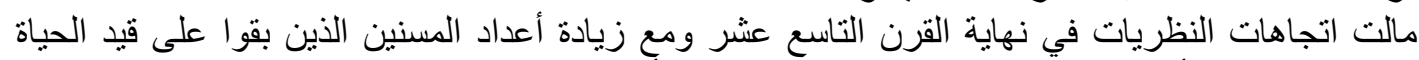

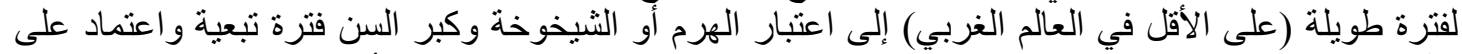

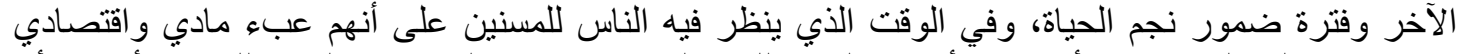

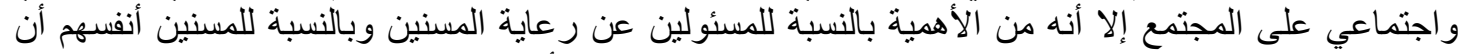

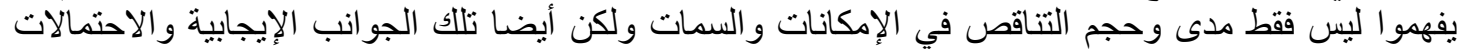
الممكنة لتحقيق المزيد من التطور ات في هذه المرحلة العمرية . لإنات

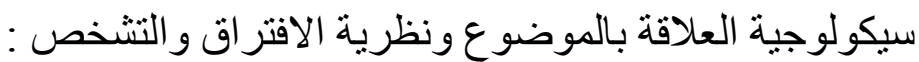

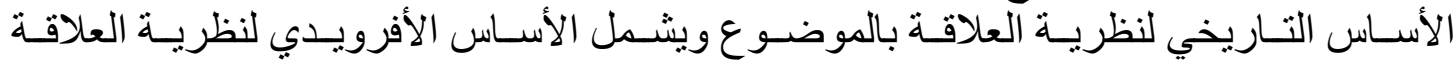
بالموضوع : ب الأبان

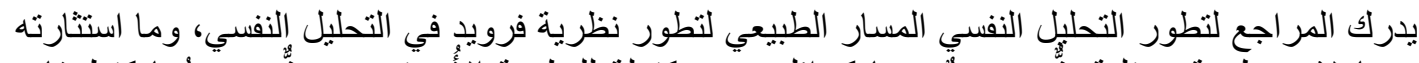

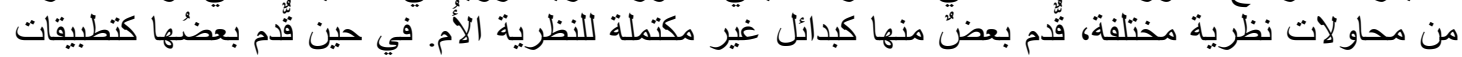

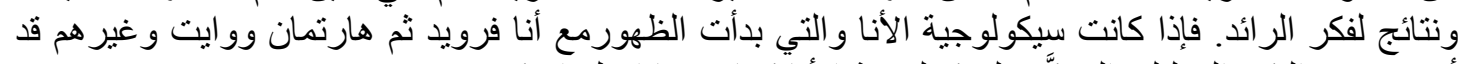

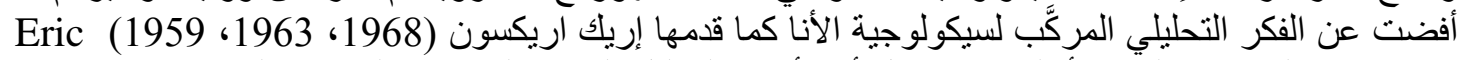
Erikson

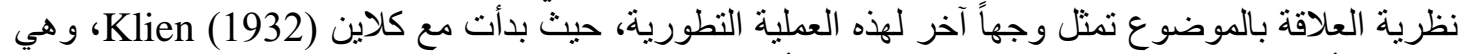

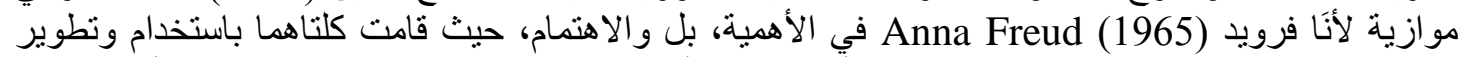

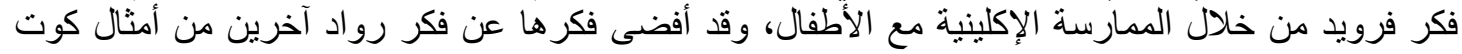

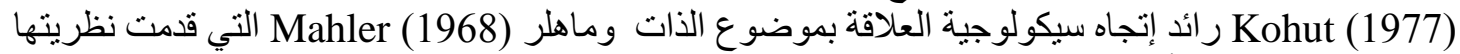

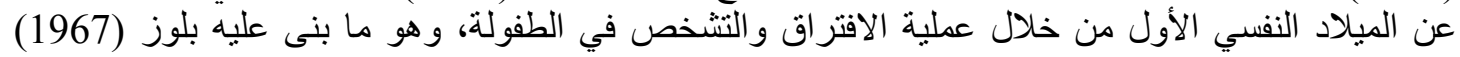

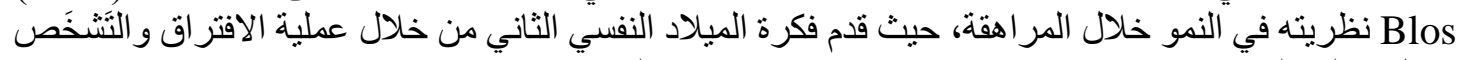

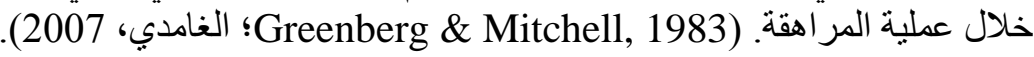

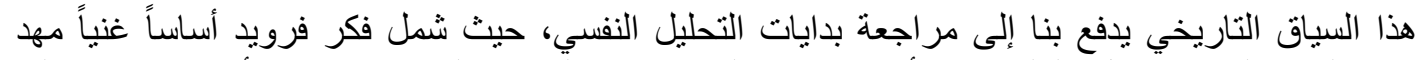

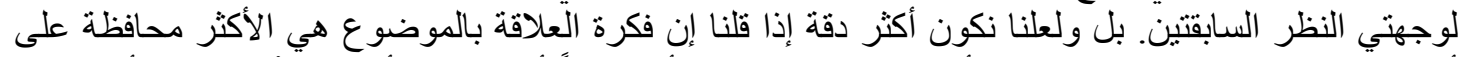

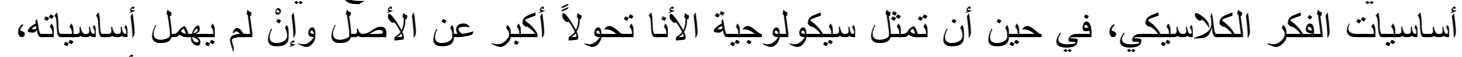

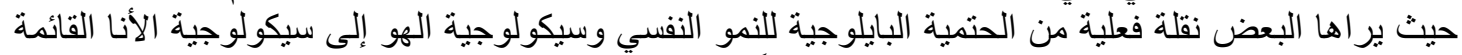

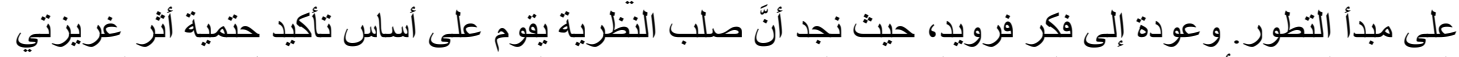

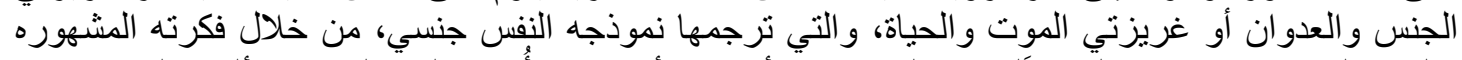

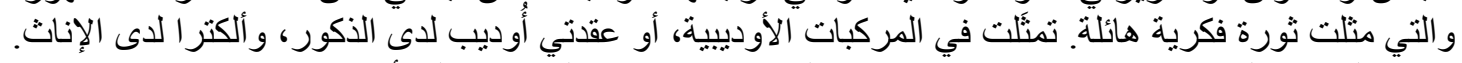

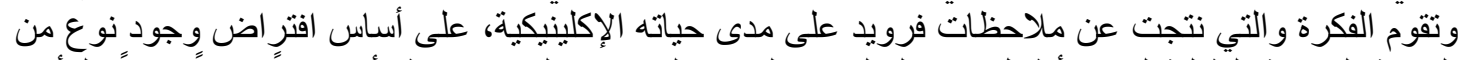

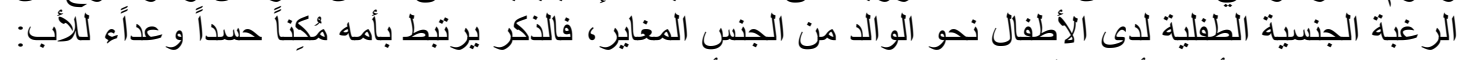

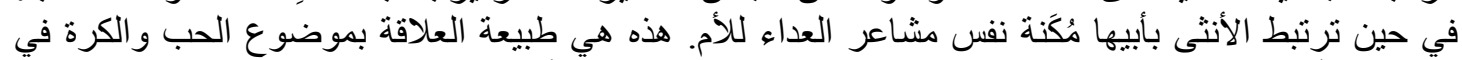
النظرية الأم. هذه العلاقة الحتمية المبنية على رغبة غير مقبولة تكون أساس ديناميكية نمو الثخصية، حيث لحل 


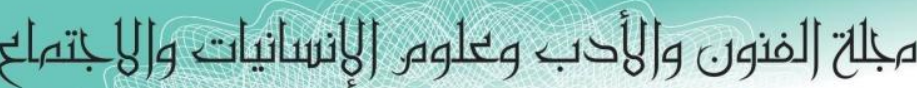

Journal of Arts, Literature, Humanities and Social Sciences

ISSN online: 2414 - 3383

ISSN print: 2616 - 3810

\section{العدد (43) ايلول - سبتمبر 2019}

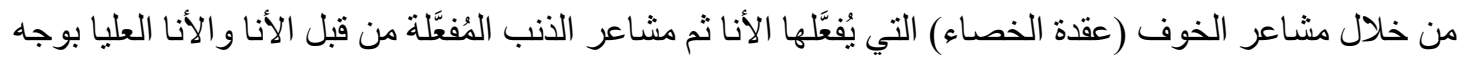

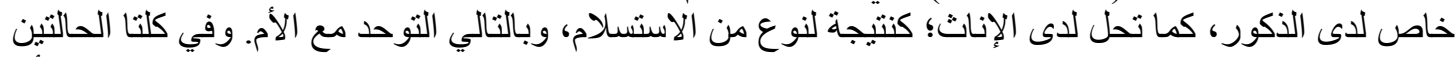

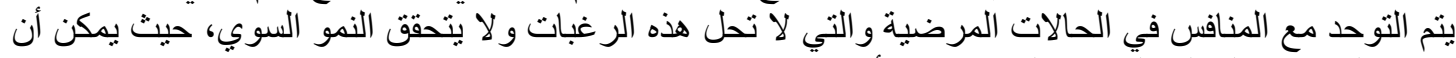

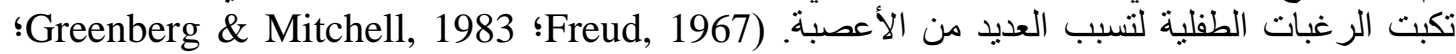

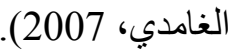

نظرية ماهلر في العلاقة بالموضوع: الافنراق و التشخص في الطفولة :

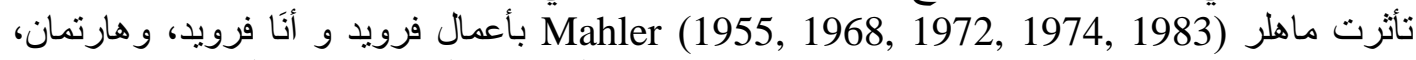

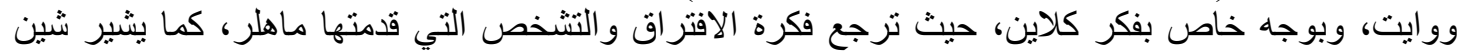

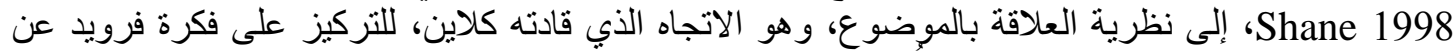

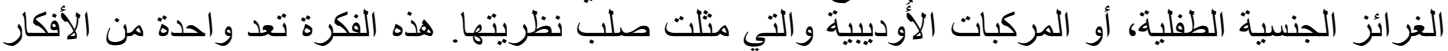

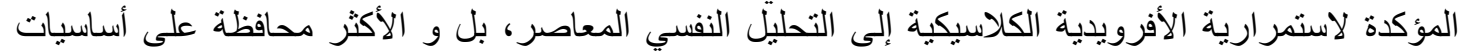

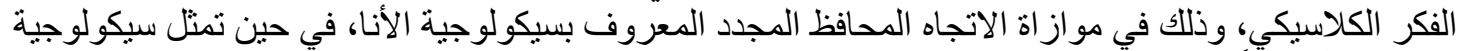

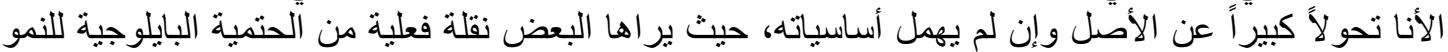

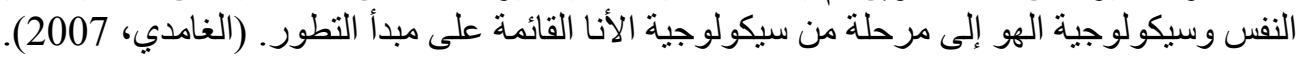

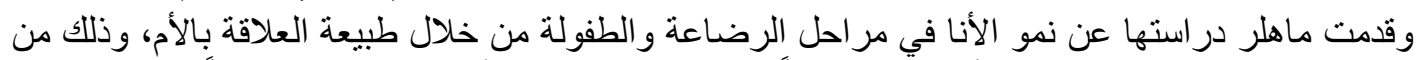

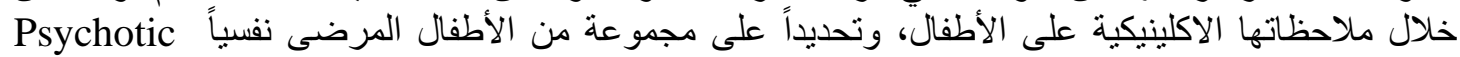
Children

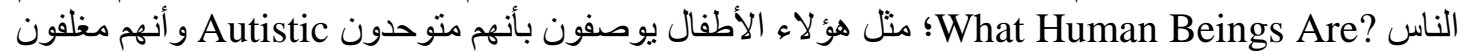

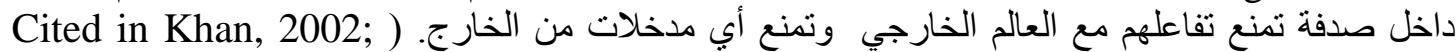
Mahler, 1963, 1968 فئ الغامدي، 2007). نظرية بلوز في العلاقة بالموضوع : الافتر اق و التشخص في المر اهقة :

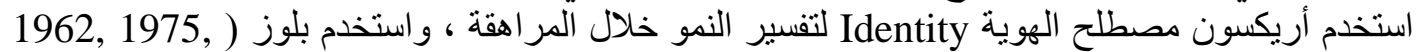
Blos (1967, 1979

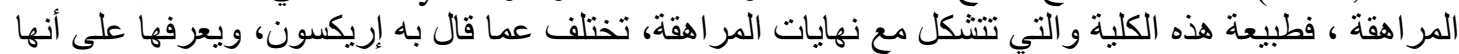

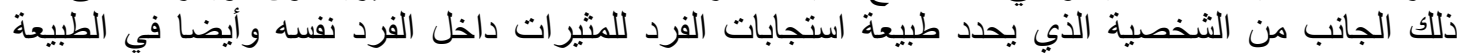

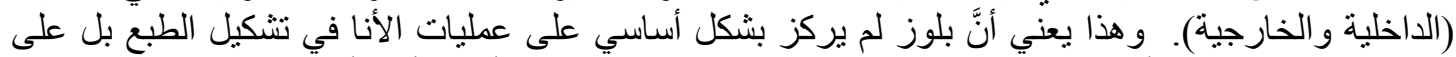

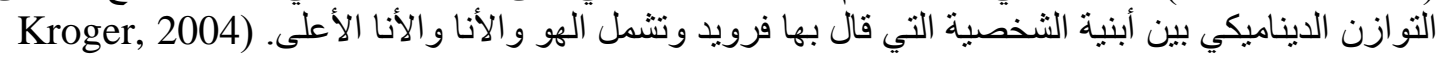

(Blos, 1967, 1979;

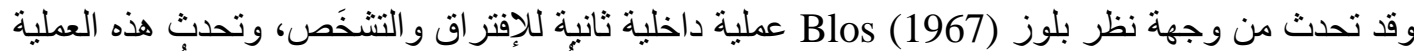

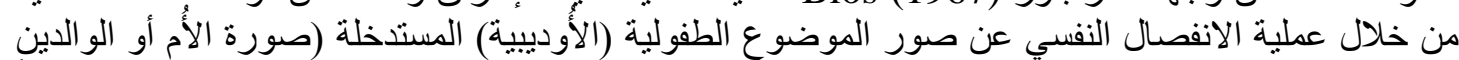

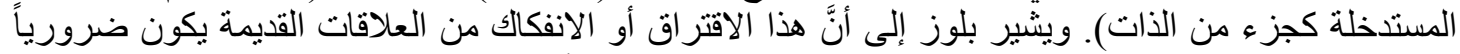

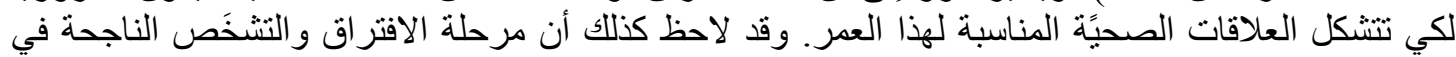

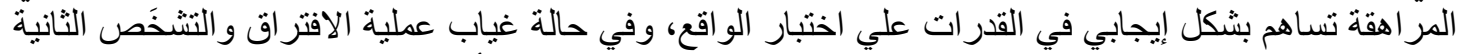

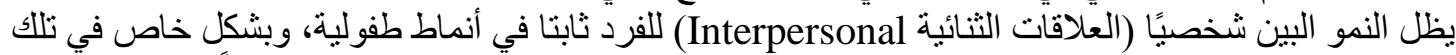

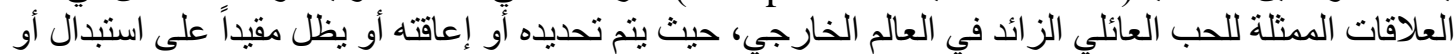
تكرار بسيط للإِثِياء الممثلة للحب القديم لدى الفرد. (Blos, 1967, 1988).

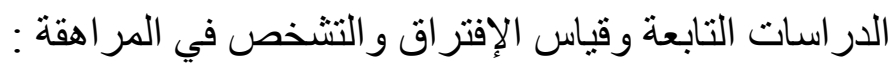

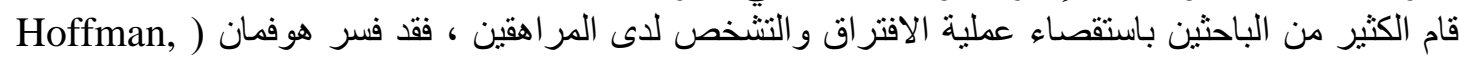

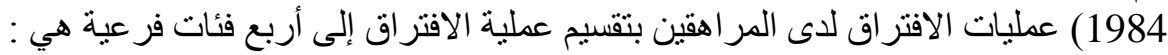

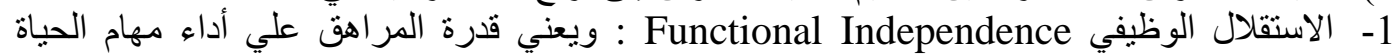
اليومية دون مساعدة الو الدين. 


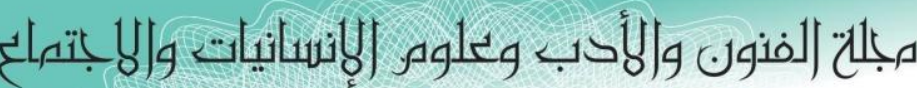

Journal of Arts, Literature, Humanities and Social Sciences

ISSN online: 2414 - 3383

ISSN print: 2616 - 3810

\section{أيلول - سبتمبر 2019}

العدد (43)

2- استقلال الاتجاهات Attitudinal Independence : ويعني أن متتقدات واتجاهات المر اهق متمايزة

(مختلفة عن معتقات واتجاهات الوالاين، و وأنه قادر علي أن تبني أفكار ومشاعر منفصله أو مختلفة

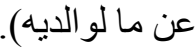

3- الاستقلال الانفعالي Emotional Independence : قدرة المر اهق علي أن يعيش دون اقتراب مبالغ فيه أو انفعالات شديدة من الو الدين.

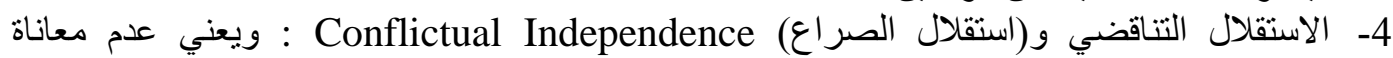

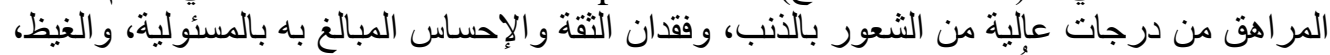
و الغضب في علاقته بالأم والأب. (Hoffman, 1984).

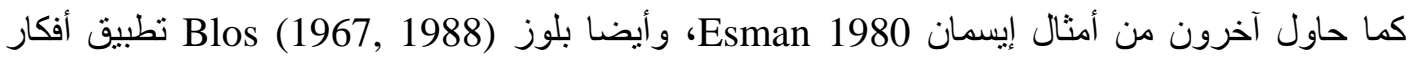

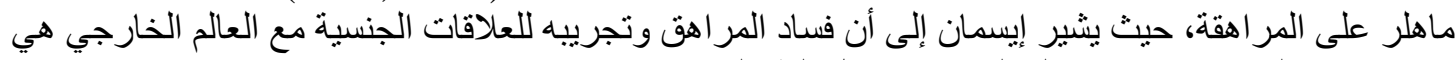

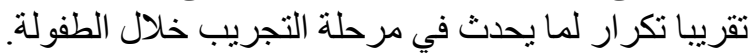

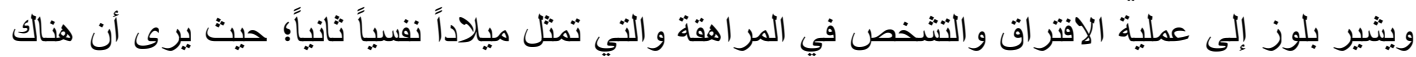

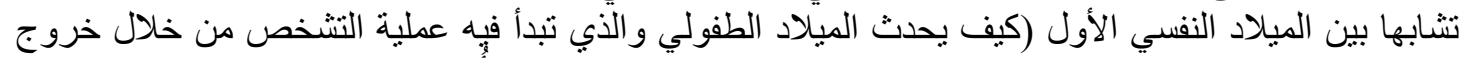

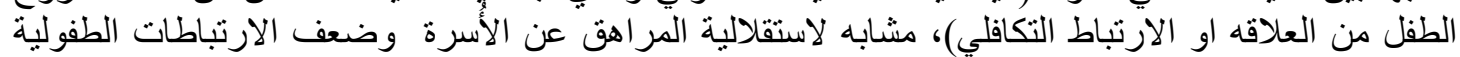

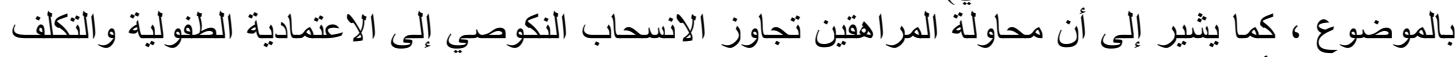

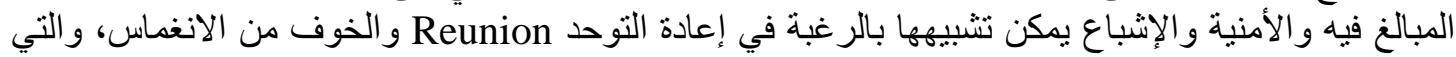

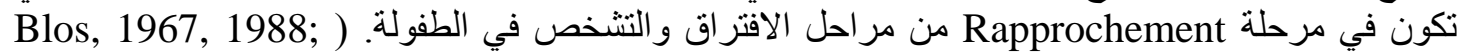
.(Shields, 2003; Moler, 2005

$$
\text { مقياس الإفتر اق و التشخص الدو البحث : للمر اهقين : }
$$

قامت الباحثة بتعريب مقياس الافتراق و التثخص للمراهقة (SITA) الذي قام بإعداده ليفين، جرين وميلون

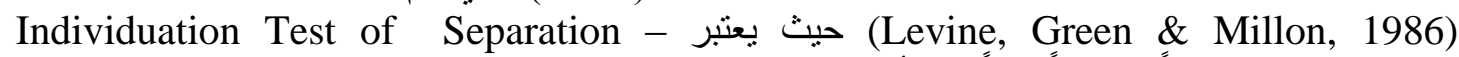
Adolescence

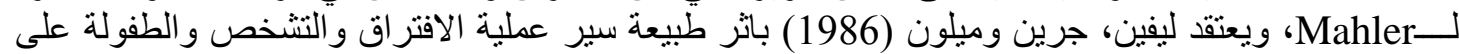

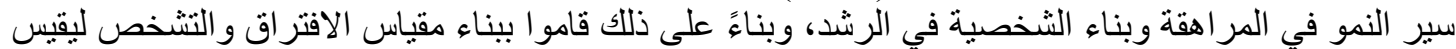

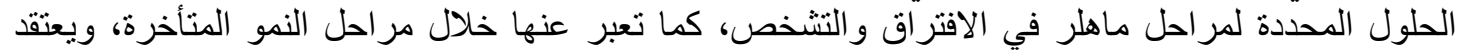

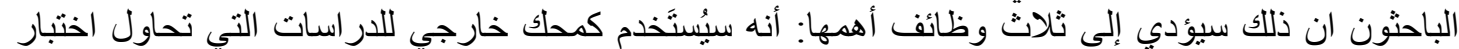

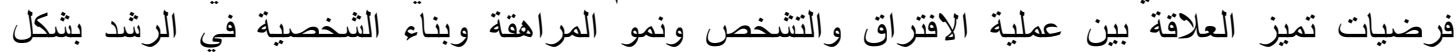

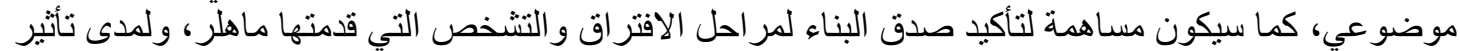

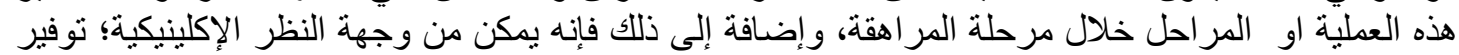

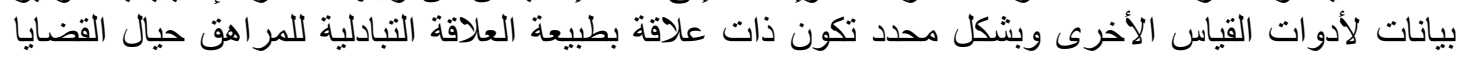
سابقة الذكر.

وبالر غم من إثنارة الباحثين إلى أنَّ محاولتهم هي الدحاولة الأولى على حد علمه لقياس الافتراق و التثخص

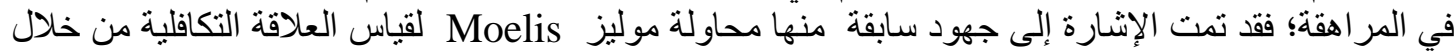

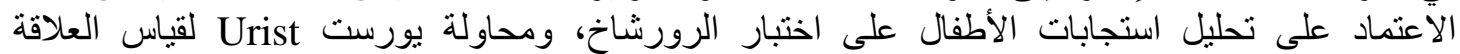

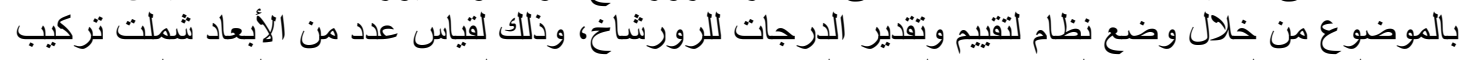

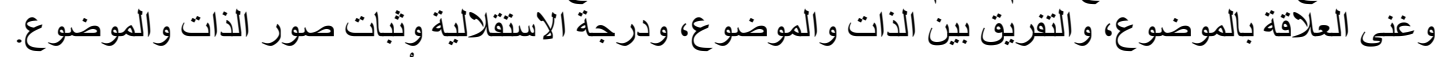

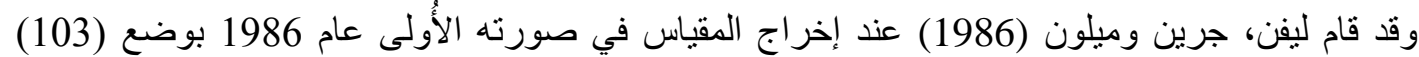

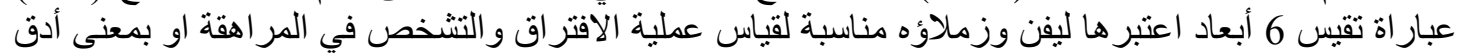

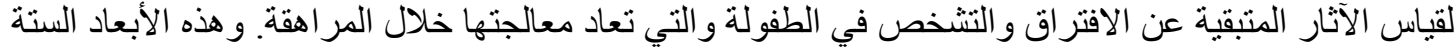
شملت: الإعتمادية Nurturance - Symbiosis، قلق الغنر Engulfment Anxiety، قلق الافتراق 


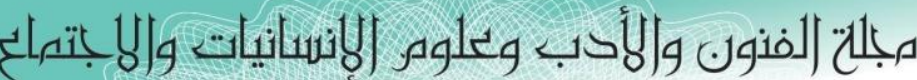

Journal of Arts, Literature, Humanities and Social Sciences

ISSN online: 2414 - 3383

ISSN print: 2616 - 3810

\section{العدد (43) ايلول - سبتهبر 2019}

وكeparation Anxiety والافتراق الصحي Healthy Separation.

وفي عام 1993 قام كل من ليفين وسانتونج (Levine, Santonge, 1993) بمر اجعة المقياس؛ حيث نم

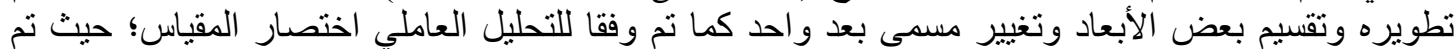

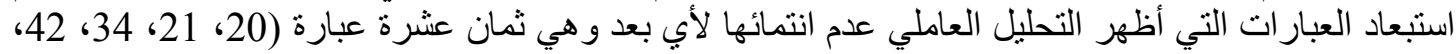

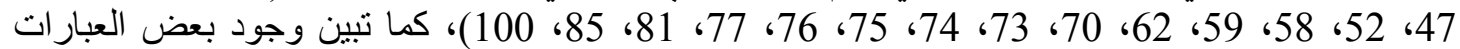

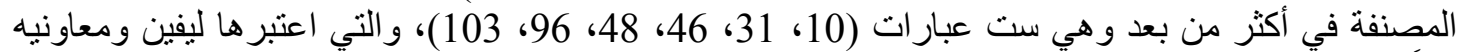

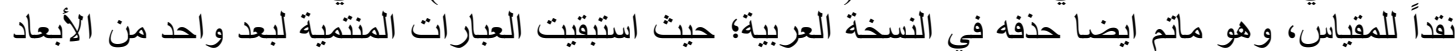

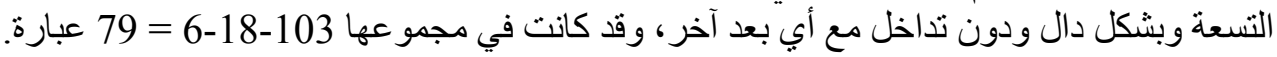

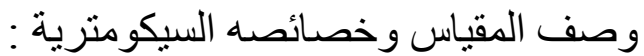

مقياس الافتراق و التشخص للمر اهقين SITA الحالي عبارة عن نسخة معدلة من النسخة الأصلية، فقد قام كل

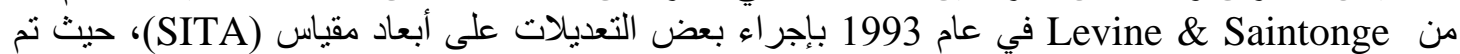

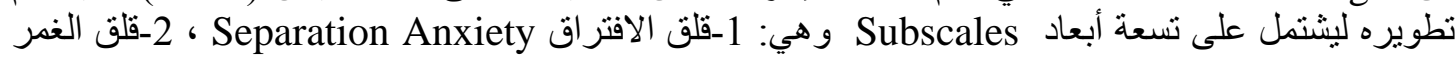
Peer Nurturance Symbiosis ، Engulfment Anxiety

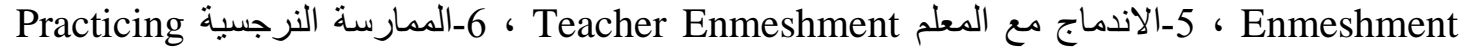

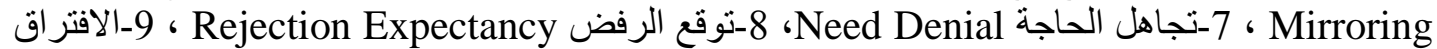

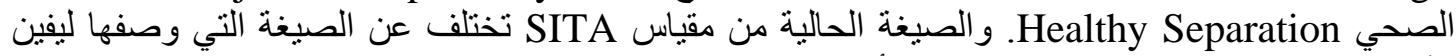
وآخرون Levine et al (1986) من ثلاثة أوجه :

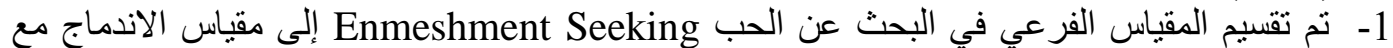

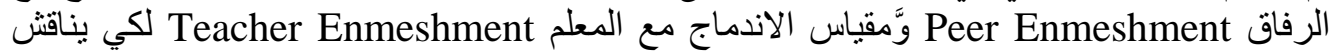
بالتفصيل جهود المر اهق في البحث عن الحب (Levine \& Saintonge, 1993). 2- في محاولات لتوسيع الاستخدام الإكلينيكي لمقياس SITA فقد تم إضافة مقياس توقع الرفض Rejection - Expentancy

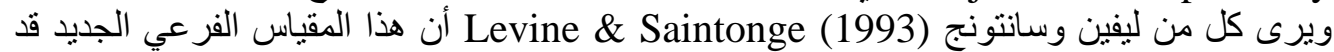

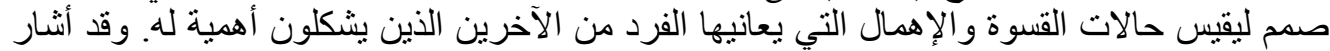
Kernberg (1975) و التشخص لدى المرضى الذين يعانون النرجسية والثين الثخصية الحدية. 3- تم إعادة تسمية مقياس "التمركز حول الذات" Self-Centeredness في النسخة الأصلية من SITA إلى "الممارسة النرجسية Practicing - Mirroring" لكي يصف المفاهيم المستهدفة بشكل أفضل ولكي يتو افق مع مصطلحات Mahler التي استخدمتها لوصف مرحلة الافتر اق و التشخص في الطفولة المبكرة والتي تتبع هذا المقياس من الناحية النظرية.

وقد سجل McClananhan And Holmbeck (1992) ثبات معاملات ألفا في النسخة الأصلية لمقياس SITA

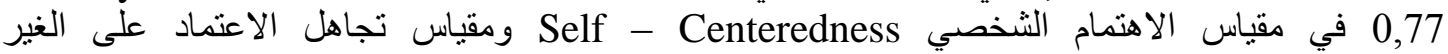

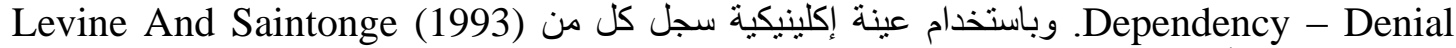
معاملات ثبات ألفا في النسخة الحالية من SAITA، و التي نراوحت من من

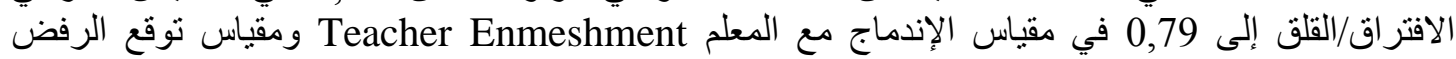

.Rejection- Expectency تم تسجيل معاملات ارتباط ألفا للنسخة الحالية من SITA حيث طبق المقات المباس على عينة غير إكلينيكية وتر اوحت معدلات الثبات من 0,64 على مقياس الافتراق الصناف الصحي إلى .(Levine \& Saintonge, 1993) Practicing - Mirroring 


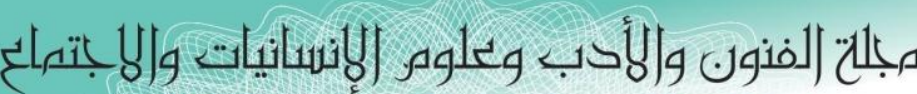

Journal of Arts, Literature, Humanities and Social Sciences

ISSN online: 2414 - 3383

ISSN print: 2616 - 3810

\section{العدد (43) أيلول - لسبتمبر 2019}

جدول (1) معاملات الاتساق (الفا) على عينات إكلينيكية و عينات غير إكلينيكية

\begin{tabular}{|c|c|c|}
\hline العينة غير الإكلينيكية (ن = 302) & العينة الإكلينيكية (ن= 117) & مقياس SITA \\
\hline 0,77 & 0,68 & قلق الافتر اق \\
\hline 0,77 & 0,75 & 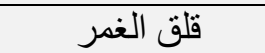 \\
\hline 0,79 & 0,74 & تجاهل الحاجة \\
\hline 0,88 & 0,85 & الممارسة النرجسية \\
\hline 0,75 & 0,74 & الإندماج مع الرفاق \\
\hline 0,64 & 0,64 & الافتر اق الصحي \\
\hline 0,70 & 0,74 & الإعتمادية \\
\hline 0,79 & 0,79 & الإندماج مع المعلم \\
\hline $\begin{array}{ll}--- \\
---\end{array}$ & 0,79 & توقع الرفض \\
\hline
\end{tabular}

وقد أكد ليفين وسانتونج (1993) Levine And Saintonge صدق النسخة الحالية من مقياس SITA بناء

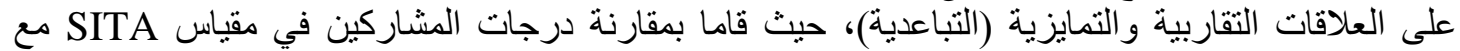

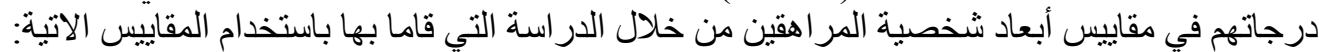

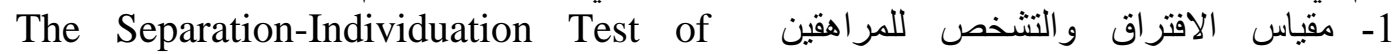
Adolescence (SITA).

2- المقياس الإكلينيكي التقييمي للافتراق و التشخص The Clinician Rating Scale of Separation -Individuation (CRSSI).

3- المقياس الإكلينيكي التقييمي للحدود والنرجسية في الأمراض النفسية The Clinician Rating

Scale of Borderline and Narcissistic Psychopathology. (CRSBNP)

4- مقاييس اختبار منسوتا للثخصية The Millon Adolescent Personality Inventory

(MAPI).

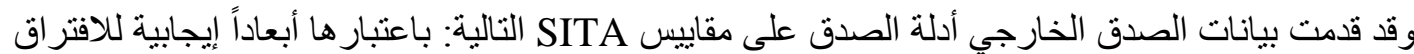

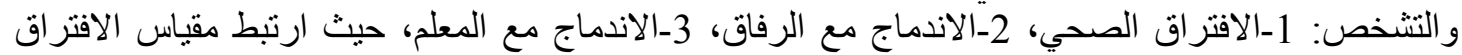

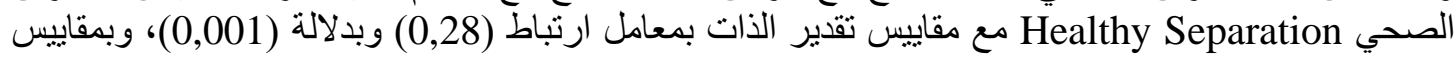

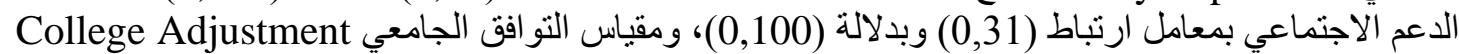
بمعامل ارتباط (0,20) و وبدلاعلة (0,001)

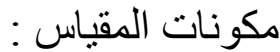

قامت الباحثة بتعريب مقياس الافتر اق و التشخص اللذب قام كل من Levine \& Saintonge في عام 1993

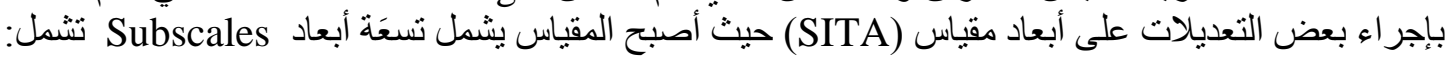

Separation Anxiety

Engulfment Anxiety

Nurturance Symbiosis

Peer Enmeshment

Teacher Enmeshment

Practicing Mirroring

Need Denial

Rejection Expectancy

Healthy Separation
1-

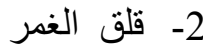

3-

4- الاندماج مع الرفاق

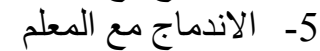

6- الممارسة النرجسية المسطة

7-

8- - توقع الرفض الأن

9- الافتراق الصحي

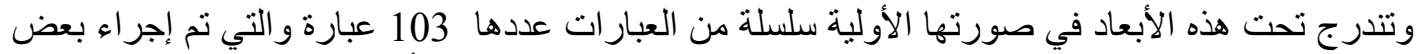

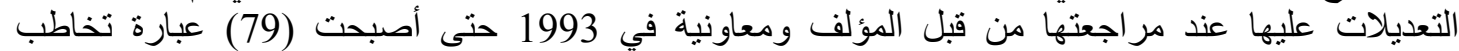
الاتجاهات نحو العلاقات مع الأبوين و المعلمين والأقران وتصف الكئن الكثير من المشاعر و السلوكيات لدى الأفراد، 


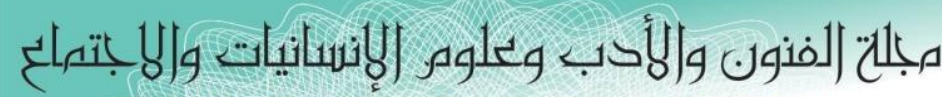
Journal of Arts, Literature, Humanities and Social Sciences

ISSN online: 2414 - 3383

ISSN print: 2616 - 3810

\section{العدد (43) ايلول - سبتهبر 2019}

ويتم تقدير استجابات المقياس بطريقة Likert كمقياس من خمس درجات بحيث تبدأ من تقدير درجة (5) لتشير إلى "تماماً" إلى (1) لتشير إلى الى "مطلقاً".

جدول (2) نوزيع أفر اد العينة وفقا للجنس

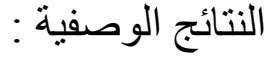

\begin{tabular}{|c|c|c|}
\hline النسبة & النكر ار & الجنس \\
\hline$\% 42$ & 162 & ذكر \\
\hline$\% 58$ & 220 & أنثى \\
\hline$\% 100.0$ & 382 & المجموع \\
\hline
\end{tabular}

جدول (3) التوزيع العمري لأفر اد عينة البحث

\begin{tabular}{|c|c|c|}
\hline النسبة & التكر ار & فئات العمر \\
\hline$\% 29$ & 112 & 14 إلى 16 سنة \\
\hline$\% 68$ & 258 & 17 إلى 18 سنة \\
\hline$\% 3$ & 12 & 19 إلى 20 سنة \\
\hline$\% 100.0$ & 382 & الدجموع \\
\hline
\end{tabular}

جدول (4) المستوى الدراسي لأفر اد عينة البحث

\begin{tabular}{|c|c|c|}
\hline النسبة & التكر ار & المستوى الدراسي \\
\hline$\% 18$ & 70 & أول ثانوي \\
\hline$\% 38$ & 144 & ثاني ثانوي \\
\hline$\% 44$ & 168 & ثالث ثانوي \\
\hline$\% 100.0$ & 382 & المجموع \\
\hline
\end{tabular}

جدول (5) التخصص الدراسي لأفر اد عبنة البحث

\begin{tabular}{|c|c|c|}
\hline النسبة & التكرار & التخصص \\
\hline$\% 18$ & 70 & عام \\
\hline$\% 46$ & 175 & علمي \\
\hline$\% 36$ & 137 & أدبي \\
\hline \%100.0 & 382 & المجموع \\
\hline
\end{tabular}

النتائج :

1- ما طبيعة نمو الأنا (حل أزمات النمو النفس اجتماعي للانانا) أثناء مرحلة المراهقة من وجهة نظر أريكسون

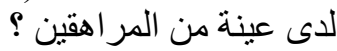
للكثف عن طبيعة تثكل جوانب النمو موضوع الدراسة، والتي شملت نمو الأنا في حل أزمات الأنا

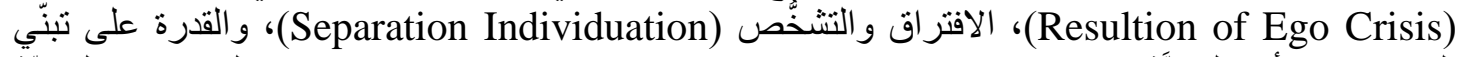

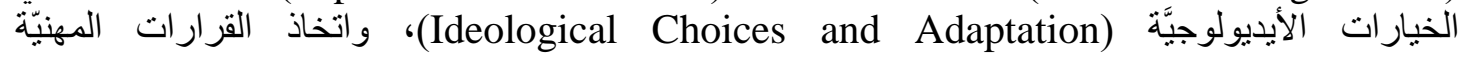

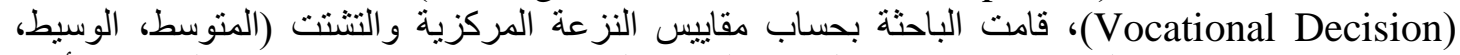

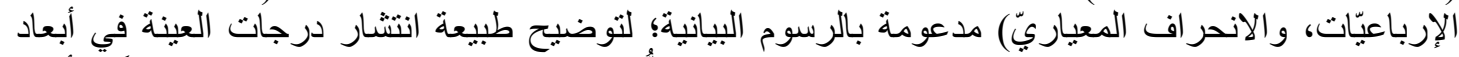

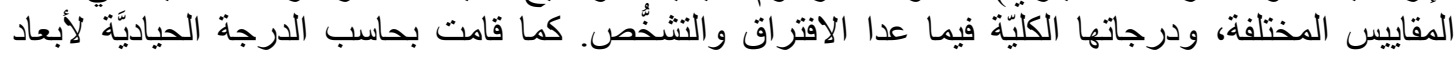

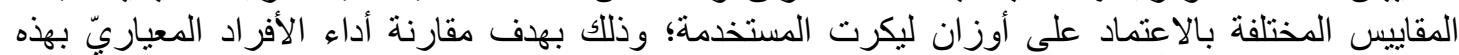

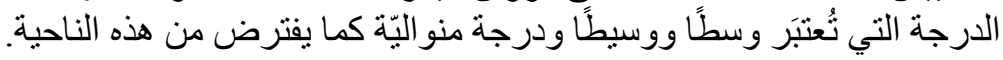




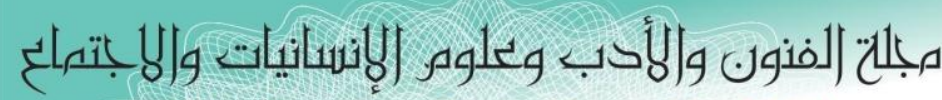

Journal of Arts, Literature, Humanities and Social Sciences

ISSN online: 2414 - 3383

ISSN print: 2616 - 3810

\section{العدد (43) ايلول - سبتهبر 2019}

جدول (6) الإحصاء الوصفي لدرجات نمو الأنا (أزمات نمو الأنا)

\begin{tabular}{|c|c|c|c|c|c|c|c|}
\hline \multicolumn{3}{|c|}{ الارباعايات } & \multicolumn{4}{|c|}{ الإحصاءات الوصفية } & \multirow[b]{2}{*}{ أزمات الانا } \\
\hline الأعلى وحجم الارباعي & الاربجاعي العينة بين & والارباعي العينة & الالانحراف & المتوسط & العليا & الدرجة الأدنى & \\
\hline$(100) 12$ & (173) 7 & $(109) 3$ & 6,03 & 7,3 & 24 & $11-$ & الثقة \\
\hline ) 9 & (159) 4 & 00 ( 113) & 7,2 & 4,5 & 23 & $19-$ & الاستقلال \\
\hline (113) 14 & (172) 10 & (97) 4 & 7,6 & 9,4 & 28 & $13-$ & المبادرة \\
\hline ( 101) 12 & ( 176) 7 & (105) 2 & 7,6 & 6,8 & 25 & $16-$ & المثابرة \\
\hline$(102) 10$ & (180) 5 & $(100)-1$ & 7,46 & 4,85 & 26 & 16- & 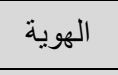 \\
\hline ( 108) 12 & ( 167) 6 & (107) 2 & 7,5 & 7,05 & 27 & $13-$ & الألفة \\
\hline ( 110) 11 & ( 173) 7 & (99) 1 & 6,95 & 6,2 & 24 & $17-$ & الإنتاجية \\
\hline 14 ( 105) & ( 166) 9 & (111) 4 & 7,7 & 8,7 & 27 & $17-$ & التكامل \\
\hline ( 98 ) 82 & ( 187) 56 & (97) 22 & 43,1 & 54,8 & 176 & 83- & الكلية \\
\hline
\end{tabular}

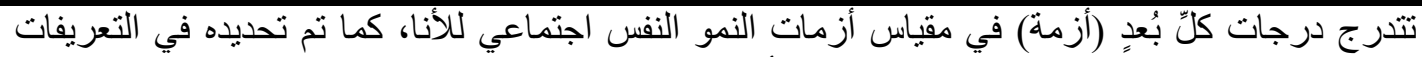

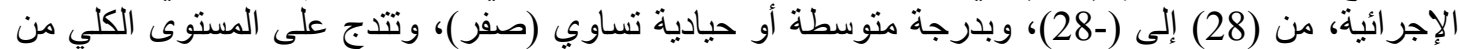

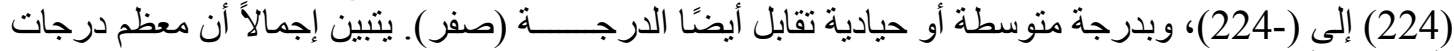

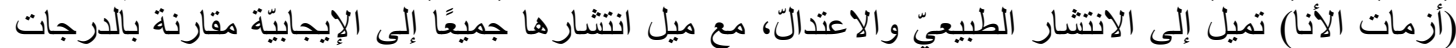

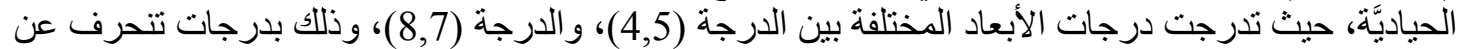

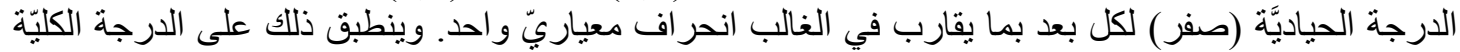

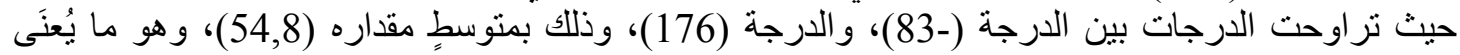

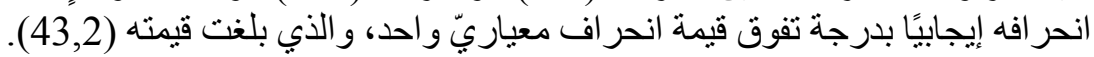

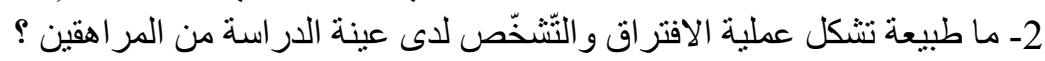

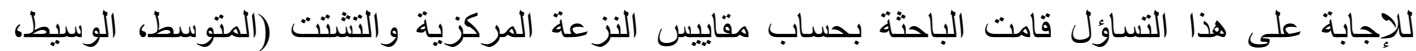

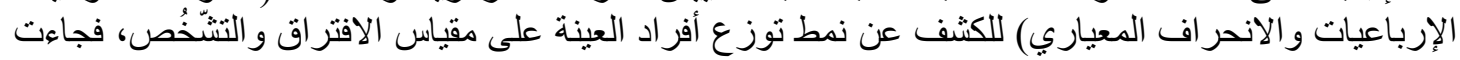

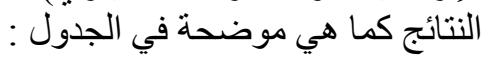




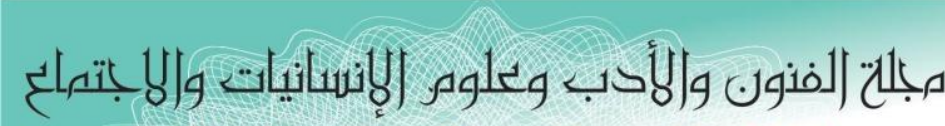
Journal of Arts, Literature, Humanities and Social Sciences

ISSN online: 2414 - 3383

ISSN print: 2616 - 3810

\section{العدد (43) ايلول - سبتهبر 2019}

جدول (7) الإحصاء الوصفي لدرجات الافتراق و التشخُّص

\begin{tabular}{|c|c|c|c|c|c|c|c|c|c|c|}
\hline \multicolumn{3}{|c|}{ الارباعايات } & \multicolumn{4}{|c|}{ الإحصاءات الوصفية } & \multirow[b]{2}{*}{ العينة } & \multirow[b]{2}{*}{ الدياد } & \multirow[b]{2}{*}{ العبارات } & \multirow[b]{2}{*}{ ألأنات } \\
\hline الأرباعى & الوالوالوبيطة & الأربنى العباعي & الانحرياري & المتوسط & العليا & الأدنى & & & & \\
\hline $\begin{array}{l}21,3 \\
(95)\end{array}$ & $\begin{array}{l}\left(\begin{array}{r}17 \\
192)\end{array}\right. \\
\end{array}$ & $\begin{array}{l}13,8 \\
(95)\end{array}$ & 4,98 & 17,5 & 29 & 8 & 382 & 21 & 7 & ق قلق الغمر \\
\hline $\begin{array}{l}60 \\
(100)\end{array}$ & $\begin{array}{l}53 \\
(178)\end{array}$ & $\begin{array}{l}48 \\
(104)\end{array}$ & 8,6 & 53,6 & 72 & 30 & 382 & 42 & 14 & النرجسية \\
\hline $\begin{array}{l}26 \\
(114)\end{array}$ & $\begin{array}{l}21 \\
(161)\end{array}$ & $\begin{array}{l}17 \\
(107)\end{array}$ & 6,5 & 21,9 & 42 & 10 & 382 & 30 & 10 & تجاهل \\
\hline $\begin{array}{l}38 \\
(117)\end{array}$ & $\begin{array}{c}34 \\
(159)\end{array}$ & $\begin{array}{l}30 \\
(106)\end{array}$ & 6,5 & 34,3 & 79 & 18 & 382 & 30 & 10 & الافتراق \\
\hline $\begin{array}{l}15 \\
(103)\end{array}$ & $\begin{array}{c}12 \\
(154)\end{array}$ & $\begin{array}{c}9 \\
(125)\end{array}$ & 4,5 & 12,1 & 25 & 5 & 382 & 15 & 5 & مع المعلم \\
\hline $\begin{array}{c}27 \\
(99)\end{array}$ & $\begin{array}{l}23,5 \\
(178)\end{array}$ & $\begin{array}{l}19 \\
(105)\end{array}$ & 4,9 & 22,7 & 30 & 10 & 382 & 18 & 6 & مع الأرفاق \\
\hline $\begin{array}{c}31 \\
(110)\end{array}$ & $\begin{array}{c}28 \\
(156)\end{array}$ & $\begin{array}{l}26 \\
(116)\end{array}$ & 3,8 & 28,1 & 35 & 15 & 382 & 21 & 7 & الاعتمادية \\
\hline $\begin{array}{l}22 \\
(101) \\
\end{array}$ & $\begin{array}{c}20 \\
(162) \\
\end{array}$ & $\begin{array}{l}18 \\
(119) \\
\end{array}$ & 3,1 & 19,8 & 49 & 10 & 382 & 15 & 5 & الافتراق \\
\hline $\begin{array}{l}25 \\
(111)\end{array}$ & $\begin{array}{l}21 \\
(154)\end{array}$ & $\begin{array}{l}18 \\
(117)\end{array}$ & 6 & 21,8 & 43 & 9 & 382 & 30 & 10 & الرفضع \\
\hline
\end{tabular}

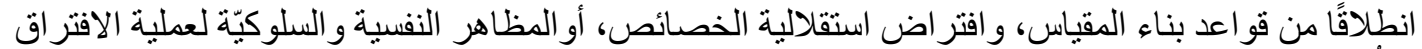

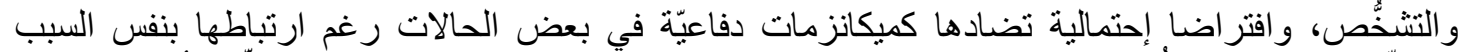

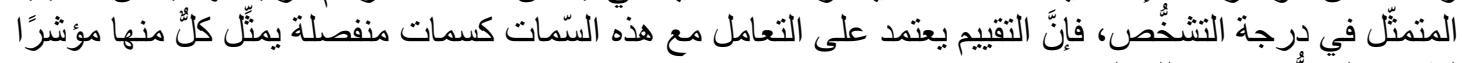
لطبيعة التشخُص في في ذللك البعد.

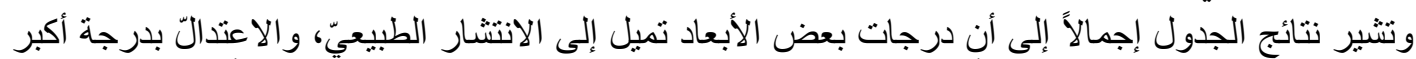

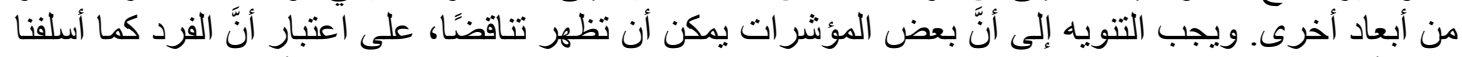

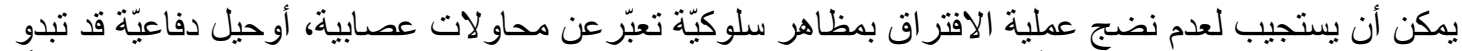

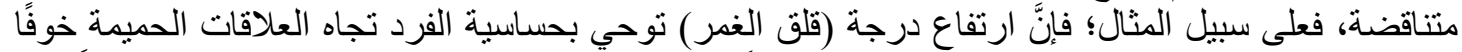

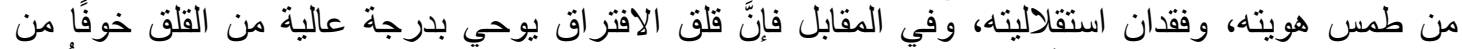

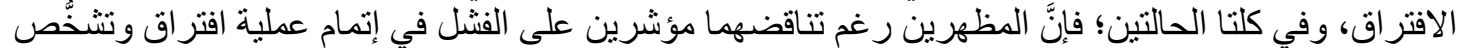

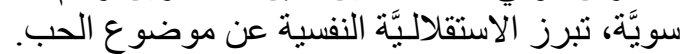

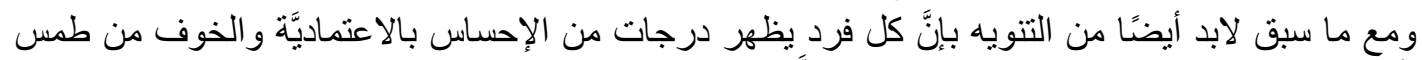

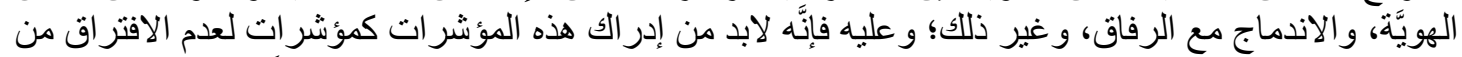

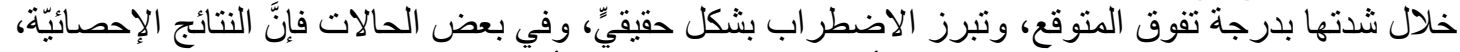

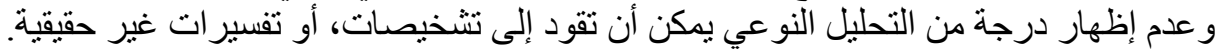




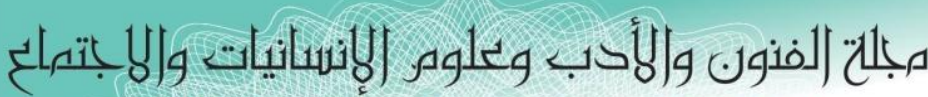
Journal of Arts, Literature, Humanities and Social Sciences

\section{ISSN online: 2414 - 3383}

ISSN print: 2616 - 3810

\section{العدد (43) ايلول - سبتهبر 2019}

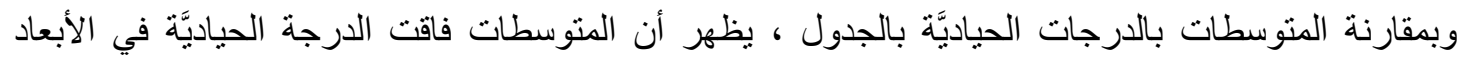

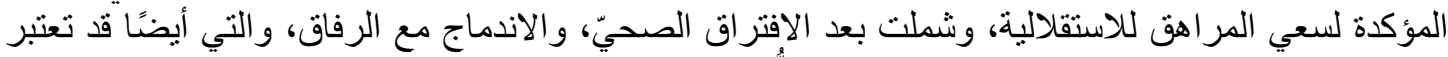

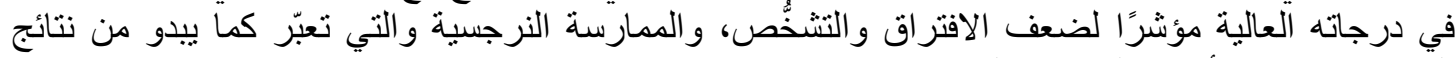

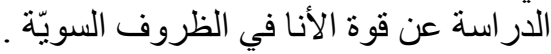
3- هل يوجد علاقات ذات دلالة إحصائية بين درجات الأفر الفر اد في كل من عملية الافتراق و التثخُّص، ونمو الأنا

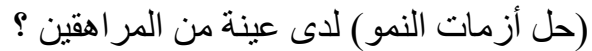

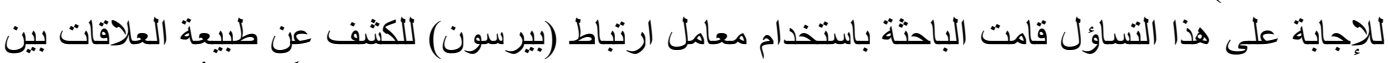

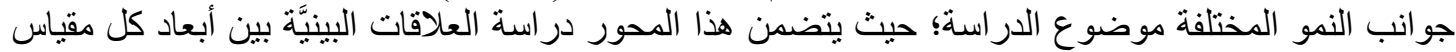
على حده، والعلاقات القائمة بين أبعاد كل مقياس والمقاييس الأخرى. جدول (8) علاقة أبعاد الأنا ببعضها

\begin{tabular}{|c|c|c|c|c|c|c|c|c|c|}
\hline الكلية & الحكمة & | الإنتاجية & الاهتمام & الهوية & المثابرة & المبادرة & | الاستقلالية & الثقة & \\
\hline & & & & & & & & 1 & الثقة \\
\hline & & & & & & & 1 & * ‘381 & الاستقلال \\
\hline & & & & & & 1 & $* * 5523$ & **، 449 & المبادرة \\
\hline & & & & & 1 & $* *$ *700 & $* * 4447$ & $* *$ *426 & المثابرة \\
\hline & & & & 1 & $* * 5548$ & $* * 534$ & $* *$ *553 & $* *_{\triangleleft} 416$ & الهوية \\
\hline & & & 1 & $* *$ *346 & $* *$ *225 & $* *$ *330 & $* *$ *134 & $* * 5516$ & الألفة \\
\hline & & 1 & $* * 4412$ & $* * 5514$ & $* *$ *722 & $* * 6666$ & $* * 355$ & $* * 4479$ & الإنتاجية \\
\hline & 1 & $* *$ *562 & $* *$ *383 & $* * 6624$ & $* *$ *561 & $* * 508$ & $* * 5503$ & $* * 564$ & التكامل \\
\hline 1 & $* * 8801$ & $* * 6797$ & $* * 5664$ & $* * 6778$ & $* * 7789$ & $* * 8002$ & ***662 & ***701 & لدرجة الكلية \\
\hline
\end{tabular}

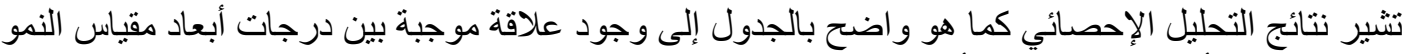

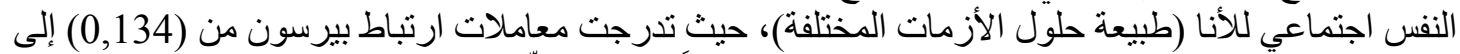

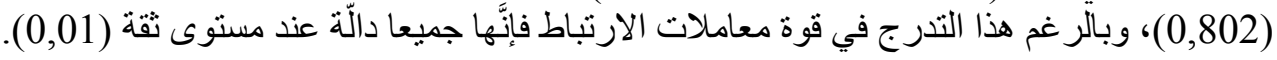

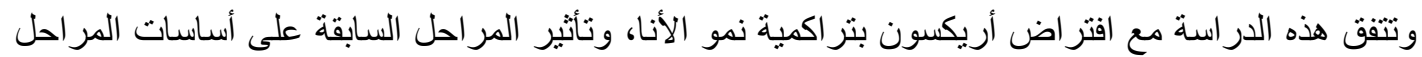

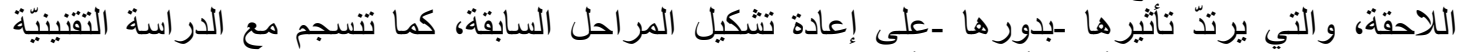

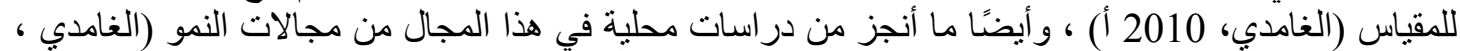

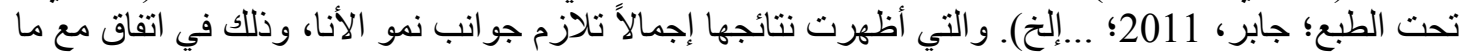

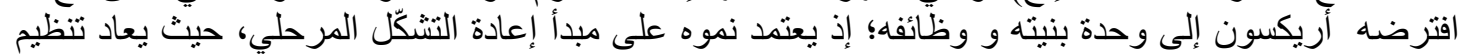

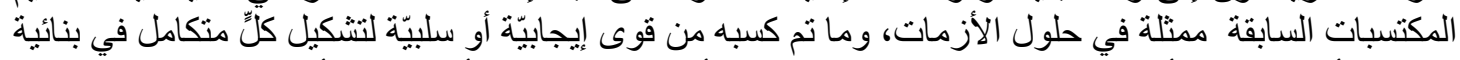

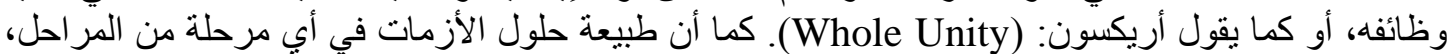

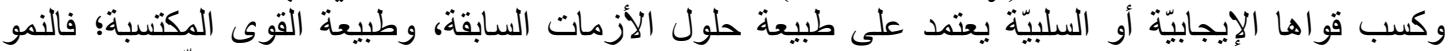

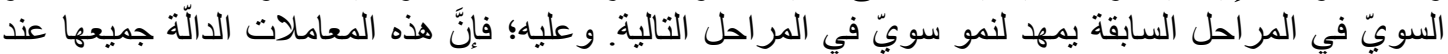

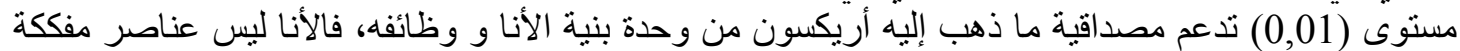

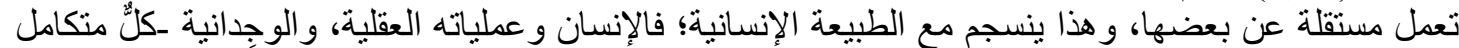

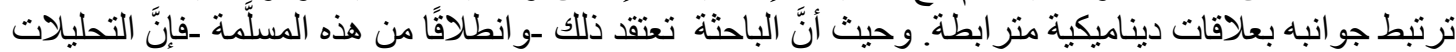

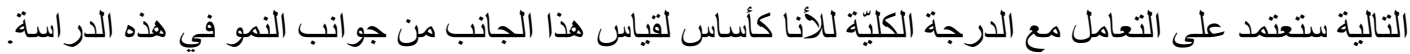




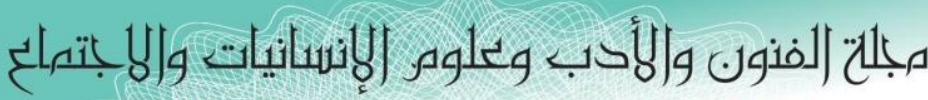
Journal of Arts, Literature, Humanities and Social Sciences

ISSN online: 2414 - 3383

ISSN print: 2616 - 3810

\section{العدد (43) أيلول - لسبتمبر 2019}

جدول (9) العلاقة بين أبعاد الافتراق

\begin{tabular}{|c|c|c|c|c|c|c|c|c|}
\hline | الافتراق & الاعتماد & الاندماج مع & الاندماج مع & الافتراق & تجاهل & النرجسية & قلق الغمر & \\
\hline & & & & & & & 1 & قلق الغر \\
\hline & & & & & & 1 & $*_{،} 106$ & الممارسة النرجسية \\
\hline & & & & & 1 & ، 063 & $* * 139$ & تجاهل الحاجة \\
\hline & & & & 1 & ، 031 & ، 050 & $* *$ 364 & قلق الافتراق \\
\hline & & & 1 & $*_{6} 114$ & 6004 & $* *$ *214 & ، 049 & الاندماج مع المعلم \\
\hline & & 1 & *،128 & **،243 & **،291- & **،293 & $*_{6108}$ & الاندماج مع الرفاق \\
\hline & 1 & $* *$ *205 & ، 014 & $* * 3341$ & ، $054-$ & $* *$ *152 & ، $023-$ & الاعتمادية \\
\hline 1 & ،043 & $* *$ *239 & *،128 & ، 080 & ،001 & **،342 & $* *$ *169 & الافتراق الصحي \\
\hline ، 088 & 006 & ،054- & 071 & **،379 & $* * 396$ & ، 020 & $* * 4405$ & توقع الرفض \\
\hline
\end{tabular}

اعنمادًا على المقياس، تتعدد مؤشرات الافتراق والتشخُّص الصحيّ، وتستقل عن بعضها، بل ويمكن وفقًا

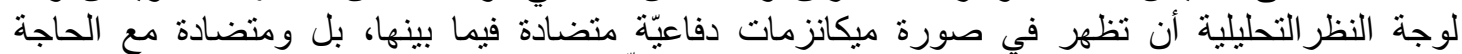

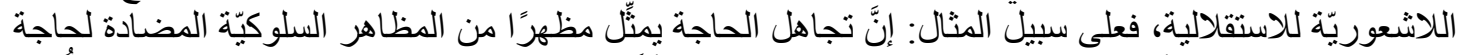

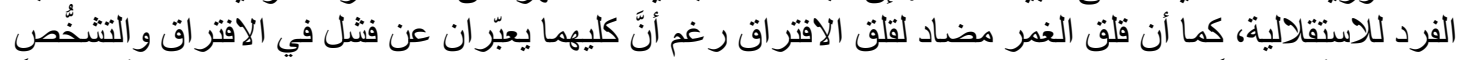

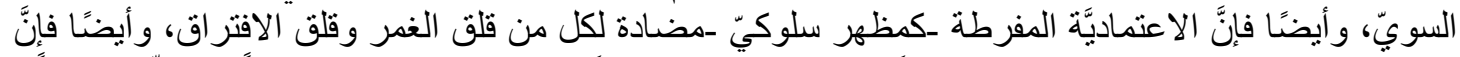

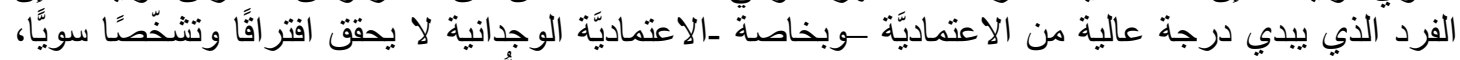

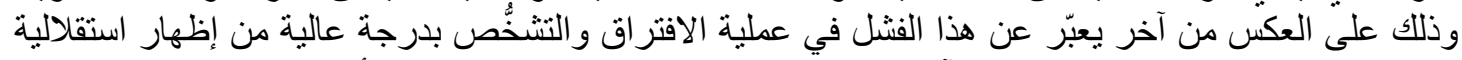

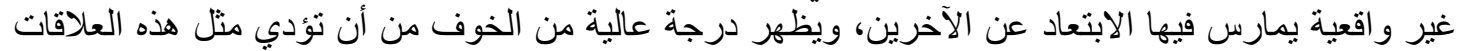

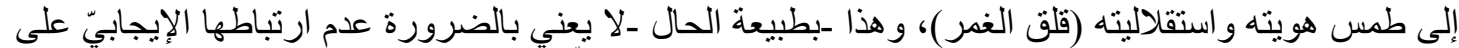

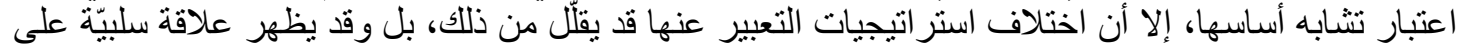

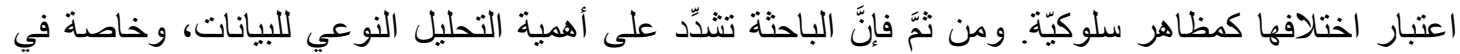
الحالات الإكلينيكية إلى جانب التحليل الكمي لهارئ.

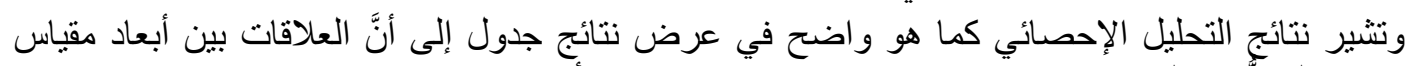

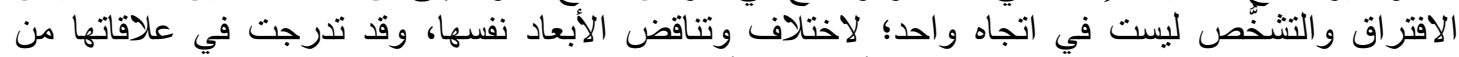

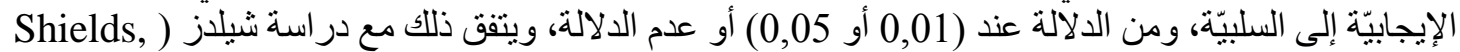

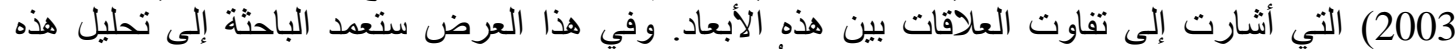

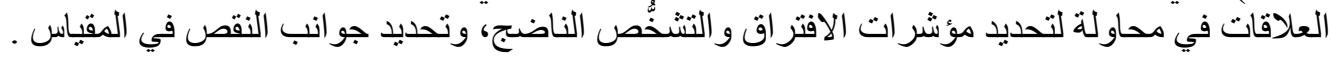

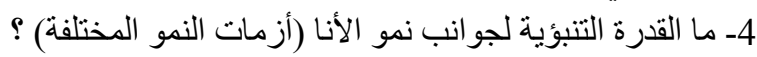




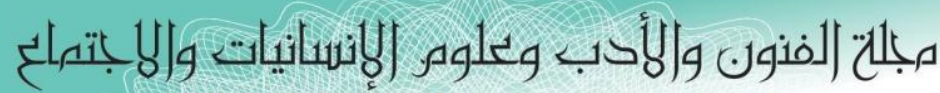

Journal of Arts, Literature, Humanities and Social Sciences

ISSN online: 2414 - 3383

ISSN print: 2616 - 3810

العدد (43) أيلول - سبتهبر 2019

جدول (10) معاملات الارتباط

\begin{tabular}{|c|c|c|c|c|}
\hline اللتقدير التياء & 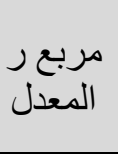 & مربع معاملات & الارتباط الجزئي & 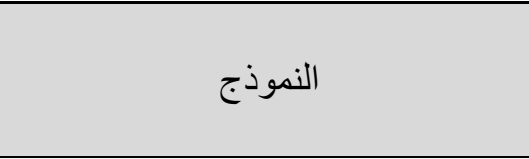 \\
\hline 12,32021 & ,306 & ,308 &, $555 \mathrm{a}$ & النموذج 1 (لثابت، أزمة الإنتاجية) \\
\hline 12,11799 & ,329 & ,332 &, $577 b$ & النموذج 2 (لثابت، أزمة الإنتاجية، أزمة \\
\hline 12,03433 & ,338 & 343 &, $586 \mathrm{c}$ & 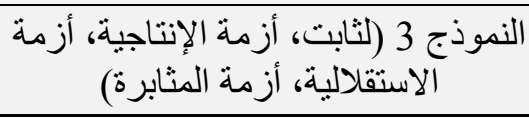 \\
\hline
\end{tabular}

جدول (11) تحليل التباين

\begin{tabular}{|c|c|c|c|c|c|c|}
\hline الدلالة & درجة ف & المتوسط & درجة الحرية & المربعات & \multicolumn{2}{|c|}{ النموذج } \\
\hline \multirow[t]{3}{*}{, $000 \mathrm{a}$} & 169,224 & 25686,093 & 1 & 25686,093 & الانحدار & \multirow{3}{*}{1} \\
\hline & & 151,788 & 380 & 57679,313 & البو اقي & \\
\hline & & & 381 & 83365,406 & المجموع & \\
\hline \multirow[t]{3}{*}{, $000 \mathrm{~b}$} & 94,354 & 13855,466 & 2 & 27710,932 & الانحدار & \multirow{3}{*}{2} \\
\hline & & 146,846 & 379 & 55654,474 & البو اقي & \\
\hline & & & 381 & 83365,406 & المجموع & \\
\hline \multirow[t]{3}{*}{, $000 \mathrm{c}$} & 65,876 & 9540,519 & 3 & 28621,558 & الانحدار & \multirow{3}{*}{3} \\
\hline & & 144,825 & 378 & 54743,848 & البواقي & \\
\hline & & & 381 & 83365,406 & المجموع & \\
\hline
\end{tabular}




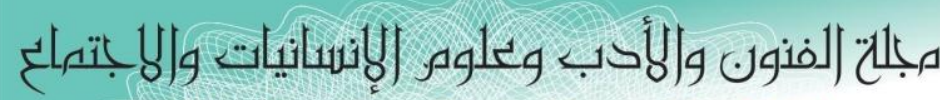
Journal of Arts, Literature, Humanities and Social Sciences

ISSN online: 2414 - 3383

ISSN print: 2616 - 3810

\section{العدد (43) أيلول - سبتمبر 2019}

جدول (12) معاملات الانحدار

\begin{tabular}{|c|c|c|c|c|c|c|}
\hline \multirow{2}{*}{ الدلالة الة } & \multirow{2}{*}{ ت } & \multirow{2}{*}{ المعباملات المبة } & \multicolumn{2}{|c|}{ المعاملات المعيارية } & \multirow{2}{*}{\multicolumn{2}{|c|}{ النموذج }} \\
\hline & & & المعياري الخطاء & ب & & \\
\hline ,000 & 159.093 & &, 843 & 134.193 & الثابت & \\
\hline, 000 & 13.009 &, 555 & ,091 & 1.182 & $\begin{array}{c}\text { أزمة الإنتاحية } \\
\end{array}$ & 1 \\
\hline ,000 & 156.028 & &, 855 & 133.424 & الثابت & \\
\hline, 000 & 11.050 &, 496 & ,096 & 1.056 & الإنتاجية & 2 \\
\hline ,000 & 3.713 &, 167 & ,092 & ,341 & 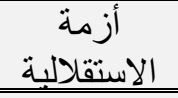 & \\
\hline ,000 & 153.878 & &, 864 & 133.019 & الثابت & \\
\hline ,000 & 6.529 & ,394 &, 128 & ,839 & أإنتاجية & ? \\
\hline ,005 & 2.834 &, 132 & ,095 & ,270 & الاستقلالية & 3 \\
\hline ,013 & 2.508 &, 158 &, 122 &, 307 & أزمة المثنابرة & \\
\hline
\end{tabular}

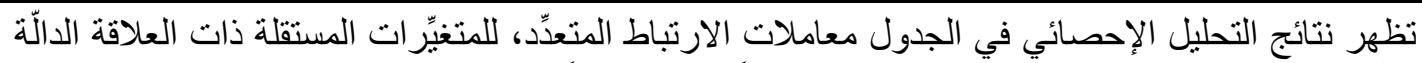

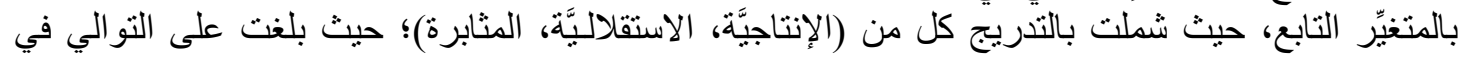

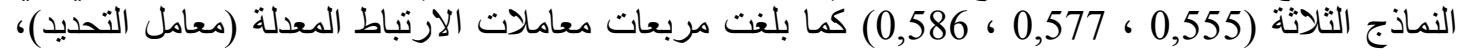

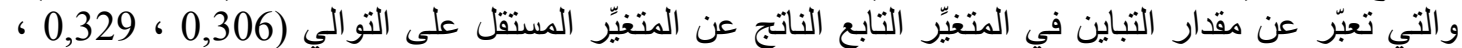

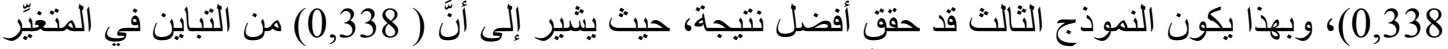

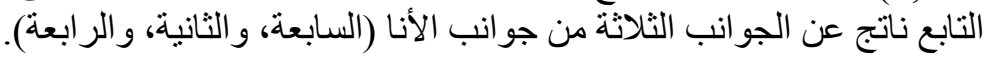

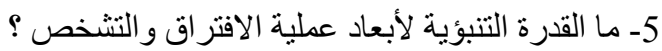

جدول (13) معاملات الارتباط

\begin{tabular}{|c|c|c|c|c|}
\hline اللتقديراري الخطاء & 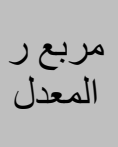 & معاملات & الارنباط & 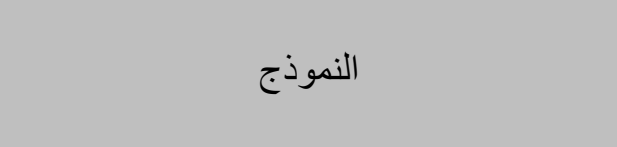 \\
\hline 14,19042 &, 080 & ,082 &, $287 \mathrm{a}$ & النموذج 1 (الثابت، توقع الرفض) \\
\hline 13,81158 &, 128 &, 133 & ,364b & النموذج 2 (الثابت، توقع الرفض، الممارسة \\
\hline 13,58619 &, 156 &, 163 & ,404c & النموذج 3 (الثابت، نوقع الرفض، المصارسة، ، المعلم) \\
\hline 13,49885 &, 167 &, 176 & ,419d & 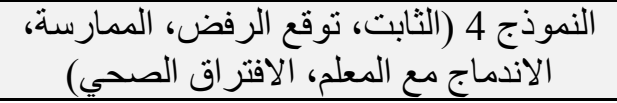 \\
\hline
\end{tabular}




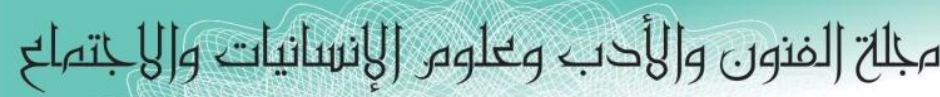
Journal of Arts, Literature, Humanities and Social Sciences

ISSN online: 2414 - 3383

ISSN print: 2616 - 3810

\section{العدد (43) أيلول - سبتمبر 2019}

جدول (14) تحليل التباين

\begin{tabular}{|c|c|c|c|c|c|c|}
\hline الدلالة & درجة ف & مربع المتوسط & درجة الحرية & مجموع المربعات & \multicolumn{2}{|c|}{ النموذج } \\
\hline \multirow[t]{3}{*}{, $000 \mathrm{a}$} & 33,995 & 6845,570 & 1 & 6845,570 & الانحدار & 1 \\
\hline & & 201,368 & 380 & 76519,836 & البو اقي & \\
\hline & & & 381 & 83365,406 & المجموع & \\
\hline \multirow[t]{3}{*}{, ,000b } & 29,009 & 5533,756 & 2 & 11067,512 & الانحدار & $\overline{2}$ \\
\hline & & 190,760 & 379 & 72297,894 & البو اقي & \\
\hline & & & 381 & 83365,406 & المجموع & \\
\hline \multirow[t]{3}{*}{, $000 \mathrm{c}$} & 24,546 & 4530,817 & 3 & 13592,452 & الانحدار & 3 \\
\hline & & 184,585 & 378 & 69772,954 & البو اقي & \\
\hline & & & 381 & 83365,406 & المجموع & \\
\hline \multirow[t]{3}{*}{, $000 \mathrm{~d}$} & 20,125 & 3667,224 & 4 & 146668,897 & الانحدار & $\overline{4}$ \\
\hline & & 182,219 & 377 & 68696,509 & البو اقي & \\
\hline & & & 381 & 83365,406 & المجموع & \\
\hline
\end{tabular}

جدول (15) المعاملات

\begin{tabular}{|c|c|c|c|c|c|c|}
\hline \multirow[b]{2}{*}{ 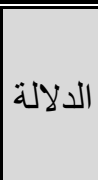 } & \multirow[b]{2}{*}{ ت ت } & \multirow{2}{*}{ المعاملات } & \multicolumn{2}{|c|}{ المعاملات ير المعيارية } & \multirow{2}{*}{\multicolumn{2}{|c|}{ النموذج }} \\
\hline & & & المعياري & ب ب & & \\
\hline, 000 & 57,258 & & 2,740 & 156,889 & الثابت & \multirow{2}{*}{1} \\
\hline, 000 & $5,831-$ & ,287- & ,121 & ,707- & توقع الرفض & \\
\hline ,000 & 26,571 & & 5,129 & 136,279 & الثابت & \multirow{3}{*}{2} \\
\hline, 000 & $6,082-$ & ,291- & ,118 & ,718- & توقع الرفض & \\
\hline ,000 & 4,704 & ,225 & ,083 & ,389 & التمركز حول & \\
\hline, 000 & 26,088 & & 5,109 & 133,293 & الثابت & \multirow{4}{*}{3} \\
\hline, 000 & $6,421-$ & ,303- & ,116 & ,747 & توقع الرفض & \\
\hline ,000 & 3,886 & , 187 & ,083 & ,323 & التمركز حول & \\
\hline ,000 & 3,699 & 179 &, 160 & ,591 & الاندماج مع المعلم & \\
\hline 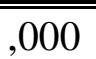 & 21,479 & & 5.872 & 126,121 & الثابت & \multirow{3}{*}{4} \\
\hline, 000 & $6,642-$ & ،312- & ,116 & ,771- & توقع الرفض & \\
\hline ,004 & 2,909 & 147 & ,087 & 254 & التمركز حول & \\
\hline
\end{tabular}




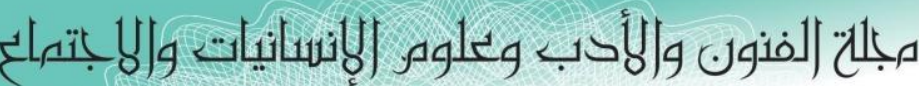

Journal of Arts, Literature, Humanities and Social Sciences

ISSN online: 2414 - 3383

ISSN print: 2616 - 3810

\section{العدد (43) ايلول - سبتمبر 2019}

\begin{tabular}{|c|c|c|c|c|c|}
\hline , 000 & 3,585 & , 172 & , 159 &, 570 & الاندماج مع المعلم \\
\hline ,016 & 2,431 &, 122 & ,242 &, 589 & الافتراق الصحي \\
\hline
\end{tabular}

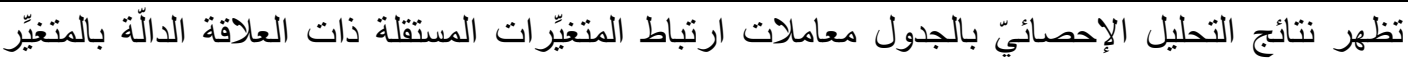

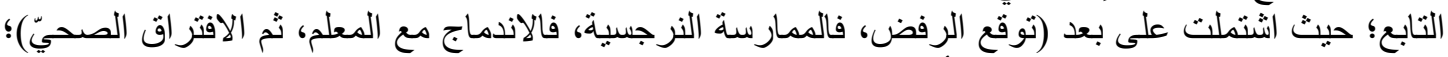

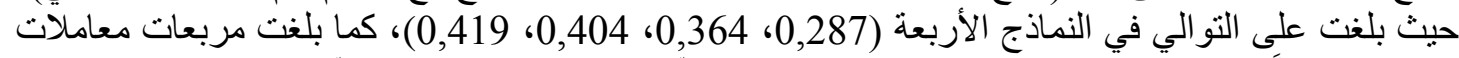

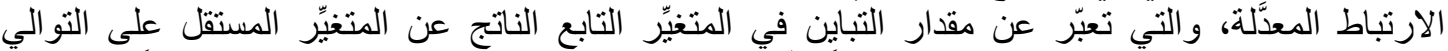

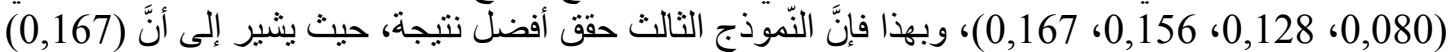
من التباين في المتغيّر التابع ناتج عن كلًّ من (توقع الرفض، الممارسة النرجسية، الاندماج مع المعلم، الافتراق

(الصحيّ).

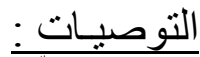

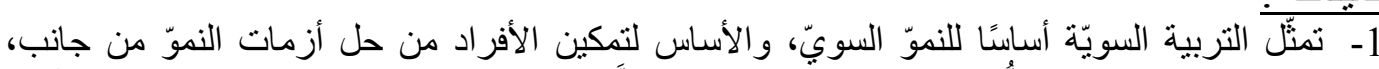

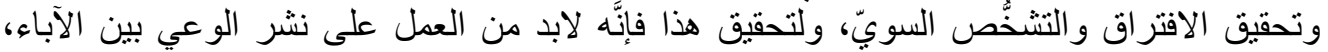

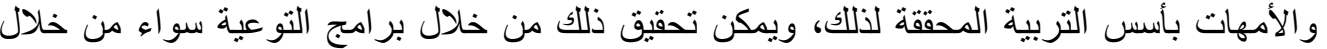

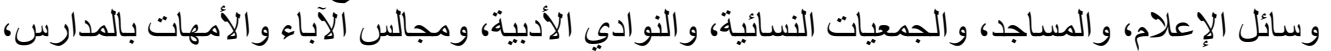

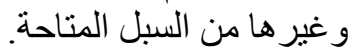

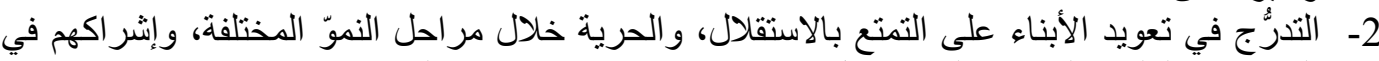

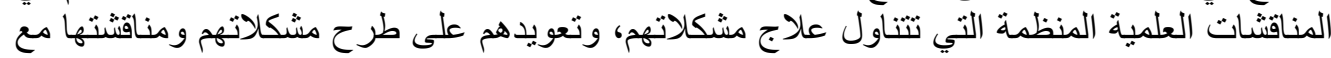

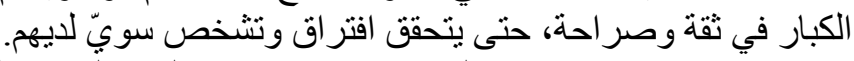

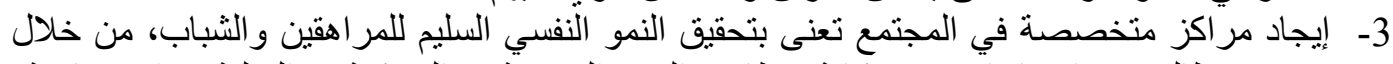
تحقيق مطالبهم، واحتياجاتهم في كافة مظاهر النمو الجسمية، والحركية، والعقلية، والاجتماعية،

و الانفعالية.

1- المر أب: جادو، صالح محمد علي (2007) علم النفس النطوري ـ الطفولة والمر اهقة (ط2). عمان: دار المسيرة للنشر و التنوزيع و الطباعة.

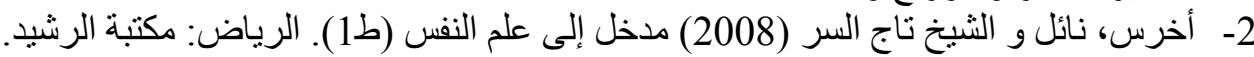

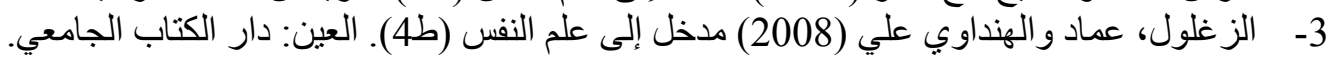

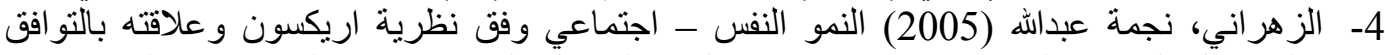

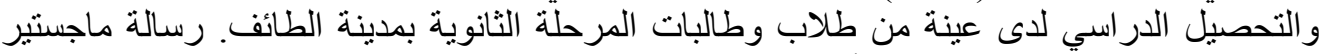

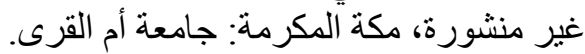

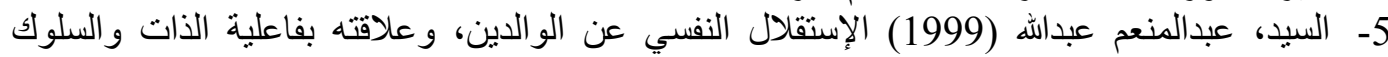

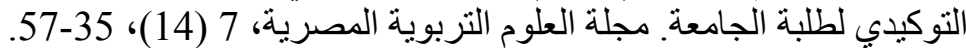

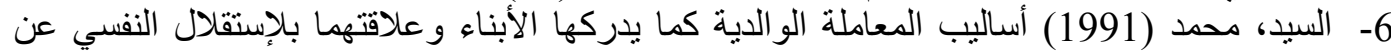

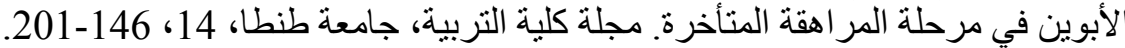

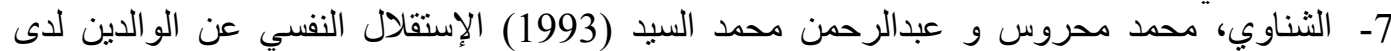

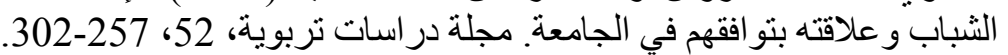

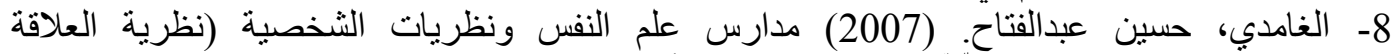

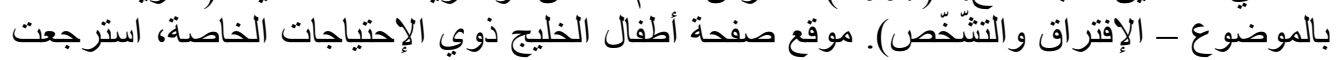

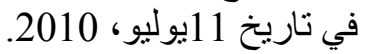

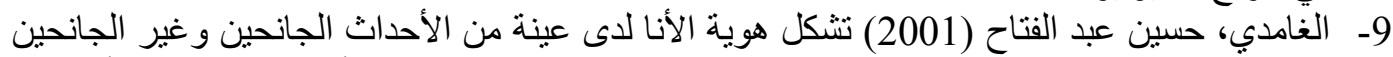

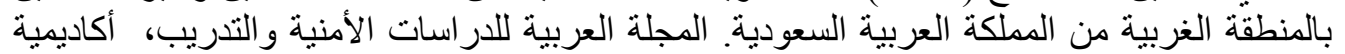
نايف للعلوم الأمنية، 5،(30)، 182-213. 


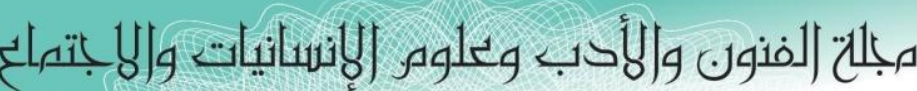

Journal of Arts, Literature, Humanities and Social Sciences

ISSN online: 2414 - 3383

ISSN print: 2616 - 3810

\section{العدد (43) ايلول - سبتهبر 2019}

10ـ الغامدي، حسين عبدالفتاح (2010 أ) مقياس النمو النفس - الإجتماعي: مقياس لتقييم طبيعة حل أزمات

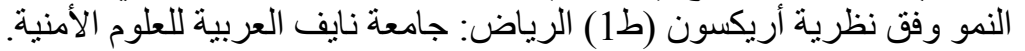

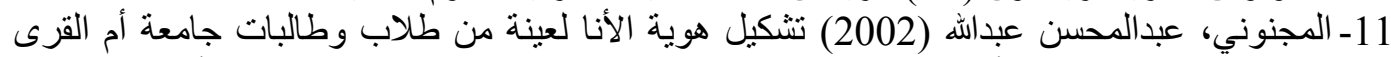

تبعا لبعض المتغيرات الأسرية الديموغر افية. رسالة ماجستير غير منشورة، جامعة أم القرى المئية مكة

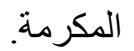

12-دليلة، بوصفر (2011) الإستقلال النفسي عن الوالدين وعلاقته بالتو افق الدراسي لدى الطالب الجامعي

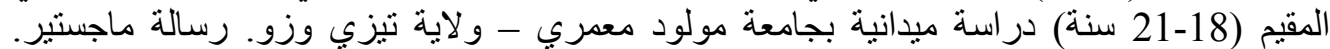

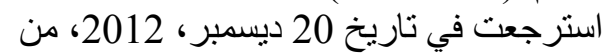

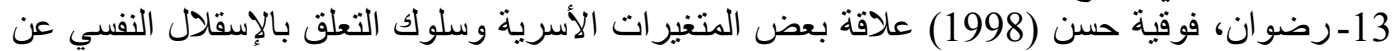

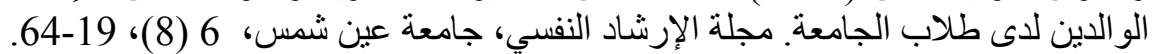

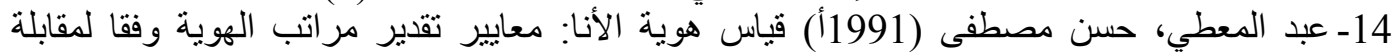

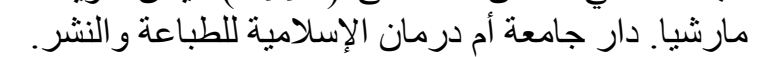

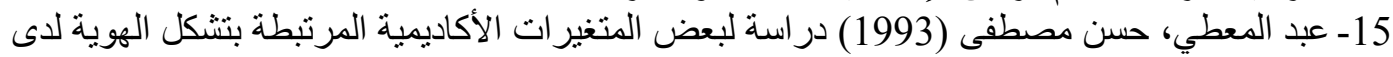

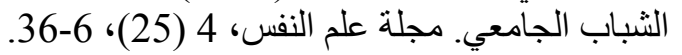

16- عبد المعطي، حسن مصطفى (2004) النمو النفسي الاجتماعي وتثكيل الهوية (ط1). القاهرة: مكتبة

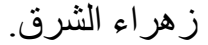

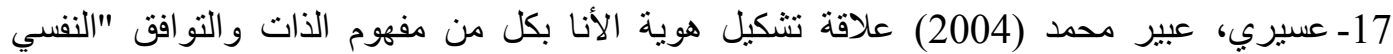

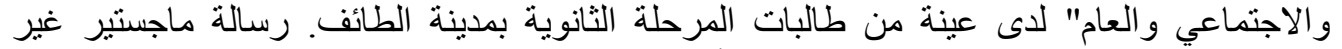

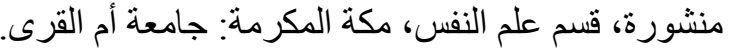

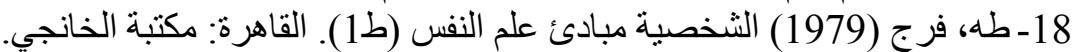

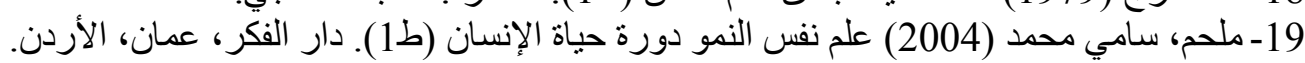

20-Boeree, C. George (2009). Personality theories Sigmund Freud. Retrieved March 20, 2011, from http://webspace.ship.edu/cgboer/freud.html

21-Blos, P. (1962). On adolescence: A Psychoanalytic interpretation. New York: The Free Press.

22-Blos, P. (1967). The second individuation process of adolescence. The Psychoanalytic Study of the Child. 22: 162 - 186.

23-Blos, P. (1975). The second individuation process of adolescence. In A. Esman (ed.) The Psy-chology of adolescence; Essential readings. New York: International Universities Press, 156-77.

24- Coles, R. (2001). The erik erikson reader. New York: Norton.

25-DeRoss, K. (2011). Developmental processes and psychopathology: Separation individuation and ego development. doctoral dissertation, Pace University.

26-Engler, J. N. (2004). The dynamics of identity development: Exploring the relevance of separation-individuation. doctoral dissertation, Dissertation. Knoxville: The University of Tennessee.

27-Erikson, E. H. (1950). Childhood and society. New York: Norton.

28- Erikson, E. H. (1964). Insight and responsibility. New York: Norton.

29- Erikson, E. H. (1965). Youth: Fidelity and diversity. In E. H. Erikson (Ed.). The challenge of youth (pp. 1-28). New York: Norton.

30- Erikson, E. H. (1967). The problem of ego integrity. In M. R. Stein. A. J. Vidich, \& M. White (Eds.), Identity and anxiety. (pp. 37-87). New York: Free Press.

31- Erikson, E. H. (1968). Identity: Youth and crisis. New York: Norton. 


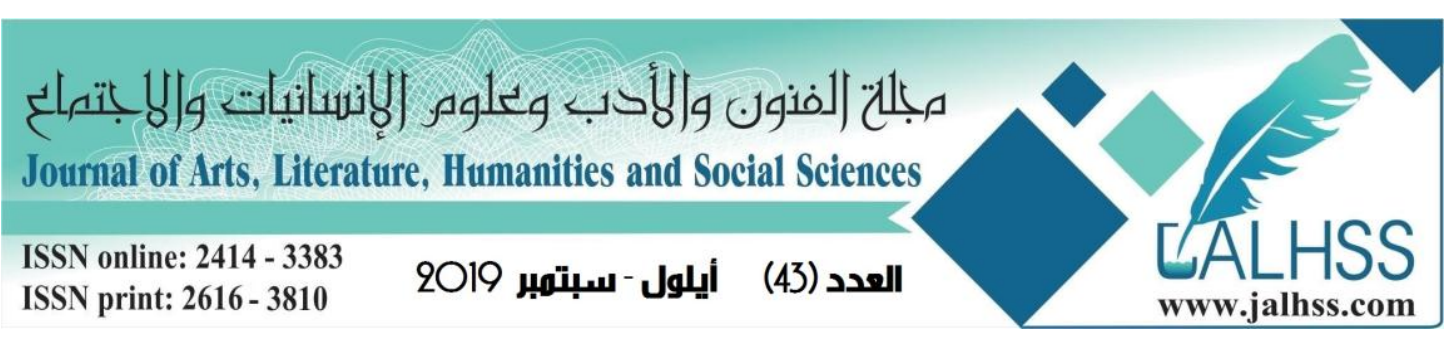

32- Erikson, E. H. (1985). The life cycle completed. New York: Norton.

33- Erikson, E. H., Erikson, J. M., \& Kivnick, H. Q. (1986). Vital involvement in old age. New York: Norton

34-Feldberg, A. (1984). Adolescent separation, individuation and identity (re)formation: Theoretical extensions and modifications (reformation). doctoral dissertation, California School of Professional Psychology - Fresno.

35- Freud, A. (1967). The Ego and the mechanisms of defense: The writing of Anna Freud, (Vol. 2). International Universities Press.

36- Freud, S. (1924). Neurosis and psychosis. Standard Edition, 19. 149-153.

37- Freud, S. (1932). An outline of psychoanalysis. London: Hogarth.

38- Freud, S. (1958). Inhibitions, symptoms and anxiety. London: Hogarth,.

39- Friedman, L. J. (1999). Erik Erikson. Cambridge: Harvard University Press.

40-George, D. (1996). The influence of family functioning on identity formation: A model of late adolescent identity development. doctoral dissertation, University of North Texas.

41-Gnaulati, Enrico et, al.; (2001). Separation-individuation in late adolescence: An investigation of gender and ethnic differences. Journal of Psychology, (Vol. 135, Issue 1, 59-70).

42-Greenberg, J. R. Mitchell, S. A. (1983). Object in relations in psychoanalytic theory.(2 nd ed.). Cambridge, Mass: Harvard University Press.

43- Hartman, H. (1950). Psychoanalytic and developmental psychology. New York: International Universities Press.

44-Hoffman, J. A. (1984). Psychological separation of late adolescents from their parents. Journal of Counseling Psychology, 31(2), 170-178.

45- Kalsner-Silver, L. (2000). Adjustment in a multicultural undergraduate population: Attachment quality, ethnic identity, and separation-individuation. doctoral dissertation, New Brunswick and University of Medicine and Dentistry of New Jersey.

46-Khan, C. (2002). Cross-cultural variation in the relationship between late adolescent separation-individuation and psychosocial adjustment. Long Island University, Brooklyn, New York.

47-Klein, M. (1932). The psychoanalysis of children. In the writings of Melanie Klein. Volume II. London: Hogarth (1975).

48-Kohut, H. (1977). The restoration of the self. New York: International Universities press.

49- Levine, J. B., Green, C. J., \& Millon, T. (1986). The separation-individuation test of adolescence. Journal of Personality Assessment, 50 (1),

50- Levine, J.B \& Saintonge, S. (1993). Psychometric properties of the separationindividuation Test of Adolescence within a clinical population. Journal of Clinical Psychology, 49, 492-507.

51-Mahler, M. \& Gosliner, B.J. (1955). On symbiotic child psychosis: Genetic, dynamic, and restitutive aspects. The Psychoanalysis Study of the Child, 10, 195212. 


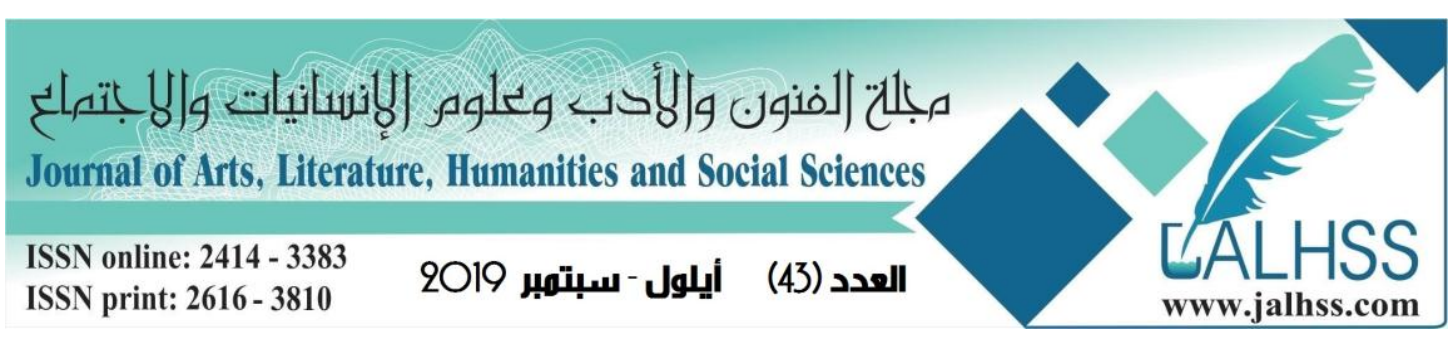

52-Mahler, M. (1963). Thoughts about development and individuation. The Psychoanalytic Study of the Child, 18, 307-324.

53- Mahler, M. S. (1968). On Human symbiosis and the vicissitudes of individuation: Infantile Psychoanalysis. New York: International Universities Press.

54- Mahler, M. (1972). On the first three sub phases of the separation-individuation process. International Journal of Psycho-analysis, 53, 333.

55- Mahler, M. (1974). Symbiosis and individuation. The Psychoanalytic Study of the Child, 29, 89-106.

56- Mahler, M. (1983). The meaning of developmental research of earliest infancy as related to the study of separation-individuation. In J.D. Call, E. Galcnson and R.L. Tyson (eds.), Frontiers of Infant Psychiatry, New York: Basic Books.

57-McClanahan, G., \& Holmbeck, G. N. (1992). Separation-individuation, family functioning and personality adjustment in college students: A construct validity study of the Separation-individuation Test of Adolescence. Journal of Personality Assessment, 59, 468-485.

58-Medlin, N. M. (1991). Adolescent psychological separation-individuation and the identity formation process. doctoral dissertation, The University of Nebraska Lincoln.

59- Pace, S. R. (2003). Surviving the freshman year of college: What psychosocial factors contribute to an easy versus difficult postsecondary transition to college? doctoral dissertation, Capella University.

60-Rice, K. G. (1991). Late adolescent attachment, separation-individuation, and adjustment to college: A time-sequential study. doctoral dissertation, University of Notre Dame.

61-Sabino, V. M. (1993). Adolescent individuation and identity formation following parental death and the mediating role of coping. Master's dissertation. University of Guelph (Canada).

62-Shields, M. (2003). Perception of father, father absence/presence, and separationindividuation in late adolescence. doctoral dissertation, Fielding Graduate Institute.

63-Shulkin, A. T. (1990). Separation-individuation and identity status among late adolescent college students. doctoral dissertation, University of Minnesota.

\section{References}

1. - 1Abu Jadu, Saleh Mohammed Ali (2007) evolutionary psychology childhood and adolescence (i 2). Amman: Dar Al Masirah for Publishing, Distribution and Printing.

2. - 2Akhras, Nael and Sheikh Taj Alsir (2008) Introduction to Psychology (i 1). Riyadh: Al-Rasheed Bookstore.

3. - 3Zaghloul, Imad and Hindawi Ali (2008) Introduction to Psychology (i 4). Al Ain: University Book House. 


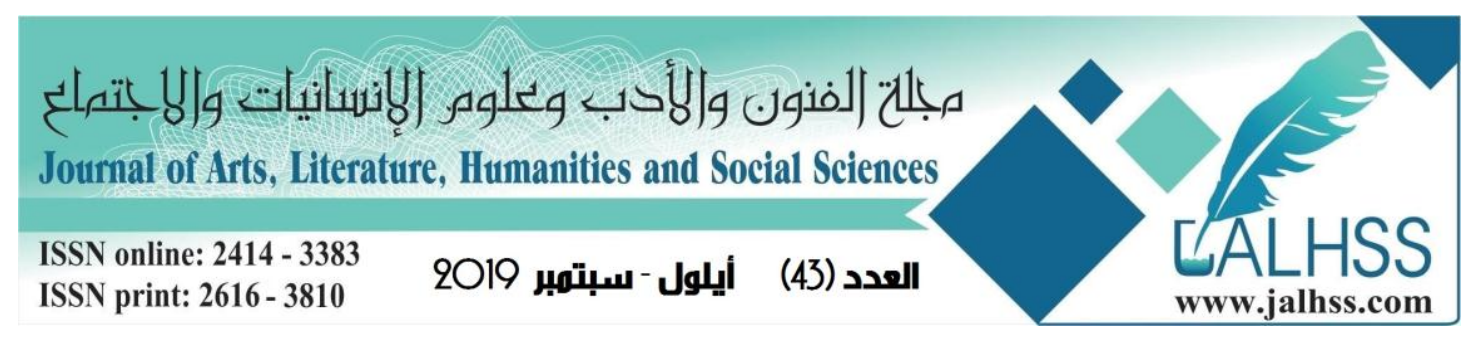

4. - 4Zahrani, Najma Abdullah (2005) self-social growth according to Eriksson theory and its relationship to the compatibility and academic achievement of a sample of secondary school students in Taif. Unpublished Master Thesis, Mecca: Umm Al-Qura University.

5. - 5Mr., Abdel Moneim Abdullah (1999) psychological independence from parents, and its relationship to self-efficacy and affirmative behavior of university students. Journal of Egyptian Educational Sciences, 7 (14), 35-57.

6. - 6Mr., Mohammed (1991) methods of parental treatment as perceived by children and their relationship to psychological independence from parents in late adolescence. Journal of the Faculty of Education, Tanta University, 14, 146-201.

7. - 7Alshnawi, Mohammed Mahrous and Abdulrahman Mohammed Elsayed (1993) psychological independence from parents in young people and its relationship to their compatibility in the university. Journal of Educational Studies, 52, 257-302.

8. -8Al-Ghamdi, Hussein Abdul-Fattah. (2007) Schools of Psychology and Personality Theories (Relation Theory - Separation and Diagnosis). Gulf Children with Special Needs website, retrieved July 11, 2010.

10- Al-Ghamdi, Hussein Abdul-Fattah (2001) The identity of the ego is a sample of juvenile and delinquent juveniles in the western region of Saudi Arabia. Arab Journal for Security Studies and Training, Naif Academy for Security Sciences, 5, (30), 182-213.

Al-Ghamdi, Hussein Abdul-Fattah (2010a) Psychosocial Growth Scale: A Scale for Assessing the Nature of Solving Growth Crises According to Ericsson Theory (i) Riyadh: Naif Arab University for Security Sciences.

11- Al-Majnouni, Abdulmohsen Abdullah (2002) Forming the identity of the ego for a sample of students of Umm Al-Qura University according to some demographic variables. Unpublished Master Thesis, Umm Al-Qura University: Mecca.

12- Dalila, Boussafr (2011) Psychological independence from parents and its relationship with the academic compatibility of the resident university student (18-21 years) field study at the University of Mouloud Mamari - Tizi Ouzou Province. Master Thesis. Retrieved on December 20, 2012, from

13- Radwan, Fawqia Hassan (1998) Relationship of some family variables and attachment behavior with psychological independence from parents among university students. Journal of Psychological Counseling, Ain Shams University, $6(8), 19-64$.

9. .14Abdul-Mu'ti, Hassan Mustafa (1991a) Measuring the identity of the ego: criteria for estimating the ranks of identity according to the interview of Marcia Omdurman Islamic University House for Printing and Publishing.

14- Abdul Muti, Hassan Mustafa (1993), a study of some academic variables associated with the formation of identity among university youth. Journal of Psychology, 4 (25), 6-36. 


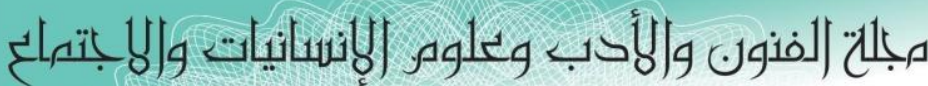

Journal of Arts, Literature, Humanities and Social Sciences

ISSN online: 2414 - 3383

ISSN print: 2616 - 3810

\section{العدد (43) أيلول - سبتهبر 2019}

15- Abdul Muti, Hassan Mustafa (2004) Psychosocial development and identity formation (I 1). Cairo: Zahraa El Sharq Library.

16- Asiri, Abeer Mohammed (2004) Relationship of the formation of the identity of the ego with the concept of self and compatibility "psychological, social and general" among a sample of secondary school students in Taif. Unpublished Master Thesis, Department of Psychology, Makkah: Umm Al-Qura University.

17- Taha, Faraj (1979) Personal Principles of Psychology (I 1). Cairo: Khanji Library.

18- Melhem, Sami Mohammed (2004). Dar Al Fikr, Amman, Jordan.

\section{ملحق (1)}

مقياس الإفتر اق و التشخص للمر اهقين

Separation- Individuation Test Of Adolescence (SITA) .

(Levine, Green \& Millon)

\begin{tabular}{|c|c|c|c|c|c|c|}
\hline \multicolumn{5}{|c|}{ مدى إنطباق العبارة عليك } & \multirow{2}{*}{ 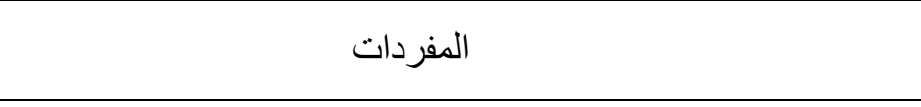 } & \multirow{2}{*}{ رقم } \\
\hline مطلقاً & نادرا & احياناً & غالباً & تماماً & & \\
\hline & & & & & مبالغة و الديّ في الحرص عليَ تخنقني. & 1 \\
\hline & & & & & أنشعر بالقوة و القدرة على مواجهة أي تحديات. & 2 \\
\hline & & & & & انز عج كثر ا من بقائي بمفردي. & 3 \\
\hline & & & & & لا افهم ما يريده الآخرون من علاقتهم القوية بي. & 4 \\
\hline & & & & & استمتع بيقائي لوحدي أو مع الآخرين بنفس الدرجة. & 5 \\
\hline & & & & & انتظر بفارغ الصبر اليوم الذي اعتمد فيه على نفسي وأتحرر من والديّ. & 6 \\
\hline & & & & & يبدو لي أن الناس يريدون إيذائي. & 7 \\
\hline & & & & & 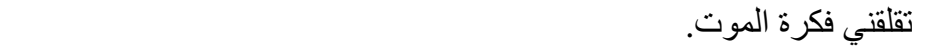 & 8 \\
\hline & & & & & يبالغ معظم الآباء و الأمهات في التحكم في الأبناء و لا يريدون لهم أن يكبروا. & 9 \\
\hline & & & & & أنا على علاقة طيبة مع أنماط مختلفة من الناس. & 10 \\
\hline & & & & & لا أرى معنى لمعظم العلاقات الحميمة. & 11 \\
\hline & & & & & أستمتع كثبراً بالنظر إلى جسمي في المرآة. & 12 \\
\hline & & & & & يعرفني و الديّ أو أحدهما جيداً، لدرجة معرفة ما أفكر فيه. & 13 \\
\hline & & & & & لو أخبرت أحداً عن مشاكلي فقد لا يفهني. & 14 \\
\hline & & & & & أقدم أفضل مالدي عندما أكون مع نفسي و لا يكون هناك من يضايقني. & 15 \\
\hline & & & & & علاقتي القوية مع الآخرين لا تفقدني استقلاليتي. & 16 \\
\hline & & & & & عندما أفعل شيئاً مع أصدقائي فإنني أتصرف كقائد لهم. & 17 \\
\hline
\end{tabular}




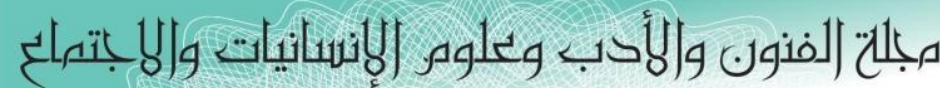
Journal of Arts, Literature, Humanities and Social Sciences

ISSN online: 2414 - 3383

ISSN print: 2616 - 3810

\section{العدد (43) ايلول - سبتمبر 2019}

LALHSS

www.jalhss.com

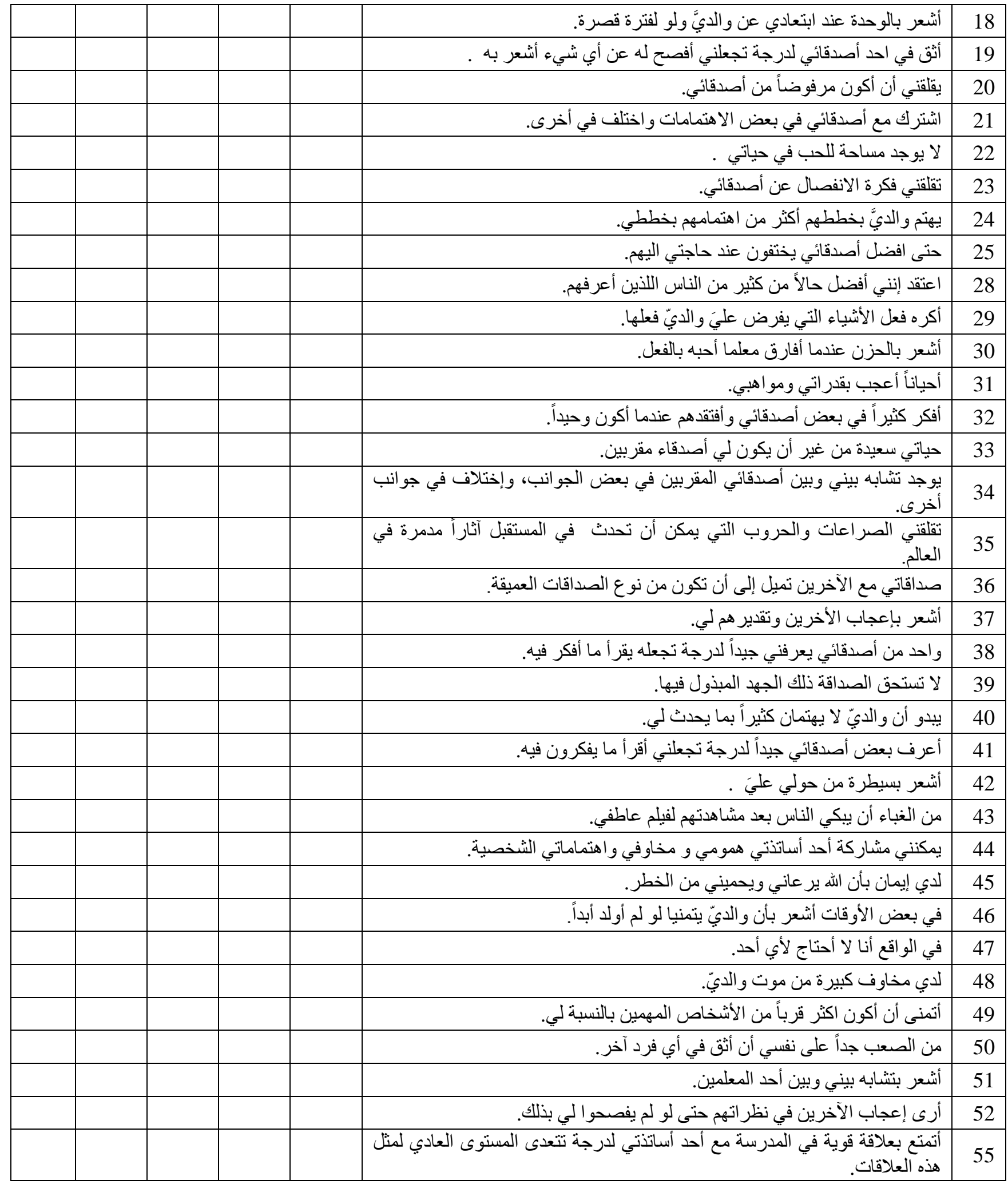




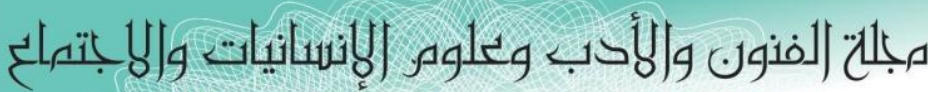
Journal of Arts, Literature, Humanities and Social Sciences

ISSN online: 2414 - 3383

ISSN print: 2616 - 3810

\section{العدد (43) ايلول - سبتمبر 2019}

LALHSS

WwW.jalhss.com

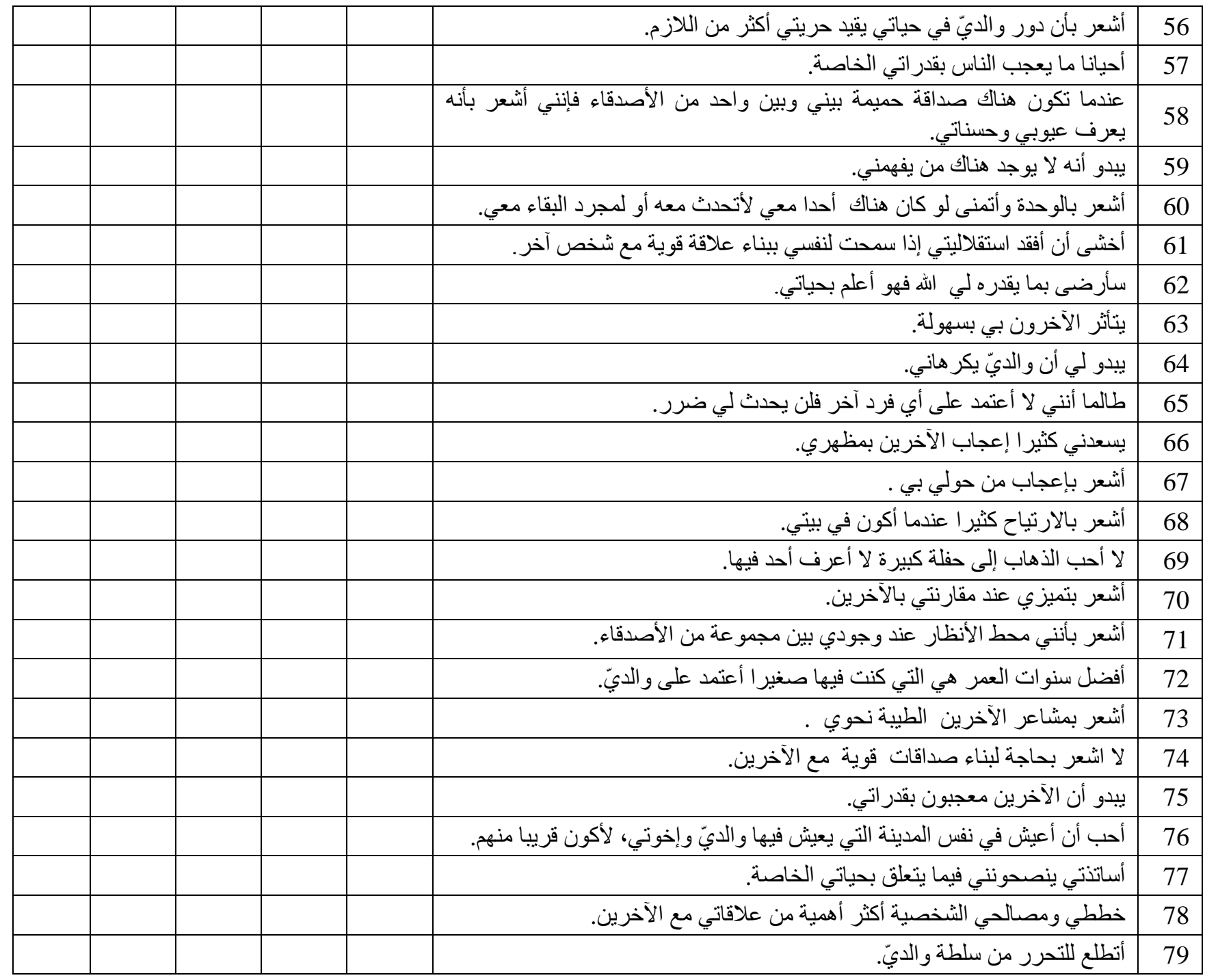

